
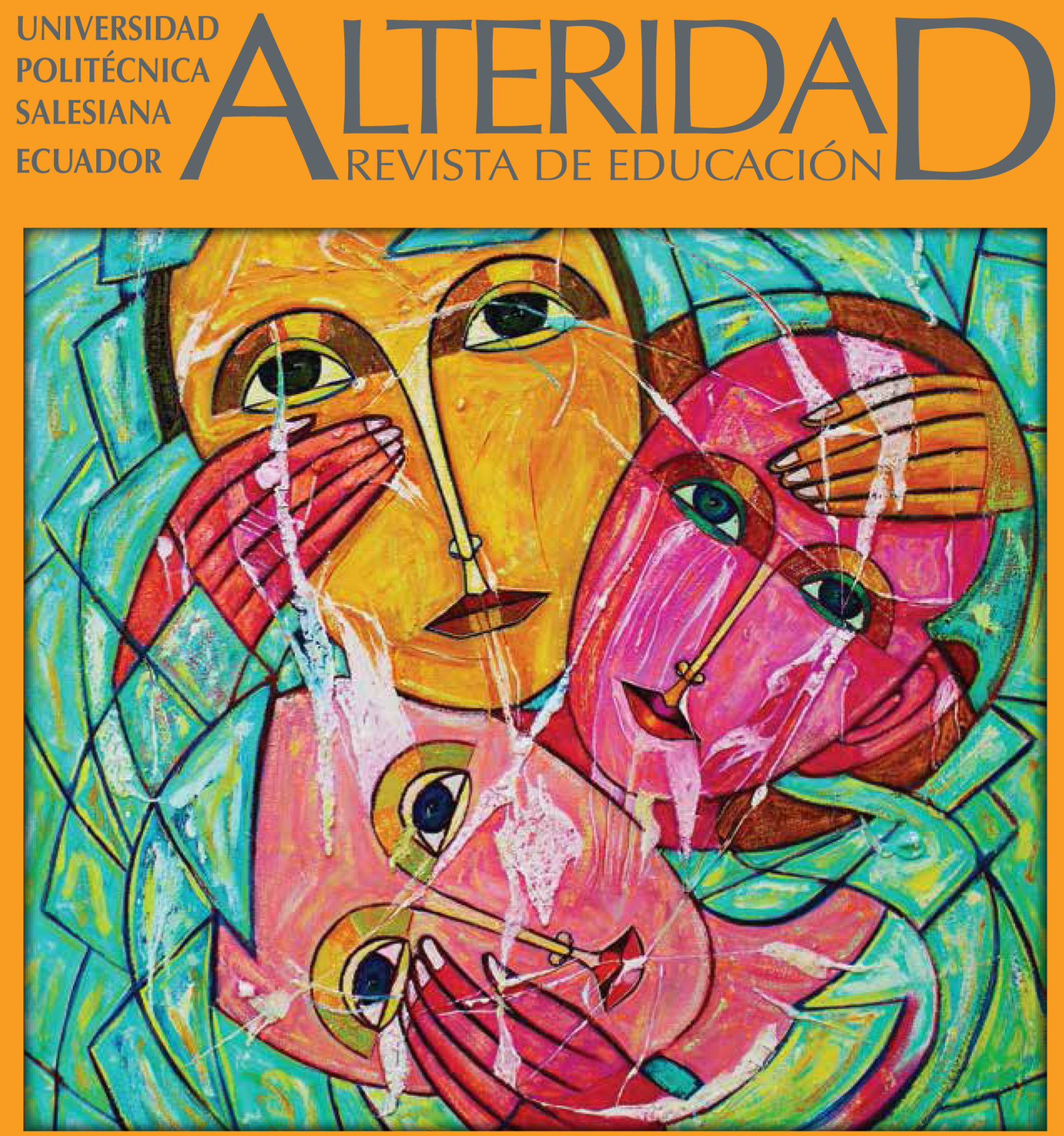

Currículo por competencias y la significatividad del proceso educativo salesiano 


\section{A}

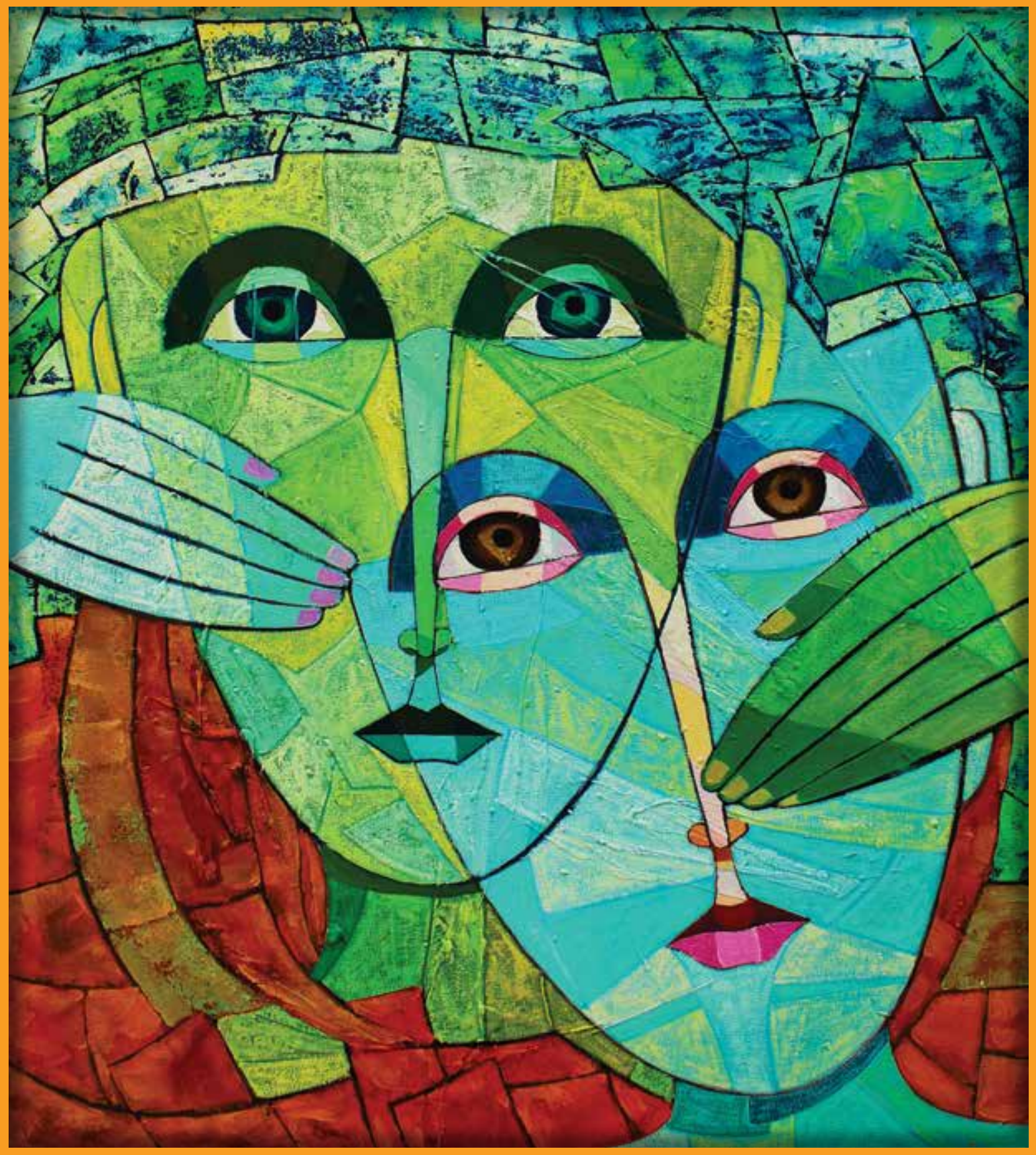

Alteridad está indexada en las siguientes Bases de Datos:

- Índice de Revistas de Educación Superior e Investigación Educativa (IRESIE)

- Directory of Open Access Journals (DOAJ)

- Academic Journals Database 


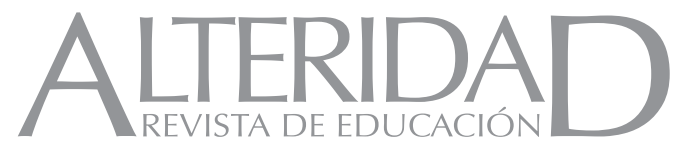

Alteridad, volumen 8, número 2 (2013)

Alteridad. Revista de Educación, es una revista académica de la Universidad Politécnica Salesiana. Se edita desde el 2005 con una periodicidad semestral, durante los meses de junio y diciembre. Su objetivo es contribuir, desde el contexto latinoamericano, a la socialización y debate de la producción académica en el ámbito de la Educación, en las siguientes líneas: Filosofía de la Educación, Currículo y Culturas, Políticas Educativas y Formación Docente, Evaluación Educativa, Educación y Tecnologías, Educación Especial e Inclusiva. La revista está dirigida, a todas las personas involucradas o interesadas en el campo educativo, en particular, a los estudiantes de las Ciencias de la Educación y a los docentes e investigadores de los diversos niveles educativos. Es una publicación arbitrada que utiliza el sistema de revisión externa por expertos (peer-review). Se edita en versión impresa (ISSN: 1390-325X); además, los artículos están disponibles en la Web de la revista (http://alteridad.ups.edu.ec/).

\begin{tabular}{|c|c|}
\hline Rector & Consejo Editorial Interno \\
\hline Javier Herrán Gómez, sdb & Jaime Padilla Verdugo (Editor responsable) \\
\hline Turuhuayco 3-69 y Calle Vieja & María Sol Villagómez (Responsable científica) \\
\hline Casilla Postal 2074 & Ana María Narváez Garzón \\
\hline Cuenca, Ecuador & Armando Romero Ortega \\
\hline Teléfono (+593 7) 2050000 & Fernando Moscoso Arévalo \\
\hline Fax: $(+5937) 4088958$ & María Elena Ortiz Espinoza \\
\hline rpublicas@ups.edu.ec & Miriam Gallego Condoy \\
\hline Tiraje: 3000 ejemplares & Miriam Gallego Navas \\
\hline $\begin{array}{r}\text { Consejo de publicaciones } \\
\text { Javier Herrán Gómez, sdb } \\
\text { PRESIDENTE }\end{array}$ & $\begin{array}{l}\text { Roberto Rangel Donoso } \\
\text { Tatiana Rosero Palacios } \\
\text { Sebastián Granda Merchán }\end{array}$ \\
\hline Juan Bottasso Boetti, sdb & Consejo Editorial Externo \\
\hline José Sánchez Parga & Alma Rosa Hernández Mondragón, Universidad La Salle, México, D.F., México \\
\hline José Juncosa Blasco & Amauris Laurencio Leyva, Universidad de La Habana - CEPES, La Habana, Cuba \\
\hline Jaime Padilla Verdugo & Antonio Bautista García-Vera, Universidad Complutense de Madrid, Madrid, España \\
\hline Floralba Aguilar Gordón & Carla Förster Marín, Pontificia Universidad Católica de Chile, Santiago, Chile \\
\hline Sheila Serrano Vincenti & Carlos Paladines, Pontificia Universidad Católica del Ecuador, Quito, Ecuador \\
\hline Fabricio Freire Morán & Claudia Cayulef Ojeda, Universidad Católica Silva Henríquez, Santiago, Chile \\
\hline John Calle Sigüecia & Cristian Desbouts, Università Pontificia Salesiana, Roma, Italia \\
\hline Armando Grijalva Brito & Cristina Allemann-Ghionda, Universidad de Colonia, Colonia, Alemania \\
\hline Alexandra Martínez Flores & Dilnei Giseli Lorenzi, Universidad Católica de Brasilia, Brasilia, Brasil \\
\hline $\begin{array}{l}\text { Alexandóa Martinez Flores } \\
\text { Mónica Ruiz Vásquez }\end{array}$ & Dora Elena Marín Méndez, UNAM, México, D.F., México \\
\hline $\begin{array}{l}\text { Mónica Ruiz Vásquez } \\
\text { Luis Âlvarez Rodas }\end{array}$ & Eduardo Fabara Garzón, Universidad Andina “Simón Bolívar”, Quito, Ecuador \\
\hline $\begin{array}{l}\text { Luis Âlvarez Rodas } \\
\text { EDITOR GENERAL }\end{array}$ & Enrique Parra Marín, Universidad Católica Silva Henríquez, Santiago, Chile \\
\hline EDITOR GENERAL & $\begin{array}{l}\text { Fábio Garcia dos Reis, Centro Universitario Salesiano de Sao Paulo, Lorena, Brasil } \\
\text { Francisco Alvarado García, Universidad Iberoamericana, México, D.F., México }\end{array}$ \\
\hline Revisión de estilo y redacción & Gabriel Suárez Medina, Pontificia Universidad Javeriana, Bogotá, Colombia \\
\hline Diana Ávila & $\begin{array}{l}\text { Gersem José dos Santos Luciano, Universidade Federal do Amazonas, Manaus, Brasil } \\
\text { Herminia Hernández, Universidad de la Habana - CEPES, La Habana, Cuba }\end{array}$ \\
\hline Diseño e ilustración & Jaime Brito Farías, Universidad Católica Silva Henríquez, Santiago, Chile \\
\hline Editorial Universitaria Abya-Yala & Javier Loredo Enríquez, Universidad Iberoamericana, México, D.F., México \\
\hline v. 12 de Octubre N23-116 y Wilson & José Antonio Fernández Bravo, Universidad Camilo José Cela, Madrid, España \\
\hline Quito, Ecuador & José Ignacio Aguaded Gómez, Universidad de Huelva, Huelva, España \\
\hline (02)2506-247/(02) 2506-251 & José Joaquín Brunner, Universidad Diego Portales, Santiago, Chile \\
\hline E-mail: editorial@ayayala.org & José Luis Guzón, Universidad Pontificia de Salamanca, Salamanca, España \\
\hline $\begin{array}{l}\text { Portal electrónico: } \\
\text { P-mail. eding }\end{array}$ & $\begin{array}{l}\text { José Luis Moral, Università Pontificia Salesiana, Roma, Italia } \\
\text { Julio Cabero, Universidad de Sevilla, Sevilla, España }\end{array}$ \\
\hline http://www.abyayala.org & Leonor Buendía Eisman, Universidad de Granada, Granada, España \\
\hline http://www.ups.edu.ec & Lorenzo Cantoni, Universidad de Lugano, Lugano, Suiza \\
\hline Impresión & $\begin{array}{l}\text { Luis Reyes Ochoa, Universidad Católica Silva Henríquez, Santiago, Chile } \\
\text { María Cristina Rinaudo, Universidad Nacional de Río Cuarto, Córdova, Argentina }\end{array}$ \\
\hline Centro Gráfico Salesiano & María Domingo Coscollola, Universitat Internacional de Catalunya, Barcelona, España \\
\hline (Antonio Vega Muñoz 10-68 & María José Batista Pinto, Universidad Federal de Minas Gerais, Belo Horizonte, Brasil \\
\hline y General Torres). & María Teresa Prieto Quezada, Universidad de Guadalajara, Guadalajara, México \\
\hline Telf.: $(+5937) 2831745$ & Mario Llanos, Università Pontificia Salesiana, Roma, Italia \\
\hline Correo electrónico: & Marlécio Maknamara da Silva Cunha, Universidad Federal de Río Grande del Norte, Natal, Brasil \\
\hline centrograficosalesiano@lns.com.ec & Marlucy Alves Paraiso, Universidad Federal de Minas Gerais, Belo Horizonte, Brasil \\
\hline Cuenca-Ecuador & Nelson Rubén Martínez Reyes, Universidad Don Bosco, San Salvador, El Salvador \\
\hline & $\begin{array}{l}\text { Ronerto Canales Reyes, Unıversidad de Los Lagos, Usorno, Chile } \\
\text { Ronarias, Centro Universitario Salesiano de Sao Paulo, Sao Paulo, Brasil }\end{array}$ \\
\hline & Shirlei Rezende Sales, Universidad Federal de Minas Gerais, Belo Horizonte, Brasil \\
\hline & Susana Barco, Universidad Nacional de Comahue, Neuquén, Argentina \\
\hline & Sylvia Schmelkes del Valle, Universidad Iberoamericana, México, D.F., México \\
\hline
\end{tabular}

Copyright: Alteridad 2013, Universidad Politécnica Salesiana, Ecuador. Se permite la reproducción total o parcial de esta revista, siempre que se cite la autoría y la fuente original de su publicación. 
Editorial.

TEMA CENTRAL

LOS NUEVOS ESCENARIOS DE LA

COMUNICACIÓN Y EDUCACIÓN

Convergencia tecnológica y pedagógica del blended learning: transiciones y perspectivas

Osbaldo Turpo Gebera

Web 2.0: plataforma para la reconfiguración de la educación en la cibercultura

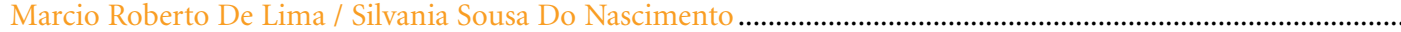

La Industria Cultural y la crítica educativa en América Latina: una perspectiva histórica

Miguel Ángel, Soto Sandoval

Apuntes para el debate ecuatoriano sobre medios: Distribución de frecuencias, ¿posibilidades para la educomunicación?

Roberto Sánchez Montoya....

\section{CONTRIBUCIONES ESPECIALES}

Currículo por competencias y la significatividad del proceso educativo salesiano

Gervásio Bassini Sobrinho

"Impacto de los estilos de liderazgo en el clima institucional del Bachillerato de la Unidad Educativa María Auxiliadora de Riobamba"

Luisa Lozado.

Memoria académica.

Novedades bibliográficas

Normas para autores

Authors' guidelines 


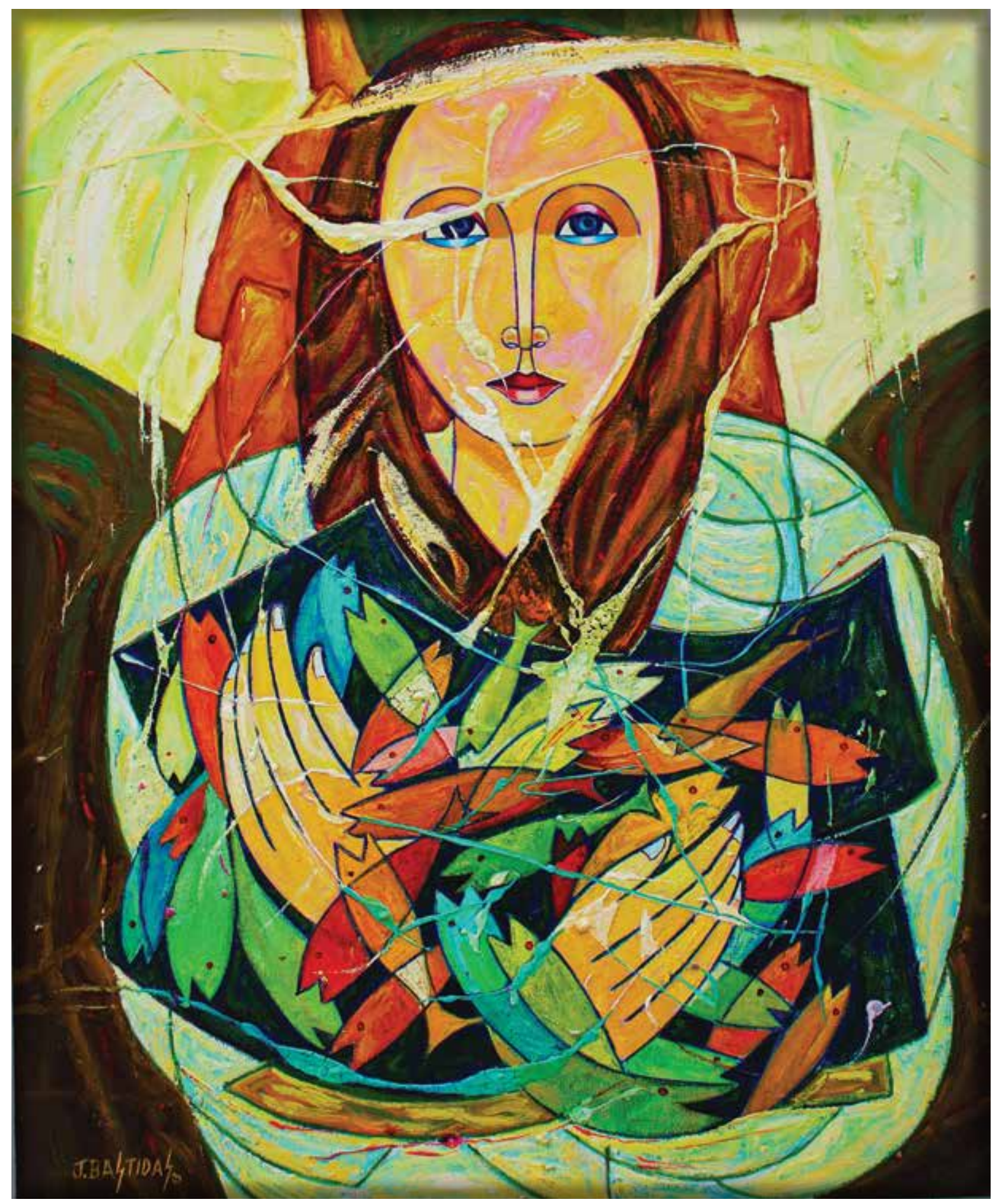

Protectora I

$70 \times 90$

GALERÍA DE ARTE

José Bastidas (pintor; Otavalo, 1960)

Vive en Quito, comparte la afición por la pintura con la docencia en la Facultad de Filosofía de la Universidad Central y en el Instituto Nacional Mejía. Ha sido merecedor de premios y menciones en varios eventos nacionales e internacionales. 
Al hablar de la comunicación y educación, casi siempre ocurren tergiversaciones de tipo reduccionista que dificultan ver la riqueza y posibilidades de esa relación. A veces se refieren al simple uso de recursos tecnológicos como el televisor, la radio o el internet; otras veces describen el tipo y la cantidad de recursos, y el volumen de información que pueden encontrar; e incluso pueden referirse al uso de un idioma nacional o extranjero como un medio de comunicación. Sin embargo, no se piensa necesariamente que la relación de los procesos educativos y pedagógicos con los comunicativos constituya la base de muchas de las expresiones de la cultura actual y sus problemáticas.

Las profundas transformaciones de la sociedad, desde lo económico, político y social, hasta lo cultural plantean nuevos retos que exigen nuevos saberes, conceptos y teorías para comprender sus procesos y actuar sobre ellos. La relación comunicación-educación constituye uno de esos campos emergentes. Estamos inmersos en un medio que posee una alta densidad comunicativa, en la cual circula una gran cantidad de saberes y de información, a gran velocidad y copando los diversos espacios de la cotidianidad; implica también que la comunicación y las prácticas comunicativas son más complejas. Las transformaciones que eso está generando en las percepciones, sensibilidades y conocimientos, especialmente de niñas, niños y jóvenes, hace que no se pueda seguir considerando la comunicación como un simple proceso de transmisión de información. Este número de Alteridad, a través del tema central "los nuevos escenarios de la comunicación y educación” propone abrir un espacio de análisis y reflexión en este campo.

Turpo Osbaldo, a través de su artículo Convergencia tecnológica y pedagógica del blen- ded learning: transiciones y perspectivas, retoma una base conceptual que ha sido discutida en el ámbito de la Educación y las Tecnologías de Información y Comunicación (TIC). Su aporte con respecto al blended learning es relevante por su manera de incorporar las TIC a los procesos educativos desde una visión evolutiva. Señala que en la actualidad, la progresiva evolución social, tecnológica y cultural hacia la convergencia, constituye un nuevo referente de la modalidad, dada la confluencia de las mediaciones pedagógicas y tecnológicas en el proceso formativo. En el ámbito educativo, la confluencia de los avances tecnológicos y enfoques pedagógicos brinda nuevas oportunidades para el diseño de los entornos formativos; por lo tanto, la convergencia entre los componentes presencial y virtual y la continuidad de las mediaciones pedagógicas y tecnológicas constituyen un aporte innovador.

La Web 2.0: plataforma para la reconfiguración de la educación en la cibercultura de los autores Marcio Roberto de Lima y Silvania Sousa do Nascimento, presenta una reflexión crítica en torno a la pertinencia y funcionalidad de la $\mathrm{Web}$ 2.0 como espacio de articulación de los referentes socioculturales, tecnológicos y educativos, conducentes a procesos de formación. Desde un enfoque triangulado de las perspectivas tecnológica, cultural y pedagógica, el autor presenta las posibilidades y funcionalidad de la Web 2.0 como alternativa válida para el desarrollo de la acción educativa en un contexto de inminente prevalencia de la cibercultura y de la democratización creativa del ciberespacio, con sus implicaciones socioculturales en el pensamiento y la actividad humanas. El autor propone que los dispositivos digitales y las redes de comunicación sean utilizadas con intencionalidad pedagógica y ciudadana. 
En el artículo La Industria Cultural y la crítica educativa en América latina: Una Perspectiva Histórica, Miguel Ángel Soto presenta a tres autores, quienes desde sus propios campos disciplinares aportan al desarrollo del saber educativo en América latina en los temas de la cultura, la comunicación y la educación. Comienza subrayando que los aportes de Andrés Bello fueron claves para la constitución de la cultura ilustrada, convirtiéndose en la primera estrategia comunicativa y educativa que busca plasmar las nuevas dimensiones de la naciente cultura latinoamericana; luego explica cómo José Martí y Rubén Darío, confrontados por una Modernidad que comienza a reemplazar la Cultura Ilustrada por la Cultura de masas, cuestionan la industria cultural desde un enfoque más académico y crítico. El análisis final de cómo surge la crítica comunicativa frente a los procesos de dominación que provienen no sólo desde lo económico sino también desde las "industrias culturales" lo llevará a concluir que es necesario e importante explorar nuevos modelos de educación desde un enfoque más crítico.

Un tema relevante para el campo político y educativo en Ecuador y Latinoamérica evidencia Roberto Sánchez, a través de su artículo Apuntes para el debate ecuatoriano sobre medios: distribución de frecuencias, ¿posibilidades para la educomunicación? abordando la temática de la distribución de frecuencias. Los cambios en la normativa que regula la distribución en frecuencias en algunos países latinoamericanos, tienen un denominador común: concesionar un tercio de estas frecuencias a medios comunitarios sin fines de lucro, otro tercio se reserva para medios de organismos públicos, y un tercio para el sector estrictamente mercantil. En este contexto, se pregunta ¿Qué posibilidades existe para un relanzamiento de propuestas de comunicación orientadas hacia la educomunicación? El ensayo de posibles respuestas lo realiza a partir del caso ecuatoriano.

Como contribuciones especiales se publican dos artículos inspirados en sendos trabajos de graduación en Maestrías. El primero de Bassini Gervásio, Currículo por Competencias y la Significatividad del Proceso Educativo Salesiano con un tema relevante de las experiencias políticopedagógicas de las escuelas salesianas. Los avances identificados giran en torno a la necesidad de considerar teórica y prácticamente, la totalidad de las dimensiones: espiritual, cultural, político y social, en el proceso educativo ofertado por las escuelas salesianas. Considerando que, generalmente, en las escuelas confesionales, la integralidad de la vida humana no es percibida en el quehacer pedagógico de los educadores ni de las instituciones; este artículo constituye un avance y una innovación en el campo de debate académico y educativo. Su originalidad está en la fuerza intelectual para abordar un tema complejo involucrando escuelas confesionales, en forma crítica, simultáneamente desde el punto de visto político-filosófico; y didácticamente educativa, desde una perspectiva académica.

El otro artículo Impacto de los Estilos de Liderazgo en el Clima Institucional del Bachillerato de la Unidad Educativa María Auxiliadora de Riobamba de Luisa Lozado, constituye un tema de mucha importancia para el contexto educativo salesiano y de las escuelas en general. El artículo, desde el enfoque teórico de Bass y Avolio, muestra, por una parte, que cuanto más democrático, participativo y transformador es el estilo de liderazgo, más cálido, familiar y de confianza es el ambiente en la institución; y por otra, que en esa Unidad Educativa se percibe un ambiente agradable, motivador, alegre, familiar y con sentido de pertenencia. Se podría realizar el mismo trabajo en otros establecimientos, para comprobar con mayor certeza que el estilo de liderazgo sí influye en el clima institucional.

En fin, la revista está avanzando a "paso firme" en el proceso de revisión externa. Ante todo, un agradecimiento particular a nuestro equipo de lectores, aunque eso implique un proceso de selección de los mejores artículos, la intención primera es ofrecer conocimientos validados por expertos en el tema, de manera que puedan servir de referentes el aprendizaje de estudiantes y docentes. Jaime Padilla. Editor responsable. 


\section{Tema central}

Los nuevos escenarios de la comunicación y la educación

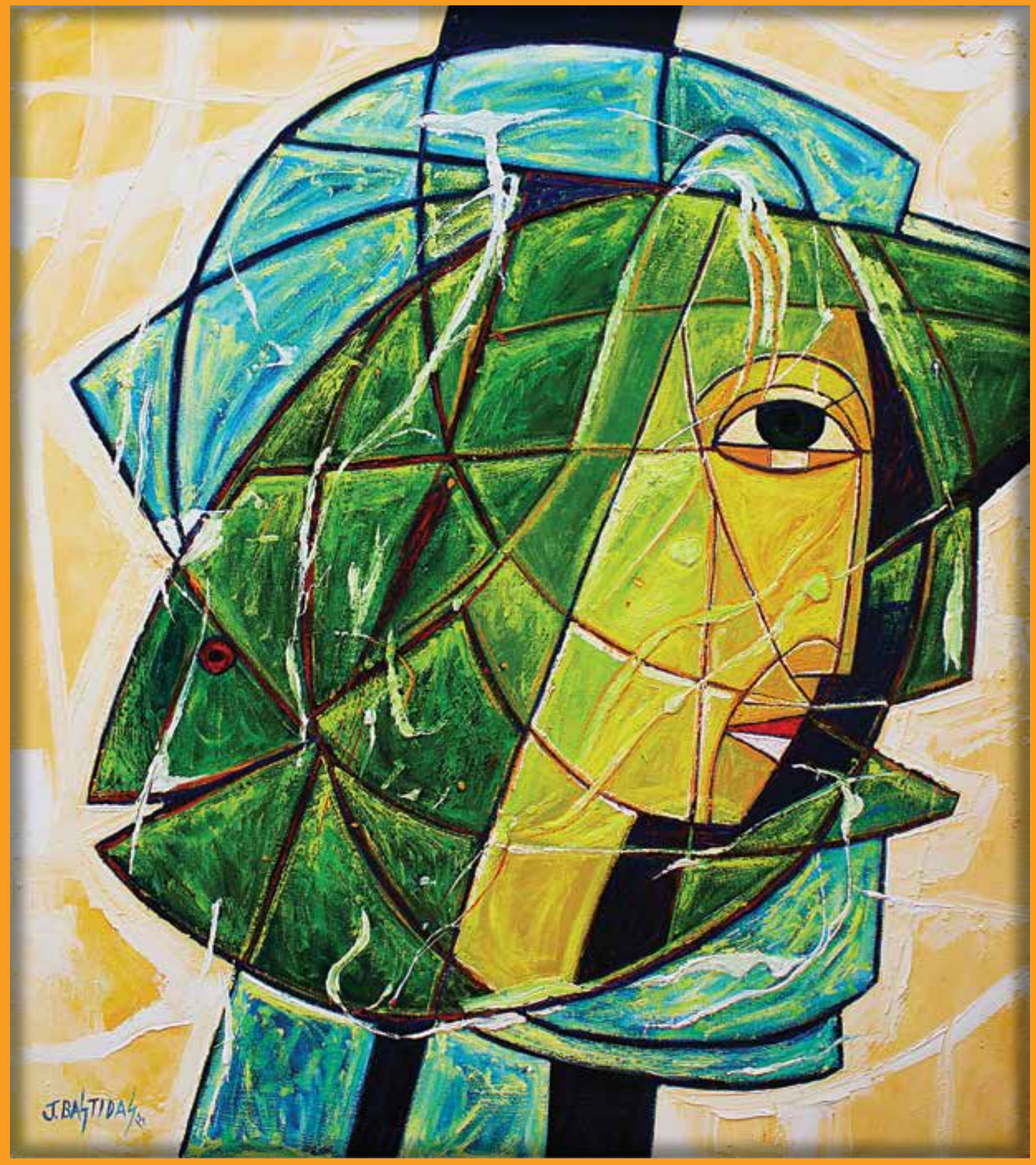




\title{
Convergencia tecnológica y pedagógica del blended learning: transiciones y perspectivas
}

\section{Tecno- teaching convergence of blended learning: transitions and prospects}

\author{
Osbaldo Turpo Gebera \\ Universidad Peruana Cayetano Heredia \\ Osbaldo.turpo.g@upch.pe
}

\section{Resumen}

Desde su emergencia en el contexto educativo, el Blended Learning emerge como una modalidad con identidad propia. Conforme a su evolución, discurre por contextos configurados por la presencialidad y la virtualidad. En un primer estadio, se sitúa como una modalidad mixta o de combinación; posteriormente se avanza a una integración, que supone la dilución de sus componentes. La progresiva evolución social, tecnológica y cultural hacia la convergencia, aporta en la actualidad un nuevo norte a la modalidad, dada la confluencia de las mediaciones pedagógicas y tecnológicas en el proceso formativo. Este posicionamiento lo ubica dentro de una nueva tendencia, que más que una posibilidad, representa una realidad más explicable sobre el devenir del Blended Learning.

La convergencia tecno-pedagógica de medios y recursos representa un modo más acorde para comprender la modalidad, en tanto proporciona un marco de interpretación sobre la transición y perspectivas de desarrollo del Blended Learning, de confluencia y continuidad de escenarios y potencialidades orientados hacia un mismo fin: el formativo.

Palabras clave: Presencialidad-virtualidad, Blended Learning, convergencia mediática, mediación tecno-pedagógica.

\section{Summary}

Since its emergence in the educational context, the Blended Learning emerges as a modality with its own identity. According to its evolution, runs through presentiality configured contexts and virtuality. In a first stage, stood as a mixed or combined mode, then advanced to integration, which resulted in the dilution of its components. The progressive social changes, technological and cultural towards convergence, today brings a new north-mode, given the confluence of pedagogical and technological mediations in the training process. This position places him in a new trend that more than a possibility, actually represents a more explicable on the future of Blended Learning.

The pedagogical and technological convergence of media and resources is a more consistent way to understand the mode, while providing a framework for interpreting the transition and development prospects of the Blended Learning, confluence and continuity and potential scenarios facing the same end: the training.

Keywords: Presentiality-virtuality, blended Learning, media convergence, mediation techno-pedagogical.

Forma sugerida de citar:

Turpo, O. (2013). Convergencia tecnologica y pedagógica del blended learning: transiciones y perspectivas. Alteridad, 8(2), pp. 128-143. Quito: Editorial Abya-Yala. 


\section{Introducción}

La modalidad Blended Learning, pese a su aún breve existencia, mantiene un intenso dinamismo, aunque su uso se remonta en el tiempo hacia unos veinte años atrás. El término forma parte de la sofisticación de nuestro lenguaje. En su traducción al español, (Aprendizaje Mezclado) sigue una tendencia marcada por la psicología escolar, al destacar el "aprendizaje" como contrapuesto a la "enseñanza" (Bartolomé, 2004).

El Blended Learning responde a distintas configuraciones educativas. Para unos, a una instrucción híbrida, al mezclar el potencial de la formación basada en web con las técnicas del aula presencial (Delialioglu \& Yildirim, 2007; Gülbahar \& Madran, 2009). Otros, como Garrison y Kanuka (2004), sostienen que es un aprendizaje combinado, en cuanto aprovecha los valores de las clases tradicionales con el entorno generado por el aprendizaje en línea (on line).

En esencia, en su dinámica concurren un amplio abanico de medios para aprendizajes diseñados y dirigidos a resolver problemas específicos en entornos mediados por la red (Brennan, 2004). Propiamente, el Blended Learning podría ser considerado como Blended e-learning (Mantyla, 2001).

Las prácticas educativas inscritas dentro de esta modalidad formativa presentan diferentes denominaciones y connotaciones, pero responden a una misma estructura básica: presencialidad y virtualidad, sea como combinación, integración, mezcla, etc. de dos modos educacionales.

Los estudios realizados evidencian que el termino Blended Learning es la denominación prevalente, comprendido como un paradigma que mezcla o hibridiza ambas modalidades. La semipresencialidad es vista como una combinación de escenarios presenciales con sesiones virtuales. Mientras que en la bimodalidad, la presencialidad se reconoce como un proceso complementario a los entornos virtuales; en la educación a distancia on line, lo virtual es una prolongación de lo presencial (Turpo, 2010). Básicamente, lo que define a la modalidad deviene de la concurrencia de la virtualidad y la presencialidad, diferenciados por el énfasis denominativo asignado, que más que determinante, es una característica meramente diferencial, que no cambia el fondo.

En su transcurrir, la modalidad ha cambiado progresivamente de concepción y práctica (Sharpe et al., 2006). No se trata de un practica nueva, puesto que durante años se combinan las clases magistrales con los ejercicios, los estudios de caso, juegos de rol y las grabaciones de vídeo y audio, como el asesoramiento y la tutoría (Brodsky, 2003). ¿Sobreviviría la educación sin hacer transformación y sin utilizar las herramientas tecnológicas, desarrolladas para las transformaciones de los demás sistemas?

En la estructura del Blended Learning coexisten procesos de reacomodo entre sus componentes. La modalidad, desde las iniciales prácticas definidas por la combinación, mezcla o hibridación de lo presencial con lo virtual, el cambio en los roles protagónicos (tutores y discentes) y la adaptación organizativa; ha transitado a propuestas de integración, como un todo orgánico, al considerar las ventajas de la presencialidad y la virtualidad como una unidad (García, 2004).

En la actualidad, el Blended Learning se orienta hacia una nueva reconfiguración: un salto inevitable, signado por la convergencia. Esta evolución presupone la síntesis de las mediaciones pedagógicas y tecnológicas, haciendo imperceptible las fronteras que las separa, e inadmisible el deslinde sobre dónde termina una y dónde empieza la otra.

Aportan a esa disposición: la relativización del acceso a la información, la (re)utilización de los recursos físicos en digitales, la redistribución de los contenidos, los nuevos alfabetismos, entre otros, que vistos en conjunto, afianzan la percepción del intercambio continuo, más allá del ámbito que delimitan sus confines.

Este "entrecruce" forja entre los entornos físicos y virtuales, un entramado donde la convergencia prima como una tendencia insalvable, una sinergia de esfuerzos, enfoques, herramientas, 
etc, resultantes de la confluencia de los medios y recursos que han propiciado las imparables innovaciones en el campo de la formación. Un proceso que explica el decurso del Blended Learning, cuya dinámica evolutiva responde a las exigencias de estos tiempos, donde todo parece confluir hacia un mismo proceso, una continuidad y trasvase indistinto de escenarios, que hacen imperceptible las fronteras y la dilución de entornos. Es este el marco de soporte y transición del proceso actual de la modalidad, y que demostraremos en los siguientes apartados.

\section{Progresivividad del blended learning}

La incorporación de las Tecnologías de la Información y Comunicación (TIC) a los procesos educativos, dio lugar a la emergencia del E-learning como modalidad formativa. El proceso significó un cambio paradigmático en la formación que supuso la utilización sistemática de la tecnología multimedia como una tecnología definitorial Bolter (1984). Según Goodyear (2000), se orientó a dotar de autonomía a los participantes, a la mejora de su aprendizaje y para conectarlos con los recursos del inter-aprendizaje.

Con el E-learning se intenta aproximar el conocimiento a todas las audiencias, ante la disociación de los diversos ambientes de aprendizaje: física y metodológica. En ese devenir se incorporan la diversidad de recursos tecnológicos, unidos en un único ambiente de aprendizaje, denominando multi-ambientes de aprendizaje (Carneiro, 2004).

Para Bahry (2001), el E-learning se fundamenta en el cambio e innovación de los medios de comunicación como factores del desarrollo formativo, que no ponen en tela de juicio sus principios, sino que forman parte de su historia.

Bolter considera una tecnología definitoria aquella que desarrolla vínculos, metáforas $u$ otras relaciones con una cultura de la ciencia, la filosofía o la literatura. Y, siempre que esté disponible a servir como metáfora, ejemplo, modelo o símbolo.
Dudezert (2002), considera que la pedagogía del E-learning no es nueva, todo lo contrario, es una continuidad del desarrollo de lo digital en la educación a distancia.

En sus inicios, el E-Learning se entronizó en el mundo empresarial, en cursos dirigidos a trabajadores, para que se sigan formando en su lugar de trabajo o estudio. Concebido como un tipo de estudios en reemplazo de la capacitación a distancia e instrucción programada, instituida a través de manuales, tutoriales, test, videos, etc. El E-Learning viene a sustituir el tiempo residencial periódico de la educación a distancia, por una instrucción instaurada principalmente en la web y los diversos recursos electrónicos; tornándose éstos, en una medida del ahorro y la rentabilidad de la capacitación.

Las esperanzas puestas en el E-learning fueron decayendo, conforme transcurría la crisis experimentada por el sector, por el aumento indiscriminado de las empresas DotCom, y su correlativa crisis con la sobreoferta de cursos de postgrado a distancia. Se empezó así, relativizando el término E-learning y apareció el uso de otro concepto: Blended Learning (Aiello \& Cilia, 2004). Fue comprendido como un modelo de naturaleza híbrida, que exige experimentación, desarrollo de actividades que conlleven la aplicación de los conceptos, ideas o contenidos (Marqués et al., 2011), y basado en la utilización de internet; propiamente, orientado a proporcionar un abanico de soluciones para la adquisición de conocimientos y habilidades (competencias).

En sus inicios, el Blended Learning irrumpe como una formación alternativa, de carácter mixto o híbrido, que mezcla o combina técnicas del E-learning como la distribución on-line de materiales a través de páginas web, foros de discusión y/o correo electrónico con los métodos tradicionales de enseñanza: conferencias, discusiones en persona, seminarios o tutorías (Graham, 2005). Este decurso de la modalidad responde a la concepción de agregar virtualidad a la educación presencial (Valzacchi, 2005); y a la flexibilidad de escenarios y metodologías de enseñanza y 
aprendizaje, así como a la accesibilidad, rapidez y actualización de contenidos (Hinojo, Aznar \& Cáceres, 2009).

En su composición, Carman (2002) identifica cinco elementos comunes: 1) eventos vivos (personas), 2) aprendizaje autónomo y autoubicado, 3) colaboración, 4) materiales de apoyo y 5) evaluación.

En conjunto se orientan a aprovechar al máximo la experiencia educativa, al superar las barreras tempo-espaciales y consentir el acceso a los recursos, desde cualquier lugar y en cualquier momento. La modalidad propicia el ajuste del proceso a las características de los participantes. El Blended Learning, en este primer estadio, la eligen las personas, fundamentalmente por: ser una pedagogía renovada, facilitar el acceso y fle- xibilidad e incrementar la rentabilidad (Graham, Allen \& Ure, 2003).

Su diseño implica el desarrollo de un ecosistema de metodologías de trabajo colaborativo (Lavrin \& Zelko, 2005), que comprende una fase de diagnóstico del contexto de aprendizaje. Se trata de superar los desajustes en la utilización de los recursos existentes, fundamentalmente, por la baja capacitación en el uso de las herramientas tecnológicas y el incremento del tiempo de trabajo para los participantes (Álvarez, Rodríguez \& Ribeiro, 2011).

En síntesis, su diseño resulta de combinar "lo mejor de ambos mundos", del virtual y presencial, proporcionando el equilibrio entre la flexibilidad e interactividad, marcada por la tecnología (Reynolds \& Greiner, 2005).

Figura 1 : Convergencia progresiva del Blended Learning $(\mathrm{BL})$

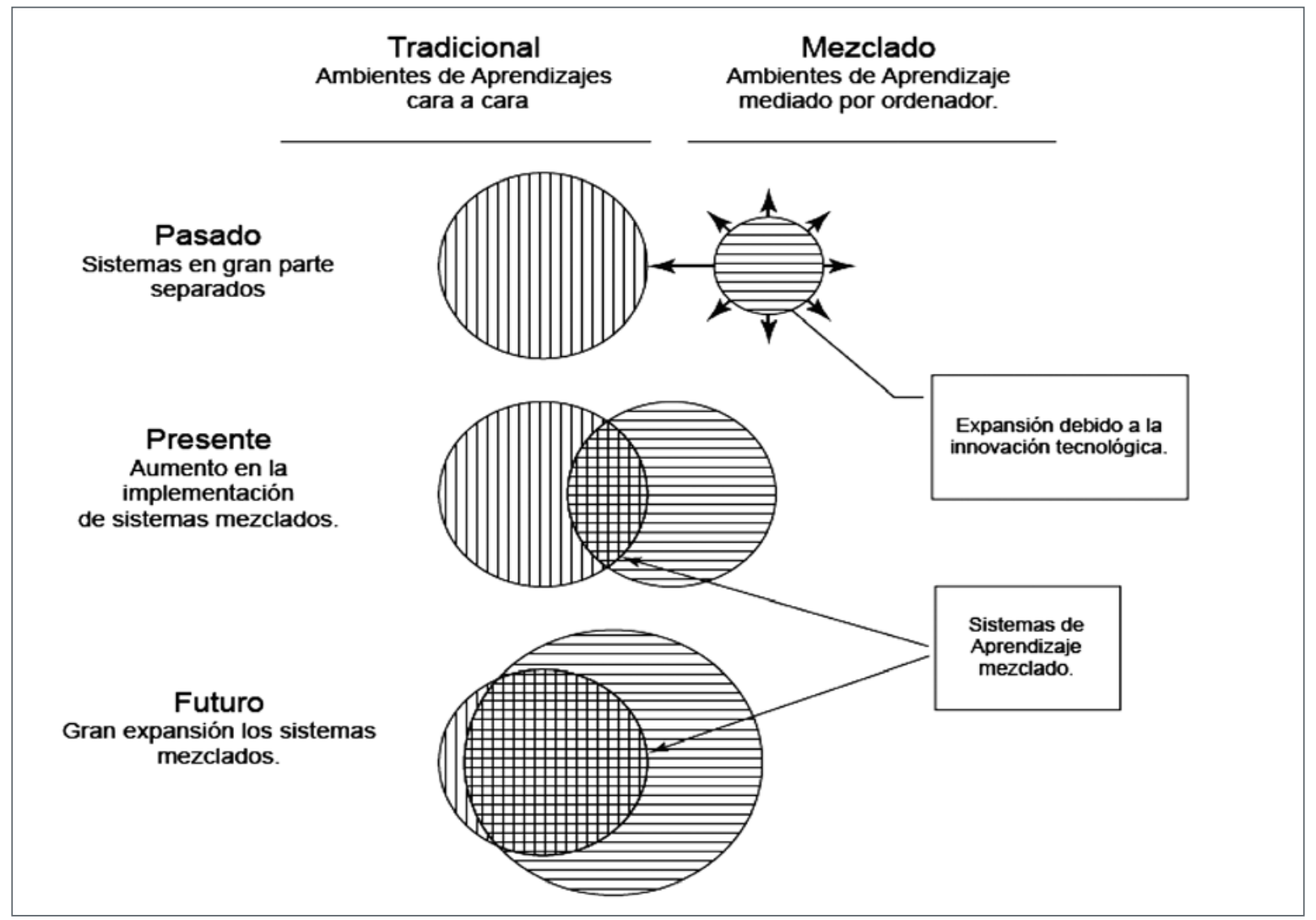

Fuente: Graham, 2007. 
2.1. Primer momento (pasado): como se observa, el Blended Learning se deriva de la mezcla del entorno convencional del "face to face" con las potencialidades provocadas por la expansión de las TIC en el aprendizaje en ambientes virtuales. Propicia así, una interacción distinta, una reordenación pedagógica a través de la combinación de: modalidades instruccionales (Bersin, 2004); de métodos instruccionales (Rossett, 2002) y la instrucción cara a cara y en línea (Ward \& La Branche, 2003).

2.2. Segundo momento (presente): reconocido el potencial que representa, se instituye como una modalidad pedagógica unificadora. No se asume más, como una combinación ni punto intermedio de dos modos de educar ni la aplicación ecléctica de dos modelos o la intersección entre lo presencial y virtual; sino como la integración armónica de medios, recursos, enfoques, metodologías, actividades, estrategias y técnicas educativas (García, 2004). Responde así, a la flexibili- dad espacio-temporal, a los contenidos del aprendizaje en la construcción colaborativa del conocimiento, al diseño instruccional que integra lo virtual con lo presencial y a la posibilidad aplicativa a una multitud de contextos (Llorente, 2008). De ese modo, los participantes adquieren las capacidades decisorias para el uso oportuno y apropiado de las herramientas tecno-pedagógicas (Novell, 2010).

2.3. Tercer momento (futuro): la proyección avizorada por Graham (2007), trasciende la integración de componentes. El uso de herramientas sincrónicas y asincrónicas favorece la integración tecno-pedagógica, reforzada por las tutorías presenciales y las acciones implementadas en red. En este estadio, el participante asume rol protagónico, es responsable de lo que necesita aprender y la disposición a solicitar y recibir el apoyo de tutores y profesores. El proceso discurre hacia una mezcla de sistemas de aprendizaje, como representa la figura siguiente.

Figura 2: Componentes para el desarrollo del b-learning

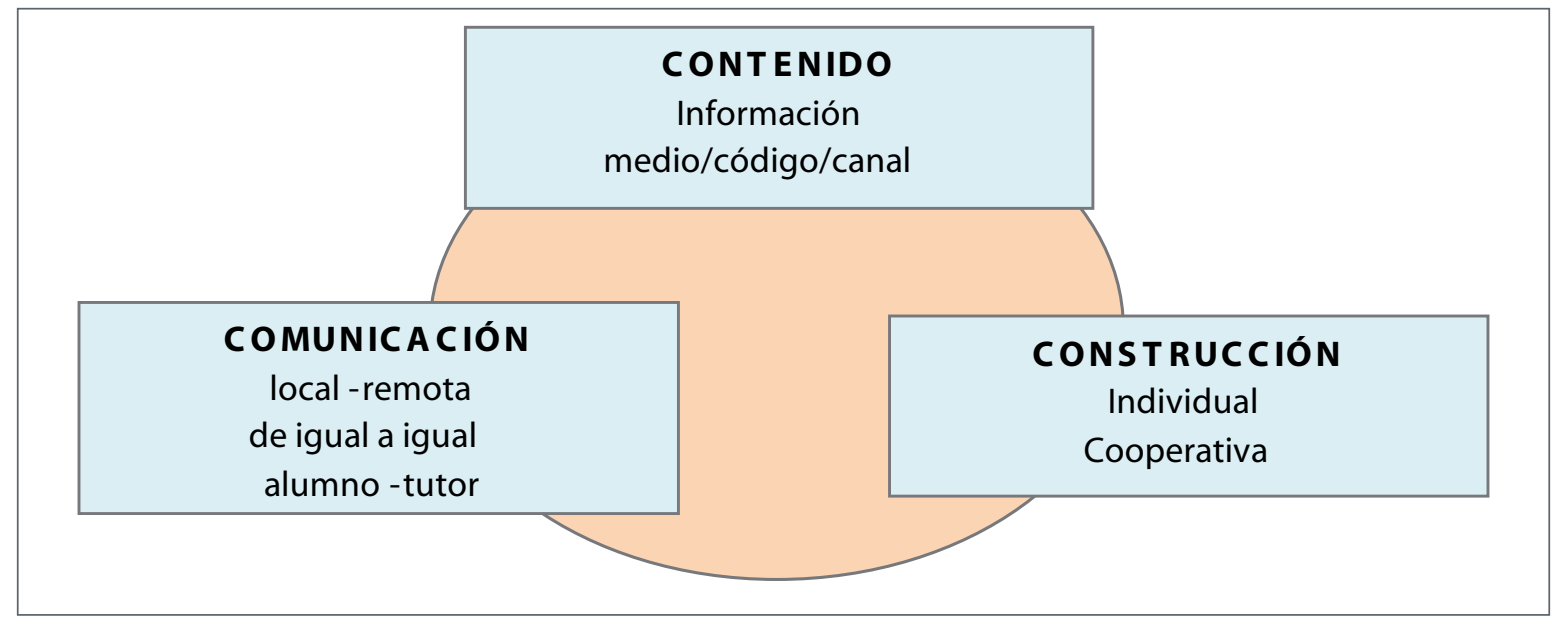

Fuente: De Witt y Kerres, 2003.

Frente al tercer momento de la propuesta, que más que una mezcla de sistemas, se percibe como realidad inmediata, una convergencia de medios, componentes, recursos, etc. Y eso es lo que se evidenciará a continuación. 


\section{¿Convergencia (mullimediática)?}

La referencia a la convergencia comprende a la convergencia multimediática2. Una contingencia situacional donde desaparecen las fronteras entre los medios y servicios de comunicación (teléfono, televisión, radio y computadora, etc.). Es entendida "como un fenómeno con múltiples dimensiones: tecnológicas, económicas, sociales y políticas" (Pérez \& Acosta, 2003: 1). El proceso permite la emergencia de un escenario para la gestión de información, fundado en sus aplicaciones, perspectivas y trascendencia.

Para la Organización de Naciones Unidas (ONU), la "convergencia es la capacidad de diferentes plataformas de red de transportar tipos de servicios esencialmente similares y la aproximación de dispositivos de consumo, como el teléfono, la televisión y la computadora" (citado en Pérez \& Acosta, 2003: 3).

El enfoque de la convergencia multimediática no supone tan solo la aparición de una serie de servicios que combinan texto, voz, imagen en movimiento y sonido; sino, básicamente, la eliminación de las fronteras mediáticas y la sucesiva convergencia. Emerge como un único mecanismo digital (World Wide Web) y de accesibilidad a una multitud de dispositivos (Villanueva, 2000), al proporcionar mecanismos de integración de medios que requerían canales diferentes y admitir la comunicación sin límites tecnológicos (León \& García-Avilés, 2000).

La convergencia de medios trasciende las fronteras mediáticas, más aún, entre las comunicaciones punto a punto (correo, teléfono $\mathrm{y}$ telégrafo) y las comunicaciones de masas (prensa, radio y televisión). En la actualidad, basta un único entorno físico (fidelidad, cables $\mathrm{u}$ ondas) para prestar los servicios ofrecidos por separado,

2 El término convergencia sugiere el movimiento de objetos hacia un mismo punto. En comunicaciones, significa la integración de la computación con las telecomunicaciones (Prado y Franquet. 1998). a través de un medio (audiovisual, prensa o teléfono), ahora ofertados en diferentes formas físicas. La relación de uno, que existía entre un medio y su uso está erosionada (de Sola, 1983).

En el plano empresarial, la convergencia implica la fusión de empresas corporativas mediáticas, orientados a la concentración de las TIC para desarrollar servicios convergentes en un solo canal.

Resumiendo, la convergencia mediática es un nuevo escenario para la gestión de información (Pérez \& Acosta, 2003: 13), en el que se destacan:

- La convergencia digital.

- La tendencia a la creación de grandes multinacionales.

- Las nuevas formas de comunicarse y de gestionar información.

- Las profundas transformaciones en el papel de los comunicadores.

- Los nuevos lenguajes y medios; interactivos, flexibles.

- La ampliación de los servicios: ofertas ilimitadas en multiplicidad de canales, los paquetes temáticos y las programaciones especializadas.

- El aumento de las productoras de contenidos. - El surgimiento de nuevos hábitos de consumo. - La profundización de la brecha digital.

- El surgimiento de nuevas oportunidades para el desarrollo social.

Esta tendencia creciente de la convergencia, en todos los órdenes del desarrollo humano y social $y$, específicamente de la convergencia multimediática, representa uno de los mayores retos de la era global y digital. Suscita en el entorno actual, la desaparición de las líneas divisorias entre medios masivos y servicios de comunicación, como el teléfono, la televisión, la radio y el ordenador, entre otros.

La convergencia se torna en un fenómeno con múltiples dimensiones (tecnológicas, económicas, políticas, entre otras). Sin ella, la creación de una sociedad del conocimiento presentaría un considerable retraso; su emergencia requiere 
un marco flexible y equilibrado que favorezca la inversión y aparición de nuevos servicios (Liikanen, 2003).

En este escenario, la educación no se presenta vacía de contenidos o carente de calidad o metodológicamente desenfocada. No se reduce al uso de la plataforma y contenidos, ni de docentes y tutores capacitados para desarrollar una acción formativa; sino que: propicia, dinamiza y aprovecha las potencialidades de interacción y trabajo colaborativo de las TIC, al igual que los aspectos organizativos y de gestión, y la forma e intensidad del uso de las herramientas didácticas (García, 2011a).

\section{Convergencia en el blended learning}

El estadio evolutivo del Blended Learning, el de la tendencia convergente, es un proceso que obedece al desarrollo consustancial de experimentar del hombre para mejorar todo lo perfectible. Una búsqueda de explicaciones sobre cómo funciona aquello que sirve a sus propósitos, de encontrar respuestas no siempre satisfactorias, pero que lo motiva a sucesivas exploraciones.

Ante esta saliente etapa, la educación no está al margen, todo lo contrario, promueve la intervención de las diversas estrategias multimedia, intermedia o transmedia; que junto a los sistemas o plataformas tecnológicas de educación a distancia, concentran y fusionan diferentes medios, instrumentos o herramientas de comunicación e información (aunque predomine uno) (Ojeda, 2004). El proceso encarna la oportunidad para consolidar la confluencia de los recursos tecnológicos con los pedagógicos, en favor de una plena interactividad de los usuarios.

La convergencia tecnológica y pedagógica implica la construcción de puentes entre mundos "separados" artefactualmente, al hiperconectar la información que fluye a través de las múltiples plataformas mediáticas y vincular los intersticios de los viejos y los nuevos medios; propiciando un viaje por el conocimiento, mediante estacio- nes interconectadas. El decurso conlleva que los sistemas mediáticos virtuales y físicos compartan recursos, espacios, procesos, etc., en concertación polivalente.

En este plano, la convergencia representaría una adherencia de propósitos sociales, políticos, culturales, etc., un reajuste en las formas de enseñar y aprender, con unos $\mathrm{u}$ otros medios o recursos; una aproximación de los espacios donde se produce el conocimiento, y en el que los aprendizajes se reconstruyen.

El proceso es favorecido por la interacción entre la abstracción y lo sensible, la inmediatez y lo extendido; al replantear los confines entre la diversidad de saberes y modos de hacer $y$, licuar la variedad formativa.

La convergencia posibilita recrearla, al considerar en el diseño didáctico, los ajustes necesarios entre las estrategias pedagógicas y los recursos y medios tecnológicos; sin mayores restricciones ni límites y como efecto previsible de la evolución que prosigue a toda creación humana.

Una posibilidad de comprensión sobre cómo funciona el Blended Learning, deviene de la indistinguibilidad de los confines que separan a lo presencial de lo virtual, y que García (2011b) la percibe bajo los siguientes interrogantes:

¿No se estará diluyendo, o quizás ya esté diluida? ¿no se trata más bien de una convergencia de sistemas? ¿pueden los sistemas de educación a distancia prescindir $100 \%$ de algún contacto presencial, aunque sea en algún momento de la evaluación en estudios oficiales y reglados? ¿no sería mejor hablar de diferente énfasis que, según modelos, se asigna a la relación presencial y la soportada, por ejemplo, en entornos virtuales de aprendizaje? ¿no es más cierto que cada vez existe menor salto entre unas y otras experiencias, modelos o formulaciones? ¿no es más cierto que deberíamos hablar de confluencia o convergencia de sistemas? ¿no es más cierto que más que contraponer sistemas deberíamos hablar de educación, de calidad de esa educación, sea con énfasis presencial o a distancia? 
Figura 3: Convergencia de la modalidad de educación a distancia y presencial

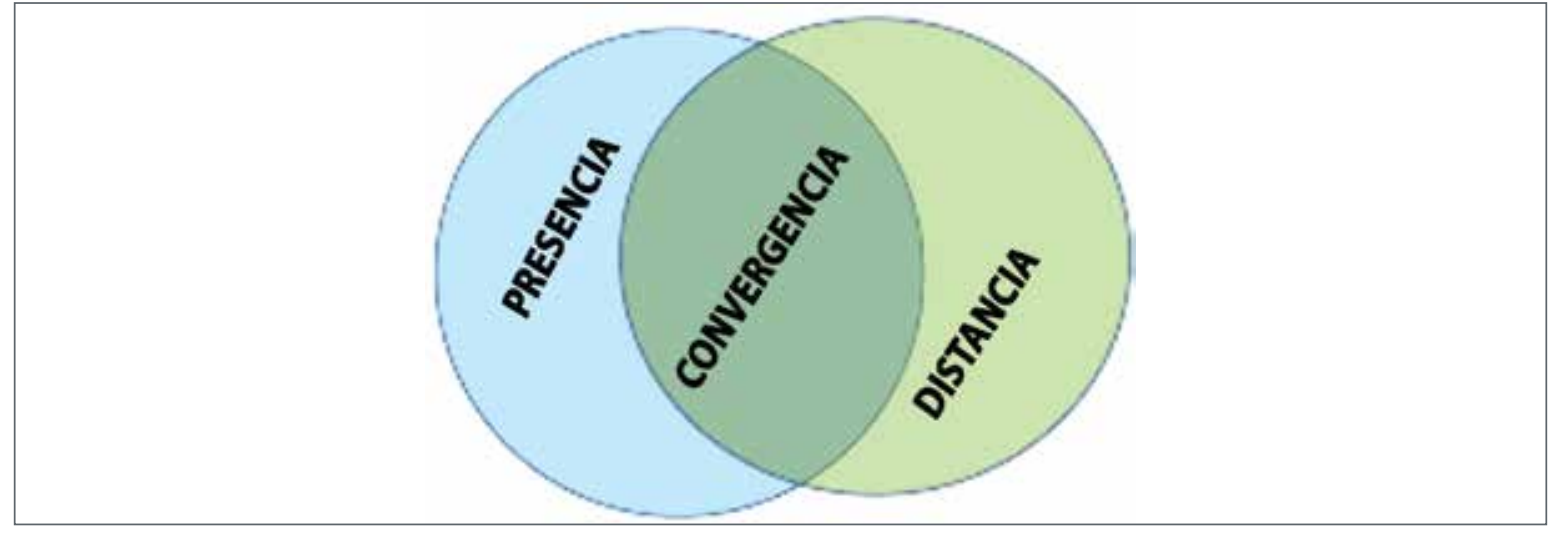

Fuente: (García, 2011 b).

Las respuestas parecen más que evidentes. Avanzamos hacia una dinámica educativa donde se hacen imperceptibles los estadios signados por lo presencial y virtual. Transitamos hacia una concepción donde todo parece converger en un todo-único, de un intervenir colaborativo. La confluencia presencial-virtual se expresa a través de la concurrencia de los componentes que la forman; involucra una mayor inversión personal, por cuanto refuerza el sentido de comunidad y favorece a la generación de un clima de colaboración y confianza para el aprendizaje conjunto (Ripa, 2007).

La convergencia admite la concurrencia de dispositivos, escenarios, roles, etc. hacia una mismo propósito; una reingeniería educativa que trasciende los contornos establecidos, la vinculación de continentes con contenidos y la intervención en y a través de varios canales mediáticos, operados paralelamente.

Un proceso convergente involucra un flujo de contenidos a través de múltiples medios, apoya la cooperación entre los mercados de múltiples medios y el comportamiento migratorio de las audiencias, en busca de experiencias de entretenimiento. "La convergencia es una palabra que puede definir los cambios tecnológicos, de mercado, sociales y culturales, en función de quién está hablando y que creemos que están hablando" (Jenkins, 2009: 27).

La potencialidad pedagógica como tecnológica hacen factible la convergencia educativa, de hecho, no parecen existir límites tecnológicos a las posibilidades que se abren (León y García, 2000). Compete a los formadores, en colaboraciones simultáneas, implementar diseños que fundan asertivamente los diferentes modelos instruccionales, adapten los recursos y medios e impliquen a los participantes en favor de una mayor criticidad formativa.

La convergencia representa la posibilidad de construir consensos y de negociaciones entre los diversos actores (Dias, 1995), a partir de los escenarios pedagógicos promovidos por la convergencia tecnológica, de un único mecanismo digital de transporte de datos (internet), mediante una interfaz o envoltorio totalizador (World Wide Web) y a través de distintos tipos de redes; para propiciar que servicios tan disimiles, se inclinen por un desarrollo más funcional (Villanueva, 2000).

La perspectiva propiciada por la convergencia, simboliza una concepción factible de ser construida colectiva y gradualmente, integrando y articulando visiones y demandas diferentes, así como a la diversidad de herramientas tecnológicas y a los emergentes enfoques pedagógicos, con los valores y propósitos de la formación. 


\section{Bases Tecno-Pedagógicas De La Convergencia}

Las TIC en la educación constituyen un paradigma pedagógico en recreación continua. Se sustentan en un diseño curricular abierto que, además de generar aprendizajes significativos, genera autonomía, promueve la interacción colaborativa y la construcción del conocimiento en redes. Es decir va más allá de la sola incorporación de las TIC. Requiere de una profunda reflexión de las decisiones asumidas, para evitar confusiones y errores en los objetivos, a fin de desarrollar las competencias más acordes a las demandas del mundo de hoy, resignificándolas con un sentido crítico.

Trascender hacia la convergencia, encarna la reacomodación de los componentes que la configuran, en esa intención, como apunta Galán (2009):

- El componente tecnológico, en una dinámica constructivista, no pretende eliminar la presencialidad, sino empoderar al participante, desde el aprendizaje autónomo.

- La presencia del componente tecnológico responde a las necesidades del servicio educativo.

- La no presencialidad no se apoya necesariamente en el componente tecnológico, porque desnatulariza la esencia pedagógica.
- La proporcionalidad de los virtual y presencial depende de las necesidades, y donde las tecnologías resultan vitales.

Un abordaje convergente entiende que entre pedagogía y tecnología, no hay antagonismo, sino un sentido de continuidad; donde el cambio permanente no es una ruptura; todo lo contrario, una prolongación de la existencia identitaria (Bonfil, 1994). La secuencia conjuga a la presencia con la distancia en el Blended Learning, a partir de un diseño y desarrollo cíclico que comprende: análisis de las necesidades, diseño, implementación, evaluación y ajuste de la propuesta (Galán, 2009).

La continuidad presencia-virtual propicia la confluencia; es decir, una convergencia que ajusta las potencialidades pedagógicas y tecnológicas a los requerimientos socio-educativos. Genera ambientes que promueven la interacción, en un marco de actividades auténticas que potencian la construcción individual y colaborativa de conocimiento y, a su vez, instituyen las condiciones para un mayor aprendizaje y mejores resultados de rendimiento académico (Osorio \& Duart, 2011).

El giro paradigmático hacia la convergencia, marca un cambio en las decisiones formativas, tanto pedagógicas como tecnológicas, desde la transferencia de la información a la construcción colaborativa del conocimiento.

Figura 4: Dinámica evolutiva de la convergencia del Blended Learning.

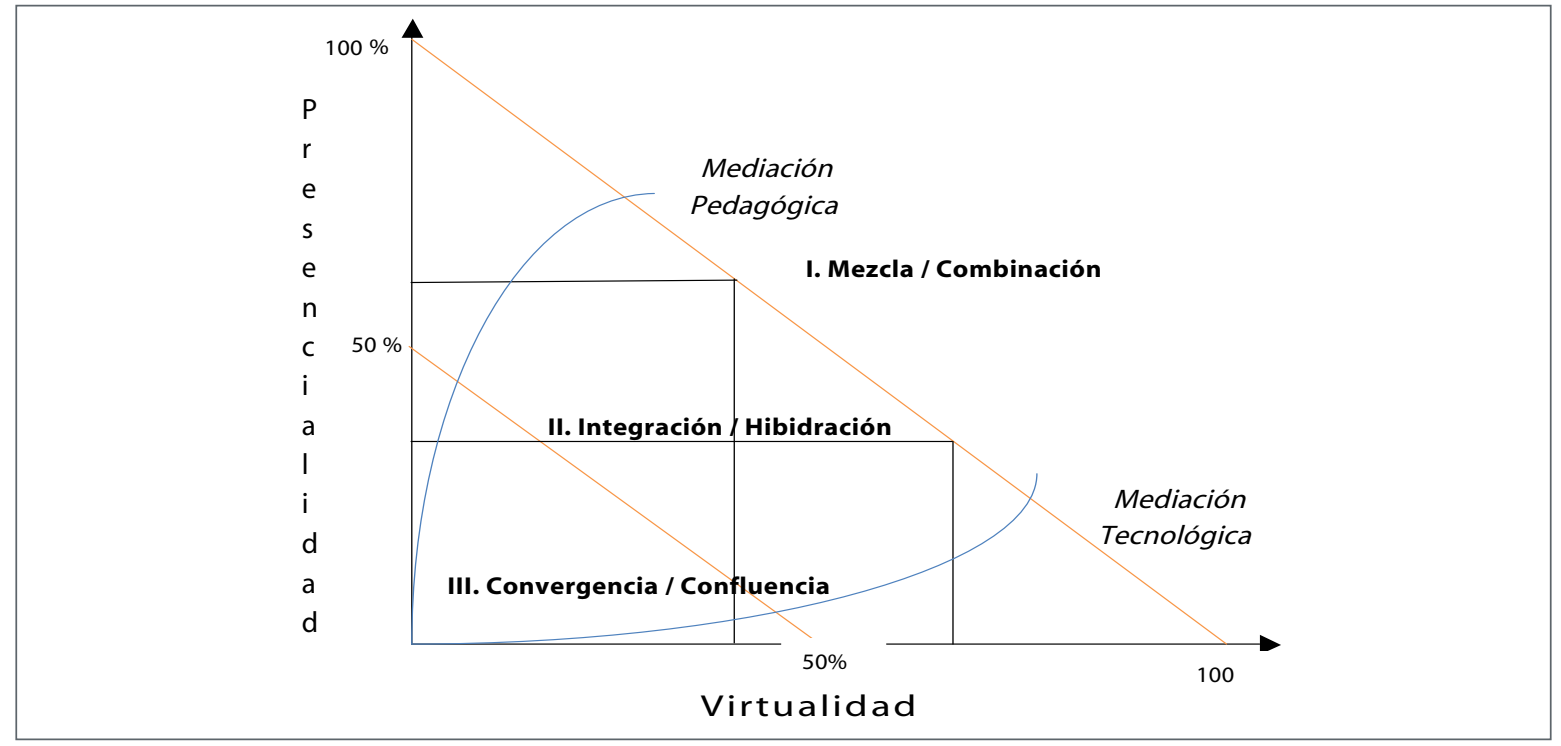


La dinámica evolutiva de la convergencia del Blended Learning (Figura 4) se asume:

I. desde las primarias mezclas o combinaciones de lo presencial y virtual, al considerar distintos momentos de las mediaciones; posteriormente,

II. se avanza a la integración e hibridación de componentes, a través de las mediaciones pedagógicas y tecnológicas, que supone compartir una importancia por igual; $y$

III. luego, a la convergencia y confluencia de los componentes y mediaciones, en una misma intención.

Estas intervenciones rubrican la capacidad de adaptación del Blended Learning, a la complejidad de las transformaciones actuales. Concebir la modalidad bajo la convergencia, es un proceso que trasciende la fusión de lo presencial y virtual, de la pedagogía y tecnología; comprende una apropiación socio-personal, a través de:

- Atracción (o inducción) sobre el tema.

- Acceso a las tecnologías.

- Uso de las tecnologías.

- Apropiación (resolver problemas utilizando estas tecnologías).

- Cultura (incluye colaboración, configuración, trabajo en red, etc.) (Pisani, 2006).

La convergencia reconoce el carácter circundante de los enfoques, recursos y medios pedagógicos y tecnológicos. Su aplicación conlleva establecer una cultura en consonancia con la sociedad del conocimiento, al favorecer que los sujetos educativos se tornen en protagonistas y constructores del aprendizaje.

$\mathrm{Al}$ decurso de la convergencia formativa contribuye la web 2.0, como actitud y no precisamente una tecnología (Cobo, 2007). Constituye una forma tecno-pedagógica de liberación de las limitaciones del espacio-tiempo, gracias a su funcionamiento asíncrono y a un alcance más contiguo, propiciado por las herramientas síncronas.

La web 2.0 posibilita el paso de la interacción a la colaboración, característica signi- ficativa de la convergencia educativa, viabiliza la combinación creativa de tecnologías que agilizan la interacción entre la plataforma y el usuario. De esta manera, la inteligencia colectiva es favorecida por la facilidad de su implementación y utilización, al ofrecer sistemas de publicación (blog, wikis, etc.), que en gran medida, hacen posible la proliferación de la información en la red.

En ese devenir, la convergencia tecnopedagógica constituye un desafío significativo para la continuidad del Blended Learning. Una etapa inevitable en su reconfiguración, que soslaya la decisión entre ¿cuánto de presencial o de virtual? ¿qué elementos físicos o ambientes virtuales?, etc. Se torna emergente por la dilución de los espacios educativos "estancos" (aulas físicas vs. aulas virtuales), al convertir en indistinguible su confluencia.

Consiguientemente, la perspectiva convergente se perfila como la solución más viable a los problemas que plantean las barreras de índole geográfica; dado que los desplazamientos físicos se reducen a lo necesario, a un mejor aprovechamiento del tiempo, al compaginar las obligaciones laborales con las familiares; al contactar con sus pares $u$ otros que compartan sus intereses e incrementen su potencialidad, como efectos de la confluencia presencial y virtual y la concomitancia tecnológica y pedagógica.

En la construcción del conocimiento, el Blended Learning apoya la capacidad de innovación de los usuarios, propiciando cambios en los modelos pedagógicos, organizativos y en el diseño de herramientas, sistemas y plataformas educativas, para que estudiantes y docentes aporten sus conocimientos (Cobo \& Pardo, 2007). El proceso exige un replanteamiento de su diseño instruccional, que posibilite elaborar mapas de entrada y contenidos, mediante la aplicación de bases ontológicas de reestructuración de los objetos de aprendizaje con significado pedagógico; personalizándolos como nuevos objetos de aprendizaje que asistan al participante en la realización de las tareas (Aguirre \& Manasía, 2009). 
El objetivo de crear interacciones significativas que contribuyan a la construcción del conocimiento en contextos Blended Learning, apoya esta nueva interpretación del modelo formativo convergente. Implica una nueva forma de concebir el diseño instruccional, al hacer confluir de manera coherente y sinérgica las mediaciones pedagógicas y tecnológicas hacia un único propósito educativo. De ese modo, se propician cambios en los modelos pedagógicos, organizativos y en el diseño de herramientas, sistemas y plataformas educativas para entornos de aprendizaje que no se consideren como simples almacenes, sino como auténticos gestores de información para su reingeniería y reutilización instruccional.

\section{Diseño instruccional. en la. convergencia blended learning}

En todo proceso educativo, el diseño instruccional asume el reto de hacer posible que la información y su representación resulten una herramienta para aprender (Chan, 2003). También, permiten aproximarse al conocimiento con seguridad y confianza (Figueroa et al., 2002). $\mathrm{Su}$ abordaje admite que el contexto formativo, las condiciones socio-culturales, los diversos estilos de aprendizaje, las motivaciones y otros aspectos de la labor docente deben ser tenidos en cuenta en la definición de los objetos de aprendizaje, para que respondan a las diferentes necesidades e intereses (Downes, 2003); dado que los procesos cognitivos se manifiestan de diversas formas (Kolb, 1976).

Figura 5: La mediación pedagógica y tecnología en la convergencia del B Learning.

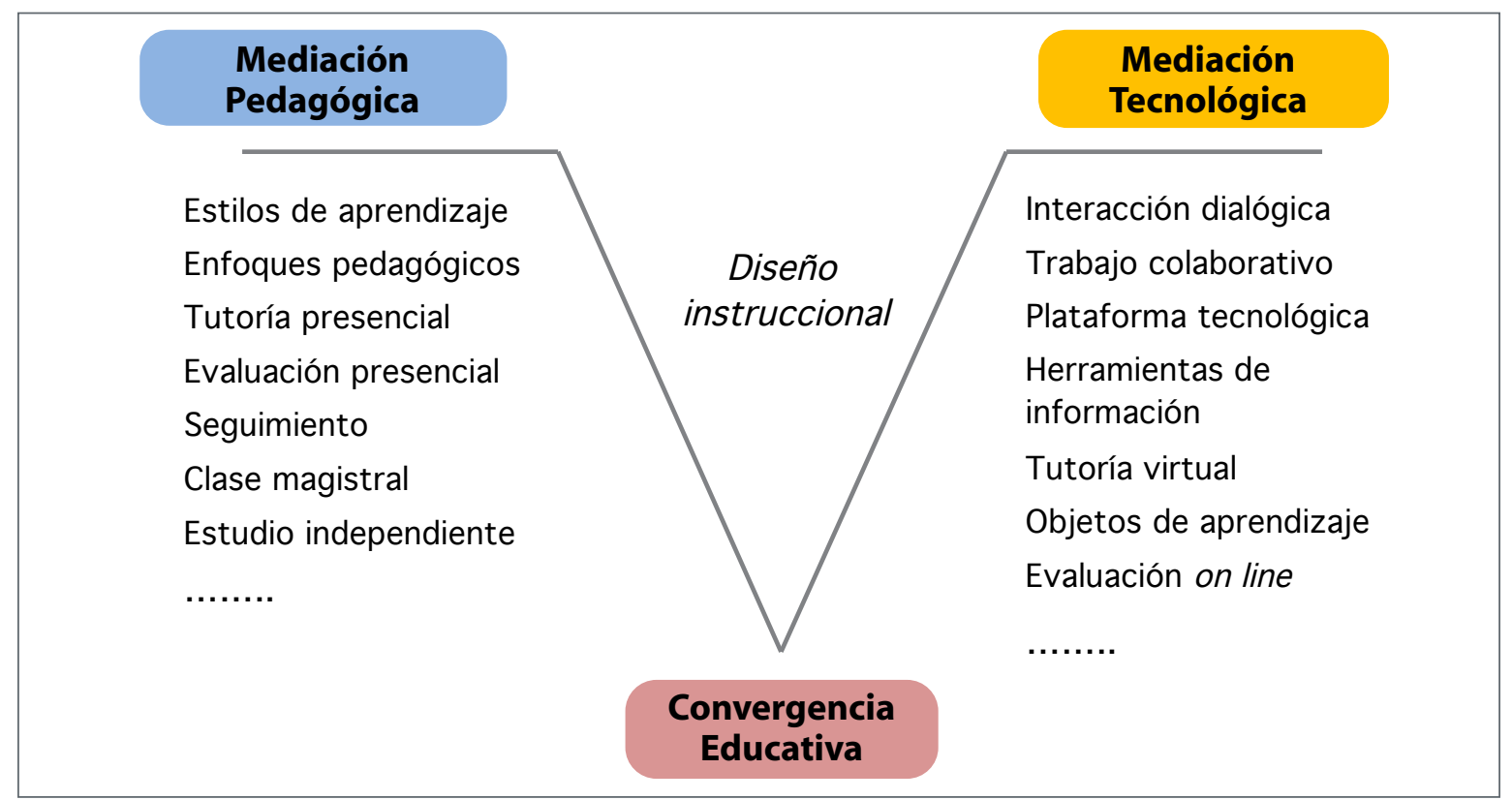

El Blended Learning al hacer converger los componentes presencial y virtual y la continuidad de las mediaciones pedagógicas y tecnológicas, hace que cada actividad, estrategia, tarea y contenido propuestos se reconstruyan, a partir de las sinergias generadas por las intervenciones didácticas. En el proceso, ninguna mediación ni componente prima más que la otra, interesa más su funcionalidad, determinada por la operatividad significativa y una concepción de construcción 
colectiva y gradual, que integra y articula visiones y demandas diferentes con los valores y propósitos de la educación (Turpo, 2013).

La convergencia de la modalidad propugna que el diseño instruccional integre la teoría educacional con las prácticas de uso de las TIC, avanzando en la dirección de un modelo pedagógico de confluencia contextual, en reconstrucción perenne y permanente optimización de las estrategias más adecuadas y oportunas.

Un diseño instruccional contextualizado y flexible permite valorar los contenidos de acuerdo a las situaciones, a los distintos actores y distintos tiempos. La propuesta se inicia con la definición del programa oficial de la asignatura, para luego ajustar los componentes, conforme se avanza en la constitución de una comunidad de aprendizaje. La planificación prevista se visualiza en una guía de clase, publicada y actualizada periódicamente, a partir del análisis cíclico de las actividades implementadas, las evaluaciones formales e informales y el feedback de los participantes.

En el Blended Learning, el diseño instruccional admite encuadrar la mediación pedagógica con la tecnológica, no como un sistema de entrega de datos y de meros transportadores y repositorios, sino constituyendo un sistema en red en el que los nudos añadan valor e inteligencia a la totalidad de ésta. Pero dada las características difusas que generan las redes, condicionadas por su naturaleza fractal y carácter recursivo y dinámico; es pertinente, asumirlas no como "piezas en secuencias independientes de los otros componentes, sino [como] una red dinámicamente mutante de partes que se conectan unas a las otras" (You, 1994: 24).

Desde la perspectiva de la convergencia, no se trata de que el Blended Learning responda a un diseño instruccional tradicional, instaurado a partir de la planificación por etapas: análisis de necesidades y definición de objetivos, diseño y desarrollo de los materiales instruccionales, implementación del evento y evaluación del sistema. El propósito es, una planificación convergente, basada en la concepción dinámica de la fractalidad, representada por un marco de soporte sucesivo para su comprensión con "cierto grado, independientemente del ambiente que lo delimita, al transitar desde un nivel autónomo de aprendizaje hasta el aprendizaje sociocultural o, a la inversa" (Turpo, 2013: 47). La propuesta no significa una continuidad lineal, sino que dentro del desorden es susceptible la capacidad de adaptación pedagógica, en función a las posibilidades de aprehensión del conocimiento.

Concebir la confluencia de las mediaciones pedagógicas y tecnológicas en una situación didáctica, implica depurar y reconstruir desde la "reflexión sobre la acción" (Schön, 1983), dos dimensiones permanentes del modelo convergente: la contextualización y la flexibilidad; así como integrar los principios de las teorías de caos, redes, complejidad y auto-organización (Siemens, 2010), a fin de comprender las decisiones que conectan las estructuras que configuran la modalidad.

El abordaje en red o fractal o ascendente facilita seleccionar los ambientes, actividades, tareas, herramientas, etc. que mejor se ajusten a los entornos presenciales y virtuales, generando un escenario didáctico para la convergencia educativa. Significa garantizar "la experiencia, la explotación y la participación de los varios nudos de la red de aprendizaje en diferentes momentos del proceso" (Filatro \& Bertholo, 2005), para responder a las necesidades e intereses de los sujetos del acto educativo. Se trata de generar una acción intencional y dinámica que ajuste el progreso del aprendizaje en la formación de una comunidad de práctica.

\section{A modo de conclusiones}

La convergencia ha marcado una nueva concepción social y educativa, por su capacidad de multiplicar ofertas (al segmentar audiencias y especializar contenidos); y de incorporar servicios de valor añadido a los contenidos mediáticos y su 
acceso a las audiencias, en los diferentes escenarios donde se ha impuesto.

Esta confluencia posicional representa para la sociedad, un nuevo escenario de intervenciones: por ende, una alternativa para la construcción de nuevas explicaciones sobre los acontecimientos sociales y formativos. En el terreno educativo, la confluencia de los avances tecnológicos y enfoques pedagógicos propicia oportunidades para el (re) diseño de los entornos formativos. Su sinergia presupone un contexto natural para introducir la tecnología en las aulas y motivar a los alumnos en su aprendizaje (Coto \& Dirckinck-Holmfeld, 2007).

El devenir del Blended Learning representa para el quehacer educativo, una progresiva búsqueda de marcos referenciales que expliciten sus potencialidades. Plantear la convergencia como marco de aproximación, constituye un flujo renovador, una disposición para buscar la confluencia de los distintos recursos formativos hacia un mismo propósito, básicamente, de una convergencia entre los componentes presencial y virtual y la continuidad de las mediaciones pedagógicas y tecnológicas.

\section{Referencias bibliográficas}

Aguirre, A. \& Manasía, N. (2009). Web 2.0 y Web semántica en los entornos virtuales de aprendizaje. Multiciencias, 9 (3), 320-328.

Aiello, M. \& Cilia, W. (2004). El Blended Learning como práctica transformadora. Pixel-Bit. Revista de Medios y Educación, 23, 21-26.

Álvarez, E., Rodríguez, A. \& Rribeiro, F. (2011). Ecosistemas de formación blended-learning para emprender y colaborar en la universidad. Valoración de los estudiantes sobre los recursos. Teoría de la Educación: Educación y Cultura en la Sociedad de la Información, 12 (4), 7-24.

Bartolomé, A. (2004). Blended Learning, Conceptos Básicos. Píxel-Bit. Revista de Medios y Educación, 23, 7-20.

Bersin J. (2004). The Blended learning book: best practices, proven methodologies, and lessons learned. San Francisco, Pfeiffer.
La evolución del Blended Learning tiene que aspirar a una identidad que la revista y distinga radicalmente de otras modalidades educativas, en razón de las propiedades referenciales y la naturaleza propia de su objeto. En esta aproximación, la propuesta desarrollada resulta vital para reflexionar sobre cómo debe ser un diseño instruccional basado en la convergencia.

Es importante tener en cuenta que su interpretación final, dependerá profundamente de la disquisición particular sobre lo que es posible hacer y cambiar en un proceso de convergencia. Por tanto, el análisis exhaustivo de la fusión y convergencia de medios y metodologías, representa una manera de desarrollar y evaluar propuestas que coadyuven a una mejor formación.

Nada quita que en un futuro próximo, lo que hoy es una innovación (la perspectiva convergente), mañana sea una rémora. Esto es, que la convergencia acelerada de estos tiempos, proporcione las bases para una divergencia de nuevas formas (Tinkler, Lepani \& Mitchell, 1996).

Bolter, D. (1984). Turing's man: western culture in the computer age. Chapel Hill and London, University of North Carolina Press.

Bonfil, G. (1994). México profundo. Una civilización negada. México: Grijalbo:.

Brennan, M. (2004). Blended Learning and Business Change. Chief Learning Officer Magazine. Consultado el 25 de mayo de 2013. Disponible en: http://clomedia.com/ articles/view/blended_learning_and_business_change

Brodsky, M.W. (2003). Four Blended Learning Blunders and How to Avoid Them. Learning Circuits. Consultado el 27 de junio de 2013. Disponible en: http://www.learningcircuits. org/how-social-software-is-used-for-learning/

Carman J. (2002). Blended learning design: Five key ingredients. KnowledgeNet. Consultado el 22 de mayo de 2013. Disponible en: 
http://knowledgenet.com/pdf/Blended $\% 20$ Learning\%20Design_1028.PDF

Carneiro, M. (2004). Multiambientes de aprendizaje en entornos semipresenciales. Pixel-Bit. Revista de medios y educación, 23, 65-68.

Cobo, C. (2007). Taller de Web 2.0. Consultado el 11 de mayo de 2013. Disponible en: http://200.76.166.4/ cristobal/tallerweb2.html

Cobo, C. \& Pardo, H. (2007). Aprendizaje colaborativo. Nuevos modelos para usos educativos, en Cobo, C. \& Pardo, H. (eds.) Planeta web 2.0. Inteligencia colectiva o medios fast food, Barcelona/México DF, Universitat de VicFlacso México, 101-116.

Coto, M. \& Dirckinck-Holmfeld, L. (2007). Comunidades virtuales de aprendizaje: el punto de vista de los participantes. Revista Electrónica de la Educación: Educación y Cultura en la Sociedad de la Información, 8 (3), 135-148.

De Sola, I. (1983). Technologies of Freedom. On free speech in an electronic age. Boston, Harvard College.

De Witt, C. \& Kerres, M. (2003). A didactical framework for the design of blended learning arrangements. Journal of Educational Media, 28 (2-3), 101-113.

Delialioglu, O. \& Yildirim, Z. (2007). Students' Perceptions on Effective Dimensions of Interactive Learning in a Blended Learning Environment. Educational Technology \& Society, 10 (2), 133-146.

Dias, J. (1995). Avaliação institucional, instrumento da qualidade educativa, en BALZAN, N. y Dias, J. (dirs.) Avaliação Institucional. teoria e experiências, São Paulo, Cortez, 53-86.

Dudezert J. (2002). Les technologies d'information et de communication en formation: Une révolution stratégique. París, Editions Economice.

Filatro, A. y Bertholo, S. (2005). Educación en red y modelos de diseño instruccional. Apertura, 5 (1), 24-30.

Galán, A. (2009). La enseñanza de la traducción en la modalidad semipresencial. Tesis Doctoral, Universidad Autónoma de Barcelona.
García, L. (2004). Blended learning ¿enseñanza y aprendizaje integrados? BENED, Boletín Electrónico de Noticias de Educación a Distancia Consultado el 10 de junio de 2013. Recuperado de http://e-spacio.uned.es/fez/ eserv.php?pid=bibliuned:333\&dsID=editoria loctubre2004.pdf

García, L. (2011a). La interacción es elemento definitorio del hacer educativo. Consultado el $12 \mathrm{de}$ mayo de 2013. Recuperado de http://aretio. blogspot.mx/2011/07/nueva-entrevista-lainteraccion-es.html

García, L. (2011b). Convergencia Presencia-Distancia. Consultado el 13 de mayo de 2013. Recuperado de http://aretio.blogspot.com/2011/05/convergencia-presencia-distancia.html

Goodyear, P. (2000). Towards the virtual classroom? Strategies for eLearning Consultado el 13 de mayo de 2013. Recuperado de http://www. csalt.lancs.ac.uk/Goodyear/ehr/materi 1. htm

Graham, C. (2005). Handbook of blended learning: Global Perspectives, local designs. San Francisco, CA, Pfeiffer Publishing.

Graham, C.; Allen, S. \& Ure, D. (2003) Blended learning environments: A review of the research literature. Unpublished manuscript, Provo, UT.

Graham, D. (2007). PESTE Factors in Developing a Framework for E-learning. E-Learning and Digital Media, 4 (2), 194-201.

Gülbahar, Y. \& Madran, R. (2009). Communication and Collaboration, Satisfaction, Equity, and Autonomy in Blended Learning Environments: A Case from Turkey. International Review of Research in Open and Distance Learning, 10 (2), 1-22.

Hinojo, F.; Aznar, I. y Cáceres, M. (2009). Percepciones de alumnado sobre el Blended Learning en la universidad. Comunicar, XVII (33), 165-174.

Jenkins, H. (2009). Cultura da convergência ( $2^{\circ}$ ed.) São Paulo, Aleph.

Lavrin, A. y Zelko, M. (2005). Knowledge Sharing in Digital Ecosystem for Small and Medium Enterprises IDIMT-2005. 13th Interdisciplinary 
Information Management Talks, Proceedings Linz, Johannes Kepler Universität Linz, 237-252. Consultado el 16 de junio de 2013. Recuperado de http://www.sea.uni-linz.ac.at/conferences/ idimt2005/session_f.pdf

León, B. \& García-Avilés, J. (2000). La información audiovisual interactiva en el entorno de convergencia digital: desarrollo y rasgos distintivos. Comunicación y sociedad, XIII (2), 141-179.

Liikanen, E. (2003). La administración electrónica para los servicios públicos europeos del futuro. Lección inaugural 2003-2004. UOC Consultado 18 de mayo de 2013. Recuperado de http://www.uoc.edu/inaugural03/esp/article/index.html

Llorente, M. (2008). Blended learning para el aprendizaje en nuevas tecnologías aplicadas a la educación. Un estudio de caso. Tesis doctoral, Universidad de Sevilla.

Mantyla, K. (2001). Blended e-Learning. The power is in the Mix. Alexandria, American Society for Training \& Development.

Marqués, L., Espuny, C., González, J. \& Gisbert, M. (2011). La creación de una comunidad aprendizaje en una experiencia de Blended Learning. Pixel-Bit. Revista de Medios y Educación, 39, 55-68.

Novell, M. (2010). The Blended Future of Learning, en PAINE, N. y MASIE, E. (eds.) Learning Perspectives. Contributed by 40 Global learning leader, The MASIE Center \& The Learning CONSORTIUM, 92-97.

Ojeda, G. (2004). Apuntes en línea: la comunicación mediatizada ante la convergencia digital de las TIC en la educación virtual y a distancia. VIII Congreso de Educación a Distancia-CREAD MERCOSUR, Buenos Aires.

Osorio, L. \& Duart, J. (2011). Análisis de la interacción en ambientes híbridos de aprendizaje. Comunicar, XIX (37), 65-72.

Pérez, A. \& Acosta, H. (2003). La convergencia mediática: un nuevo escenario para la gestión de información. ACIMED, 11 (5) Consultado el 4 de mayo de 2013. Recuperado de http://bvs. sld.cu/revistas/aci/vol11_5_03/aci03503.htm
Pisani, F. (2006). Las aplicaciones Web 2.0. Del uso a la apropiación de tecnologías Consultado el 21 de junio del 2013. Recuperado de http:// www.portal.educ.ar/noticias/entrevistas/laweb-20-del-uso-a-la-apropia.php

Prado, E, \& Franquet R. (1998). Convergencia digital en el paraíso tecnológico: claroscuros de una revolución. Zer, 3 (4), 15-40.

Reynolds, T. \& Greiner, C. (2005). Integrated field experiences in online teacher education: A natural blend? en BONK, C.J. y GRAHAM, C.R. (eds.) Handbook of blended learning: Global perspectives, local designs. San Francisco, Pfeiffer Publishing, 209-220.

Ripa, M. (2007). ¿Cómo abordar el estudio de una comunidad de aprendizaje Blended Learning. Revista Electrónica de la Educación: Educación y Cultura en la Sociedad de la Información, 8 (3), 200-221.

Rossett, A. (2002). The ASTD e-learning handbook. New York, McGraw-Hill.

Schön, D. (1983). The Reflective Practitioner: how professionals think in action. London, Temple Smith.

Sharpe, R., Benfield, G., Roberts, G. \& Francis, R. (2006). The Undergraduate Experience of Blended E-learning: A Review of UK Literature and Practice. The Higher Education Academy Consultado el 30 de abril de 2013. Recuperado de http://www.heacademy. ac.uk/assets/documents/research/literature_reviews/blended_elearning_exec_summary_1.pdf

Siemens, G. (2010). Conectivismo: Una teoría de aprendizaje para la era digital, en Aparici, R. (coord.) Conectados en ciberespacio. Madrid, UNED, 77-132.

Tinkler, D., Lepani, B. \& Mitchell, J. (1996). Education and Technology Convergence. A Survey of Technological Infrastructure in Education and the Professional Development and Support of Educators and Trainers in Information and Communication Technologies. Australian Government Publishing Service. 
Turpo, O. (2010). Contexto y desarrollo de la modalidad educativa blended learning en el sistema universitario iberoamericano. Revista Mexicana de Investigación Educativa, 15 (45), 345-370.

Turpo, O. (2013). La fractalidad de la educación virtual: naturaleza y estructura. Educación, XXII (42), 29-50.

Turpo, O. (2013). Perspectiva pedagógica y tecnológica de la modalidad Blended Learning. RED Revista de Educación a Distancia, 39, 1-14. Consultado 25 de mayo de 2013. Recuperado de http://www.um.es/ead/red/39

Valzacchi, J. (2005). Los caminos del Blended Learning. Editorial. El Magazine de Horizonte.
Informática Educativa. IV (66) Consultado 23 de abril de 2013. Recuperado de http://www. educoas.org/Portal/boletin/horizonte/66mayo05-oea.aspx

Villanueva, E. (2000). Convergencia multimedia: más allá de la Internet. Sao Paulo, Federación Latinoamericana de Facultades de Comunicación Social.

Ward, J. \& LaBranche, G. (2003). Blended learning: The convergence of e-learning and meetings. Franchising World, 35 (4), 22-23.

You, Y. (1994). What can we learn from chaos theory? An alternative approach to instructional design. Educational Technology Research and Development, 41 (3), 17-32. 


\title{
Web 2.0: plataforma para la reconfiguración de la educación en la
} cibercultura

\section{Web 2.0: platform for the reconfiguration of education in cyberculture}

\author{
Marcio Roberto De Limal \\ Universidade Federal de São João del-Rei \\ marcinholima@ufsj.edu.br \\ Silvania Sousa Do Nascimento² \\ Universidade Federal de Minas Gerais \\ silnascimento@ufmg.br
}

1 Doctorado en Educación por la Universidad Federal de Minas Gerais (UFMG), Máster en Educación por la Universidad Federal de São João del-Rei (UFSJ, 2009). Profesor del Departamento de Ciencias de la Educación de la Universidad Federal de São João del-Rei (DECED/UFSJ). E-mail:marcinholima@ufsj.edu.br; marcinholima@ufmg.br

2 Doctora en Didáctica de las Disciplinas (Université Pierre et Marie Curie, Françia, 1999), Profesora Titular del Departamento de Métodos y Técnicas de Enseñanza (DMTE) de la Facultad de Educación (FaE) de la Universidad Federal de Minas Gerais (UFMG). E-mail: silnascimento@ufmg.br

\section{Resumen}

Este artículo busca reflexionar sobre el momento cibercultural contemporáneo y las nuevas posibilidades para la enseñanza-aprendizaje ofrecidas por la emergencia de la Web y su reconfiguración en Web 2.0. En ese sentido, establece relaciones entre los principios de la cibercultura (Lemos E. \& Levy, 2010; Lemos, 2005; Lemos, 2003) y el contexto educacional. Evidencia posibilidades y recursos para la reconfiguración de la práctica pedagógica en la cibercultura. Propone que los dispositivos digitales y las redes de comunicación sean utilizados con intención pedagógica y al servicio de la promoción de la ciudadanía en la cultura digital.

Palabras clave: Cibercultura, educación, enseñanza-aprendizaje.

\begin{abstract}
This paper discusses cyberculture and new possibilities for teaching and learning offered by the emergence of Web and its evolution to Web 2.0. It relates the principles of cyberculture (Lemos \& Levy, 2010; Lemos, 2003; Lemos, 2005) to education. It evidences opportunities and resources for the reconfiguration of pedagogical practice in cyberculture. It proposes that digital devices and communication networks are used with intent to promote learning and citizenship in the digital culture.
\end{abstract}

Keywords: Cyberculture, education, teaching-learning.

Forma sugerida de citar:

De Lima, M. y Sousa, S. (2013). Web 2.0: plataforma para la reconfiguración de la educación en la cibercultura. Alteridad, 8(2), pp. 144-154. Quito: Editorial Abya-Yala. 


\section{Introducción}

Las tecnologías digitales de la información y comunicación (TDIC) y los recursos virtuales asociados a ellas están fuertemente presentes en lo cotidiano. La rápida y creciente apropiación social de esas tecnologías señala la expansión y consolidación de la cibercultura (Lévy, 1999; Lemos, 2002; Lemos \& Lévy, 2010).

De esa manera, la contemporaneidad se caracteriza por los nuevos hábitos sociales de producción y consumo de informaciones, reconfiguraciones de las relaciones de trabajo/ocio y creación de nuevas formas de comunicación, lo que incita a transformaciones de orden económica, sociocultural, políticas, etc., todas mediadas por las TDIC. La misma perspectiva es propuesta por Medeiros (2005:31), que al reflexionar sobre el pensamiento de Kenski (2003), asume que "las evoluciones tecnológicas vividas por la sociedad actual no se restringen apenas al uso de nuevos equipos y productos [...] implica la modificación de comportamientos, de cierta forma, imponiéndose la cultura existente y transformando individuos, grupos y sociedad".

Este artículo busca reflexionar sobre ese momento cibercultural y las nuevas posibilidades para la enseñanza-aprendizaje ofrecidas por la emergencia de la Web y su evolución hacia la Web 2.0. Establece relaciones entre los principios de la cibercultura (Lemos \& Levy, 2010; Lemos, 2005; Lemos, 2003) y la educación, evidenciando posibilidades y recursos para la reconfiguración de la práctica pedagógica en la cibercultura. Propone que los dispositivos digitales y las redes de comunicación sean utilizados con intención pedagógica y al servicio de la promoción de la ciudadanía en la cultura digital.

\section{La cilbercultura y la Web; conceptos, orígenes y evolución}

Lévy (1999) conceptualiza "cibercultura" como un conjunto de técnicas, prácticas, actitudes, modos de pensamiento y valores que
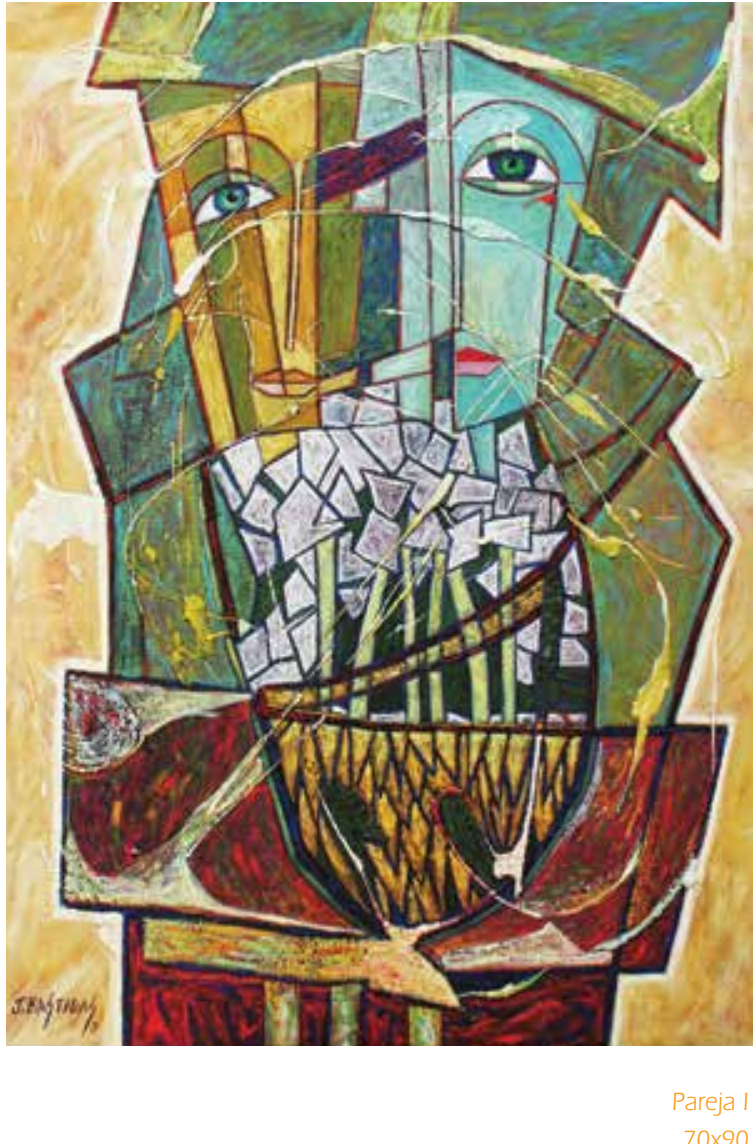

se instituyeron con el ciberespacio; es decir: la unión de redes e infraestructura y comunicación formada por la interconexión global de los computadores. Es en ese espacio virtual e interactivo que se efectivizan los accesos a los recursos remotos de servidores de redes, las transacciones de comercio electrónico, la permuta digital de archivos, la comunicación en tiempo real en formato textual o audiovisual, el correo electrónico, etc.

En Lemos (2002:16) se encuentra la afirmación de que la cibercultura "nace en los años 50 con la informática y la cibernética". Para Castells (1999) las décadas de los 50 y 60 fueron precursoras de la "Era de la información" en grande escala. El período comprendió iniciativas 
de estrategia militar e investigación académica ${ }^{3}$ que justificaron el desarrollo de las tecnologías digitales y de las redes de computadores. Incluso con Lemos (2002) percibimos que la década de los 70 señaló el inicio de la popularización de la cibercultura (lo que es justificado por la aparición del microcomputador y el progreso tecnológico asociado). El autor destaca que las décadas siguientes marcaron la consolidación de la cultura digital, eso con la informática masiva (80), con la expansión de las redes temáticas y la llegada del World Wide Web (90).
La primera generación de internet se configuró como un grande depósito de informaciones que, por el formato de organización y software de lectura (browsers o navegadores), se tornó bastante amigable con los usuarios. Sintéticamente, la Web representó en su origen, un sistema de documentos electrónicos que agregaba la información en diferentes formatos (texto, audio, animaciones y gráficos). Tales documentos se encontraban conectados por hyperlinks que permitían a los usuarios una forma fácil y rápida de acceso e interacción con las informaciones deseadas/catalogadas (Figura 1).

Figura No. 1: Ejemplo de documento electrónico en formato original WWW.

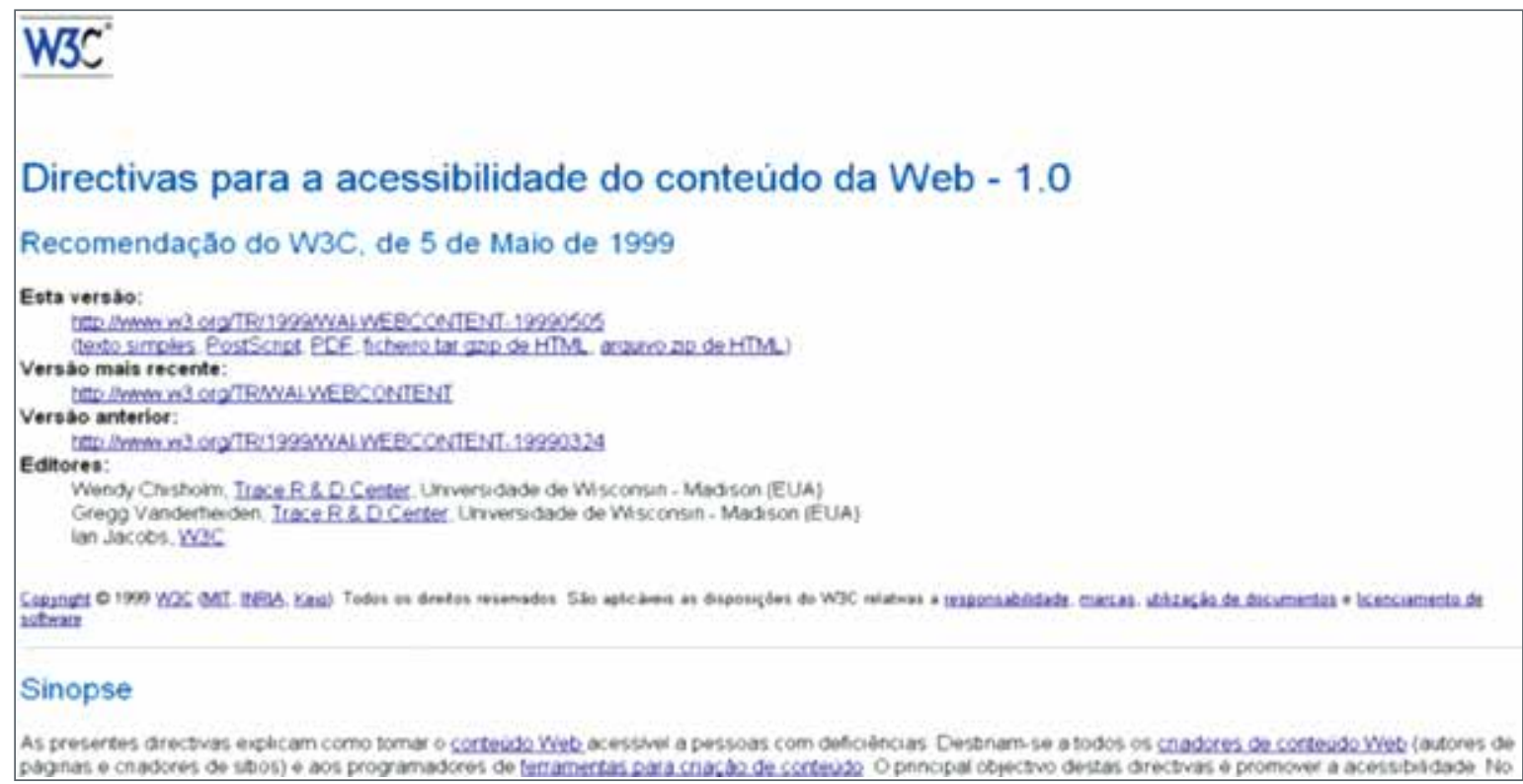

Fuente: http://mww.utad.pt/wai/wai-pageauth.html <Acesso en 03/08/2011>

3 Castells (1999) hace referencia a los trabajos desarrollados en la ARPA (Agencia de Proyectos de Investigación Avanzada) de los Estados Unidos, que buscaban la creación de una red de comunicación sin un centro de control determinado e inmune a ataques nucleares. De esos esfuerzos surgió en 1969 la ARPANET, primera red de computadoras que conectan a las Universidades de California (en Los Ángeles y Santa Bárbara), el Instituto de investigación de Stanford y la Universidad de Utah. La ARPANET fue la precursora del internet.
Una característica importante de esa primera fase de la Web hace referencia a la forma de interacción con la información. Para la mayoría de los usuarios eso se restringía a la localización y acceso al que estaba previamente disponible. Ese contenido era elaborado, organizado y sistematizado en red por proveedores de acceso, que tenían equipos técnicos responsables para construir esos 
documentos, siguiendo el patrón establecido. Es un hecho que en apenas cuatro años ${ }^{4}$ la Web se popularizó como una plataforma eficiente para la vinculación y acceso a contenidos, de forma general y en régimen 24/7 (horas/días por semana).

La rápida consolidación de la Web y el perfeccionamiento de sus recursos ampliaron la adopción de las tecnologías digitales, lo que posibilitó modificaciones en las formas de trabajo de las organizaciones y proporcionó nuevas maneras para el "hacer" $y$, primordialmente, de pensarse el "hacer" (Moraes, 1997). Un ejemplo de esa realidad son los emprendimientos tradicionales que incorporaron las facilidades virtuales a su campo de acción: las empresas "puntocom" tienen en el internet una plataforma de negociación directa con sus clientes (tiendas virtuales, internet banking, sitios de subastas, etc).

Ese continuum de innovaciones y las transformaciones asociadas tipifican la cibercultura. Desde sus orígenes hasta el presente, acompañamos una dinámica fecunda de renovación y perfeccionamiento expresada por la acelerada virtualización de las entidades sociales y sus actividades. La propia Web es un ejemplo de esa constante y ventajosa reconfiguración. Si en sus primeros momentos la red funcionaba como una plataforma para la divulgación de contenidos (lo que replica el funcionamiento de un medio masivo) en un segundo momento ${ }^{5}$ (Web 2.0), las posibilidades interactivas con el contenido, la facilidad de expresión personal en múltiples formatos y la comunicación establecida en el ciberespacio, son

4 La National Center for Policy Analisis indica que la Web acogió a 50 millones de usuarios en el período indicado.

5 Primo (2007:1) explica que la Web 2.0 es un "pequeño cambio con el tipo de notación en informática que indica la versión de un software, fue popularizado por la O'Reilly Media y por la MediaLive International'. La expresión fue utilizada por primera vez en 2004 como nombre de una serie de conferencias. Sin embargo, el término merece críticas de especialistas, que lo consideran inadecuado y alegan que apenas ocurrió una evolución natural de la Web len virtud del aumento de la velocidad de acceso y de usuarios de internet). En este texto, el término Web 2.0 es empleado para caracterizar las nuevas posibilidades de uso de la red, que se efectivizaron a partir del año 2001. funcionalidades que expresan una evolución ${ }^{6}$ sin precedentes en la configuración de ese espacio virtual y también en sus formas de utilización.

La Web 2.0, es la segunda generación de servicios online y se caracteriza por potencializar las formas de publicación, la forma de compartir y organizarla información, además de ampliar los espacios para la interacción entre los participantes del proceso [...] tiene repercusiones sociales importantes, que potencializan procesos de trabajo colectivo, de intercambio afectivo, de producción y circulación de informaciones, de construcción social de conocimiento apoyada por la informática (Primo, 2007:1).

La reflexión presentada por el autor amplía la comparación entre los dos momentos de la Web: en términos de recursos y postura de quienes interactúan. En su primera versión, las funcionalidades de la red caracterizaban un (ciber) espacio de acceso y lectura de contenidos estáticos y producido por pocos, siendo que los muchos usuarios de esas informaciones podían ser comparados a espectadores/ consumidores. Con la Web 2.0 los conceptos se expanden: además del acceso y lectura de informaciones, quien interactúa pasa a contar con la posibilidad de producción personal y colectiva de los contenidos presentes en la red. Los servicios ${ }^{7}$ Web 2.0 permiten el ejercicio de la autoría y de la intervención en el mensaje presente en un sitio de internet, lo que estimula la participación interactiva de los usuarios, revelando una fusión entre productores y consumidores de los contenidos vehiculados (Figura 2).

6 El curso de las sucesivas reconfiguraciones y expansiones de los recursos de la Web introduce funcionalidades que acaban por crear nuevos términos de calificación de la Grande Red. Ya es posible encontrar el término "Web 3.0" (http://www.labnol.org/internet/web-3-concepts-explained/8908/ e http://husseinahmed. com/2010/09/web-1-0-2-0-3-0-and-counting\%E2\%80\%A6/). En Lemos y Lévy (2010), el segundo autor presenta reflexiones sobre una investigación reciente, suscitando el término "esfera semántica" para la caracterización de la web que operará sobre el sentido de la información catalogada, independiente de su formato y/o lengua de codificación (ver también http://gl globo. com/Noticias/Tecnologia/0,,MUL1284962-6174,00.html).

7 Los senvicios Web 2.0 son innumerables, pudiendo ser citados como ejemplo: blogs, wikis, redes sociales, mensajería electrónica, videologs, fotologs, servicios para agregar contenido personalizado, etc. 
Figura 2: Esquema comparativo entre Web 1.0 y Web 2.0: funcionalidades y caracterización del usuario.

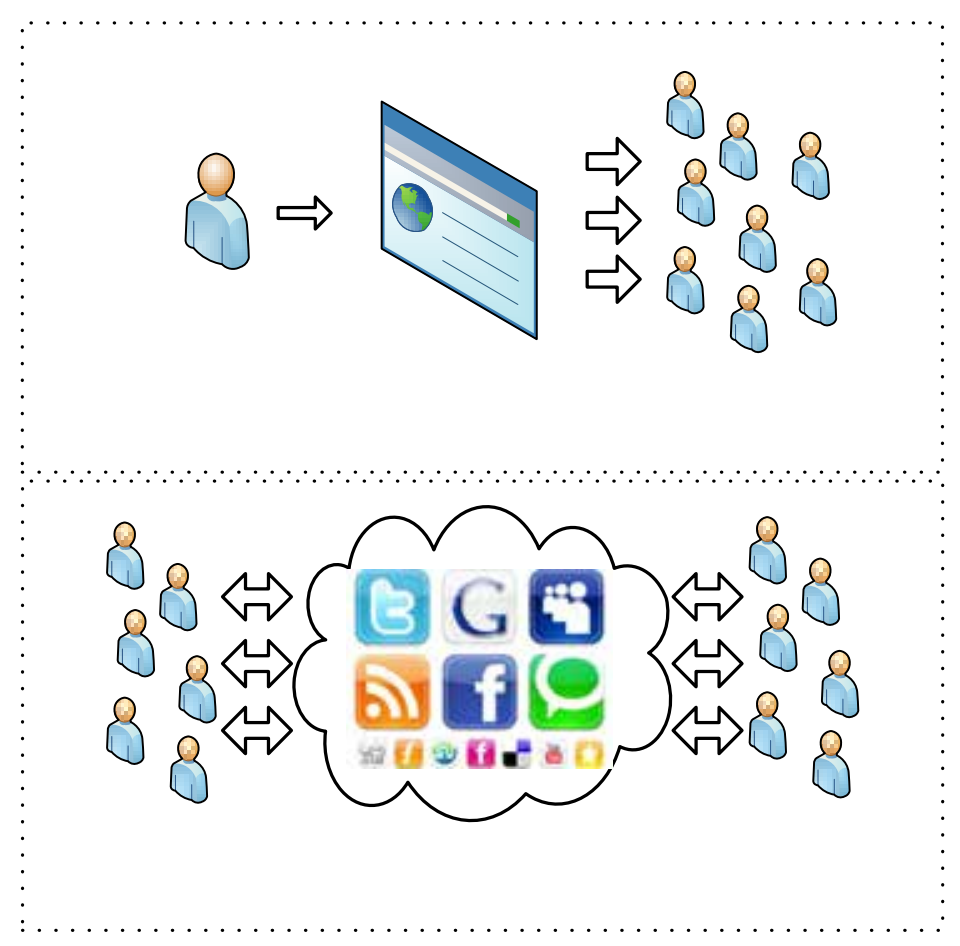

En ese sentido, buscando evidenciar los nuevos status de los sujetos en las (inter) acciones desarrolladas en el ciberespacio, ampliando la definición para los tipos de aplicaciones y de las posibilidades de uso introducidas por la $\mathrm{Web}$ 2.0, el filósofo Pierre Lévy introduce el término "computación social", justificando que:

La computación social construye y comparte de manera colaborativa las memorias numéricas colectivas en escala mundial, ya sea que se trate de fotografías (Flickr), de videos (YouTube, DailyMotion), demúsica (BitTorrent), de "favoritos" web (Delicious, Furl, Diigo) o entonces de conocimientos enciclopédicos (Wikipedia, Freebase). En todos los casos, las distinciones de status entre productores, consumidores, críticos, editores y gestores de la mediateca se borran en función de una serie continua de intervenciones donde cada uno puede desempeñar el papel que desee
[...] En la era de la computación social, los contenidos son creados y organizados por los propios usuarios [...] En el clima intelectual de la computación social, la validación, la crítica, la categorización ya no son reservadas a los mediadores culturales tradicionales (clero, profesores, periodistas, editores) sino que retorna a las manos de las multitudes (Lemos \& Lévy, 2010: 10).

En la definición, el autor destaca a la cibercultura en potencia, enfocando la virtualización del conocimiento humano y su reconfiguración en el formato digital (codificación en números binarios). Esa dinámica confiere plasticidad a la sistematización y a la producción de conocimiento, pues flexibiliza las formas de su representación y construcción en red colaborativa. Los sujetos que interactúan pueden asumir una postura activa y ejercer/experimentar la autoría, eso de forma simplificada, gratuita, democrática y colectiva. 


\section{Cibercultura y Educación: ¿una combinación posible o necesaria?}

Todo ese panorama de innovación sociotécnica está acompañado de oportunidades y desafíos. El contexto educacional no queda apartado de esa realidad. El uso de recursos digitales en los enfoques educativos viene siendo motivo de diferentes trabajos (Almeida, 2010; Baracho, Lopes \& Lima, 2011; Barreto, 2008; Lapa \& Pretto, 2010; Lima, 2009; Lima \& Leal, 2010, Lima, 2011a, Lima, 2011b; Medeiros, 2005, Medeiros \& Nascimento, 2010; Santos, 2005; Sommer, 2010; Silva, 2000; Silva, 2006; Silva, 2010; Valente \& Almeida, 2007), que buscan señalar tanto la mejor comprensión de su adopción, como las reconfiguraciones que le son inherentes. Parte de estos esfuerzos se justifica por el hecho de que la cibercultura instauró un intenso ritmo de producción/apropiación de nuevos conocimientos/contenidos/conceptos. Ese hecho, a su vez, terminó por generar nuevas demandas, habilidades y competencias a los sujetos de educación; entretanto cabe la observación de que:

No se trata aquí de usar la tecnología a cualquier costo, pero sí de acompañar consciente y deliberadamente un cambio de civilización que cuestiona profundamente las formas institucionales, las mentalidades y la cultura de los sistemas educacionales tradicionales y sobre todo los papeles del profesor y el alumno (Lévy, 1999: 172).

Así, es necesario continuar reflexionando sobre las prácticas educativas y sobre los procesos de formación en el contexto de la cultura digital, a fin de permitir al sistema educacional una efectiva apropiación de esa realidad, creándose nuevos ambientes de aprendizaje, nuevas maneras de construir el conocimiento; y, fundamentalmente, una readecuación de los papeles de docentes y alumnos al espíritu cibercultural. Para eso, se retoman enseguida los trabajos de Lemos y Lévy (2010), Lemos (2005) y Lemos (2003), los cuales introducen tres principios interdependientes - reconfiguración social, liberaciones de la emisión, conexión generalizada - que ayudan en la comprensión de la cultura contemporánea y sus desdoblamientos para la educación.

La popularización de las TDIC y del ciberespacio, instrumentalizó e instrumentaliza transformaciones en la esfera social en lo que se refiere a las prácticas y sus espacios de efectividad. Ese hecho habla respecto al principio de reconfiguración, el cual no considera el proceso como una mera substitución del formato analógico por el digital Lévy (1999) nos esclarece que:

¿La fotografía substituyó a la pintura? No, todavía hay pintores activos. Las personas continúan, más que nunca, visitando museos, exposiciones y galerías, compran las obras de los artistas para ponerlas en casa. En contraparte, es verdad que los pintores, los diseñadores, los grabadores y escultores no son más -como fueron hasta el siglo XIX- los únicos productores de imágenes. Como la ecología del ícono cambió, los pintores tuvieron que reinventar la pintura: del impresionismo al neo-expresionismo, pasando por la abstracción y por el arte conceptual, para que ella conquiste un lugar original, una función insustituible en el nuevo ambiente creado por los procesos industriales de producción y reproducción de imágenes (Lévy, 1999: 212).

Lo que se percibe, una vez más, es un movimiento de renovación y potencialidad. Surge, entonces, la problemática referente a las prácticas educacionales y su consonancia a esa dinámica. El ciberespacio - hoy instrumentado por la Web 2.0 - introdujo la flexibilidad de tiempo y lugar a la enseñanza y el aprendizaje, posibilitó la creación de ambientes ágiles, organizados y dinámicos. Eso sugiere el pensamiento de que está en curso una posibilidad para la reconfiguración de la pedagogía.

Superando la inmediatez del uso de las TDIC en el contexto educacional, esa reconfiguración engloba fundamentalmente a los sujetos involucrados, que necesitan reelaborar el sentido tradicional atribuido a la clase, a la enseñanza 
y al aprendizaje. El profesor puede utilizar los recursos del ciberespacio (buscadores de informaciones, wikis, para la escritura colectiva/colaborativa, blogs, foros de discusión, redes sociales, mensajeros online, podcasting, etc.) para estimular la participación de los alumnos, promoviendo la reflexión sobre los conocimientos que se imparten. Así, el sentido común pedagógico (basado en la transmisión/memorización/repetición de informaciones) cede espacio al posicionamiento colectivo/colaborativo en red. En ese enfoque se expanden las posibilidades de diálogo, de posicionamiento personal frente a un determinado tópico de estudio, de la valorización de asociaciones significativas/evocativas entre un nuevo conocimiento y otros ya interiorizados. En ese sentido, Ferreira, Silva y Siman (2009) refuerzan que:

Los alumnos están cada vez más motivados para las tecnologías informáticas y menos motivados para los métodos tradicionales de enseñanza. Quedarse sentado en una silla escuchando, copiando y señalando partes importantes del libro didáctico acaba siendo menos atractivo que ir a la sala multimedia, crear una Wiki, un blog o producir un video (Ferreira, et al., 2009: 4).

Las autoras enfatizan que el redireccionamiento frente a lo aprendido involucra la postura activa de los alumnos. Los nuevos recursos se constituyen como medios instrumentadores y estimuladores del desarrollo personal y colectivo frente a las propuestas de aprendizaje.

Análogamente en el mapa de las posibles reconfiguraciones de los campos de acción de los agentes de conocimiento en la cibercultura, se justifica el principio de liberación de la emisión (Lemos E Levy, 2010; Lemos, 2005; Lemos, 2003). Según los autores, la nueva esfera mediática inaugurada por el ciberespacio difiere substancialmente del mass media -predominantemente transmisora y unidireccional - prevaleciendo una nueva dinámica comunicacional, o sea: en el ciberespacio emergen voces y discursos multidireccionales en red. Estableciendo un paralelismo al campo edu- cacional, en las nuevas interfaces virtuales, la clase pasa a poder contar con recursos que estimulan la interactividad.

El término "interactividad" no es nuevo. Surgió en la década de 1970 como una crítica a los medios unidireccionales, pero se consagró solamente en los años 1980, a partir de la inserción del computador con "ventanas" móviles que permiten un adentramiento y operatividad, y en la década siguiente con la llegada del internet y de la web (Silva \& Claro, 2007: 84).

Silva (2000) justifica la interactividad en tres binomios conceptuales: la participación-intervención, que incita a los integrantes a superar el juicio simplista de "sí o no" frente a las reflexiones, valorando la crítica; la bidireccionalidadhibridación, que reconfigura la polaridad entre emisores y receptores en un proceso de coautoría (ambos codifican y decodifican cooperativamente en la construcción del discurso); la permutabilidad-potencialidad, que considera la construcción del conocimiento en una red abierta y rica en articulaciones, conexiones, asociaciones y (re) significaciones.

Freire (1999: 84) afirma que "educación auténtica [...] no se hace de A para B o de A sobre $B$, pero de A con B, mediatizados por el mundo". Es en ese sentido que la liberación de la emisión y el ejercicio de la interactividad en las interfaces virtuales contribuyen para que profesores y alumnos puedan superar la condición de usuarios de informaciones, instaurando una dinámica de construcción colectiva del conocimiento y rompiendo con la lógica de transmisión (Lima \& Leal, 2010).

El último principio de la cibercultura conexión generalizada (Lemos, 2003; Lemos, 2005; Lemos \& Lévy, 2010) - se refiere al uso masivo de los equipamientos digitales conectados en red. Históricamente, en la década de los 90 ocurrió una reconfiguración del computador personal (PC - personal computer) en computador colectivo (CC), principalmente por la emergencia de la Web (1995). Los autores defienden que esa masi- 
ficación sigue un curso en la contemporaneidad con los dispositivos móviles (tablets, smartphones, laptops, etc), lo que amplía los efectos de la interconectividad global.

El principio de conexión generalizada viene, gradualmente, actuando en el contexto educacional y también en el de sus sujetos (inclusive fuera del ambiente escolar). La Investigación ${ }^{8}$ sobre el uso de las Tecnologías de la Información y Comunicación en las Escuelas Brasileñas 2010,

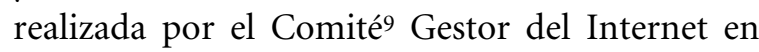
Brasil trae datos que confirman esa perspectiva. Se percibe que en la muestra probabilística de 497 escuelas públicas del área urbana, la presencia media de computadores es de 23 , siendo que en un $87 \%$ de las escuelas existe conexión en banda ancha. El número medio de alumnos por escuela, en la muestra, es de 800 , lo que sugiere un acceso limitado e insuficiente a los equipos/red. Los números más promisorios se refieren al número de profesores con computadoras y acceso internet en sus domicilios, que llega al $90 \%$ y $81 \%$, respectivamente.

Paralelo al escenario presentado anteriormente, merece atención el PROUCA (Programa un Computador por Alumno), política pública de educación en curso en Brasil desde 2007. En su inicio, PROUCA preveía la disponibilidad de una laptop para cada niño de algunas escuelas brasileñas, así como su utilización dentro y fuera del ambiente escolar. En 2010 fue firmado un acuerdo para la donación de 150.000 laptops educacionales a aproximadamente 300 escuelas brasileñas. Además de los computadores, el Proyecto prevé la implantación de infraestructura para el acceso a internet en las escuelas participantes y la capacitación de gestores y profesores para el uso de las tecnologías. Se destaca en esa política educacional la iniciativa UCA TOTAL (Un computador por Alumno Total), que contempla todas

8 La publicación compila indicadores del uso de las tecnologías en las escuelas públicas de Brasil y se puede acceder en: http:// www.cetic.br/tic/educacao/2010/index.htm

9 http://cgi.br/ las escuelas de seis ${ }^{10}$ municipios brasileños. En ese enfoque, la práctica pedagógica puede ganar una nueva dimensión, pues la presencia de las laptops conectadas a internet en la sala de clase permite, por ejemplo: simulación, investigación simultánea y presentación de contenidos, producción individual y colectiva en diferentes formatos (texto, video, fotografía, etc), ejercicios de raciocinio lógico vía computador (Lenguaje LOGO) etc.

Finalmente, entiéndase que la conexión generalizada en el contexto escolar fortalece las iniciativas de inclusión digital. Si en un primer momento eso se refería a aumentar el acceso a las tecnologías, no se puede perder de vista que lo fundamental es la apropiación crítica de los dispositivos digitales y del ciberespacio, de forma que fortalezca significativamente el aprendizaje y la ciudadanía en la cultura digital.

\section{Consideraciones finales}

Este texto buscó evidenciar los orígenes de la cibercultura y la continua expansión del ciberespacio instrumentada por la llegada de la Web y, posteriormente, por la Web 2.0. Partiendo de los trabajos de Lemos y Lévy (2010), Lemos (2005) y Lemos (2003), que introdujeron la triada reconfiguración social-liberación de la emisión-conexión generalizada como principios de la cibercultura, se buscó aproximarse a los desdoblamientos de esos principios en el campo de las prácticas educativas, sugiriendo la reconfiguración de las acciones emprendidas por profesores y alumnos frente a la construcción de conocimientos.

La cultura digital inspira la revisión de los procesos educacionales en lo que se refiere a sus espacios de eficacia y al propio tiempo de enseñanza-aprendizaje. Eso porque "la evolución social del hombre se funde con las tecnologías desarrolladas y empleadas en cada época" y, de esa forma, "el hombre transita culturalmente

10 Barra dos Coqueiros/SE, Caetés/PE, Santa Cecília do Pavão/PR, São João da Ponta/PA, Terenos/MS, Tiradentes/MG. 


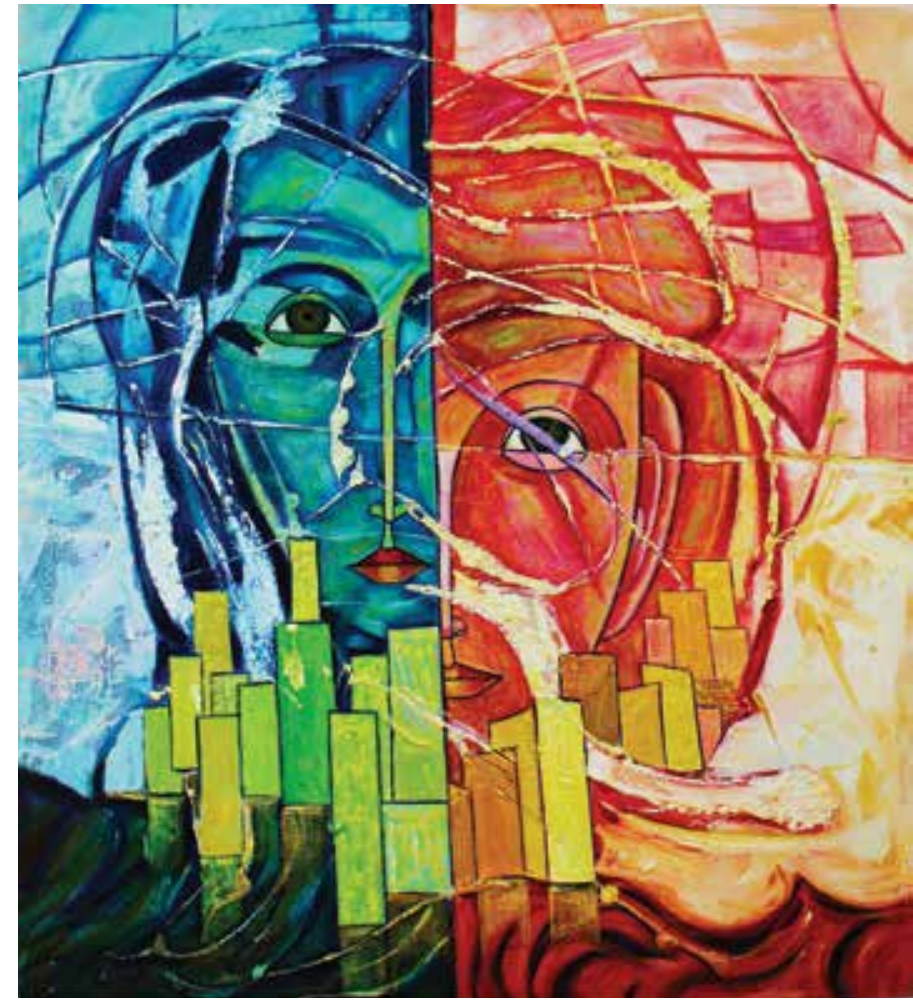

Pareja en una Metrópoli $70 \times 90$
Flickr, MySpace, GoogleDocs, Picasa, redes sociales como: Facebook/Orkut, Twitter etc.) aseguran formas accesibles y gratuitas de que se estimulen $y$ se aborden esos enfoques. Asumir que tales funcionalidades pueden potenciar la enseñanzaaprendizaje, no significa una negación o substitución definitiva de procedimientos de enseñanza basados en la oralidad y en la instrucción (que también tiene su valor). Se repudia, por tanto, la posible adopción indiscriminada e irreflexiva de las tecnologías digitales. Lo que se considera es la oportunidad de construcción de procesos pedagógicos que sean más significativos, efectivos y compatibles con la contemporaneidad.

Así, los recursos virtuales se consolidan como medios para la promoción del aprendizaje, es decir: "las tecnologías nos ayudan a realizar aquello que ya hacemos o deseamos [...] si tenemos propuestas innovadoras, facilitan el cambio" (Moran, MasetoBehrens, 2000: 27). "El gran desafío es el de inventar y descubrir usos creativos de la tecnología educacional que inspiren profesores y alumnos gustosos de aprender para siempre" (Kenski, 2007: 67).

Es un hecho que, si la aproximación social de las tecnologías digitales refleja una cultura, no son las tecnologías que deben ser interpuestas a la educación. Es la educación que necesita compatibilizarse con la cultura digital, revelándose incluida y promoviendo la inclusión en esa cultura. Si en un primer momento es necesario adornar las escuelas asegurando infraestructura para el trabajo con las TDIC, no se puede perder el carácter primero de esa iniciativa de reconfiguración: la (re)concepción de los currículos con la (re)adecuación de la intencionalidad pedagógica a las exigencias de la cibercultura.

Se espera de esa manera, que esas herramientas digitales pierdan el status de ayudantes en la enseñanza-aprendizaje y sean integradas al cotidiano educacional visualizando una ganancia efectiva en el aprendizaje y un perfeccionamiento de las prácticas y de las relaciones pedagógicas, de la misma forma como se incorporaron y configuraron las prácticas sociales en la cibercultura. 


\section{Referencias bibliográficas}

Almeida, M. E. B. (2010). Transformação no trabalho e na formação docente na educação a distância on-line. Em Aberto, 84, 67-77.

Almeida, M. E. B. \& Silva, M. G. M. (2011). Currículo, Tecnologia e Cultura Digital: Espaços e Tempos de WEB Currículo. Revista e-curriculum, 7, 1-19.

Baracho, A. F., Gripp, F. J., \& Lima, M. R. (2012). Os exergames e a educação física escolar na cultura digital. Revista Brasileira de Ciências do Esporte, 34 (1), 111-126.

Barreto, R. G. (2008). As tecnologias na política nacional de formação de professores a distância: entre a expansão e a redução. Educação \& Sociedade, 29 (104), 919-927.

Castells, M. (1999). A sociedade em rede. São Paulo: Paz e Terra.

Coutinho, C. P. \& Bottentuit Junior, J. B. (2007). Blog e Wiki: os futuros professores e as ferramentas da Web 2.0. Simpósio Internacional de Informática Educativa, Porto, Portugal.

Ferreira, A. A., Silva, B. D. \& Siman, L. M. C. (2009). Web2.0 e o ensino de História: trabalhando com wiki. Encontro Nacional Perspectivas do Ensino de História, Uberlândia, MG, Brasil.

Freire, P. ( 1999). Pedagogia do Oprimido. Rio de Janeiro: Paz e Terra.

Kenski, V. M. (2003). Tecnologias e ensino presencial e a distância. Campinas, SP: Papirus.

Kenski, V. M. (2007). Educação e Tecnologias: o novo ritmo da informação. 6 ed. Campinas: Papirus.

Lanza, H. H. (2007). Uso pedagógico do blog no ensino-aprendizagem de espanhol: elaboração e avaliação de uma tarefa. (Dissertação de Mestrado). Pontifícia Universidade Católica de São Paulo, São Paulo.

Lapa, A. \& Pretto, N. L. (2010). Formação de professores na modalidade on-line: experiências e reflexões sobre a criação de espaços de convivência digitais virtuais. Formação inicial de professores a distância: questões para debate. Em Aberto, 84, 79-96.
Lemos, A. (2002). Cibercultura: Tecnologia e Vida Social na Cultura Contemporânea. Porto Alegre: Sulina.

Lemos, A. (2003). Cibercultura: alguns pontos para compreender a época. En Lemos, A.; Cunha, P. (Orgs), Olhares sobre a cibercultura. Porto Alegre: Sulina.

Lemos, A. (2005). Ciber-cultura-remix. Seminário Sentidos e Processos, São Paulo, SP, Brasil.

Lemos, A. \& Lévy, P. (2010). O futuro da Internet: Em direção a uma ciberdemocracia planetária. São Paulo: Paulus.

Lévy, P. (1999). Cibercultura. São Paulo: Editora 34.

Lima, M. R. (2009). Construcionismo de Papert e ensino-aprendizagem de programação de computadores no ensino superior. (Dissertação de Mestrado). Universidade Federal de São João del-Rei, São João del-Rei.

Lima, M. R. (2011a). Blog como recurso didático: instrumentação e reconfiguração da prática docente na cibercultura. Revista Tecnologias na Educação, 1.

Lima, M. R. (2001b). Aprendizagem de programação de computadores no ensino superior: percepções e motivação/desmotivação discente. Seminário Internacional Redes Educativas e as Tecnologias: Práticas e Teorias Sociais na Contemporaneidade, Rio de Janeiro, RJ, Brasil.

Lima, M. R. \& Leal, M. C. (2010). Ciberpedagogia: indicativos para o rompimento com a lógica da transmissão. Vertentes, 35, 24-35.

Medeiros, Z. Apropriação da cultura tecnológica na formação das redes sociotécnicas: Um estudo sobre o portal da Rede Municipal de Ensino de São Paulo. (Dissertação de Mestrado). Centro Federal de Educação Tecnológica de Minas Gerais, Belo Horizonte.

Medeiros, Z. \& Nascimento, S. S. (2010). Letramento digital na escrita em fóruns on-line. III Colóquio sobre Letramento e Cultura Escrita, Belo Horizonte, MG, Brasil. 
Moraes, M. C. (1997). O paradigma educacional emergente. 11. ed. Campinas: Papirus.

Moran, J. M., Maseto M. T. \& Behrens, M. A. (2000). Novas tecnologias e mediação pedagógica. 16 ed. Campinas: Papirus.

Ornelas, B. S. (2007). Cibercultura e Educação Física: o virtual na formação de professores. (Mestrado em Educação). Universidade Federal da Bahia, Salvador.

Peres, P. (2006). Edublogs como mediadores de Processos Educativos. Revista Prisma, 3, 189199.

Primo, A. (2007). O aspecto relacional das interações na Web 2.0. E-Compós, 9, 1-21.

Santos, E. (2005). Educação online: cibercultura e pesquisa-formação na prática docente. (Tese de doutorado). Universidade Federal da Bahia, Salvador.
Silva, M. (2000). Sala de aula interativa. Rio de Janeiro: Quartet.

(2006). Criar e professorar um curso online: relato de experiência. En Silva, M. (Org.). Educação online. São Paulo: Loyola.

(2010). Formação de professores para docência online: uma pesquisa interinstitucional. Encontro Nacional de Didática e Prática de Ensino, Belo Horizonte, MG, Brasil.

Silva, M. \& Claro, T. (2007). A docência online e a pedagogia da transmissão. (Boletim Técnico do Senac, 33 (2), São Paulo: Senac.

Sommer, L. H. (2010). Formação inicial de professores a distância: questões para debate. Em Aberto. Brasília, 84, 17-30.

Valente, J. A. \& Almeida, M. E. B. (2007). Formação de educadores a distância e integração de mídias. São Paulo: Avercamp. 


\title{
La Industria Cultural y la crítica educativa en América Latina: una
} perspectiva histórica

\section{The Cultural Industry and educational criticism in Latin America: A Historical Perspective}

\author{
Miguel Ángel Soto Sandoval
}

msoto@ups.edu.ec

Recibido: 07 de noviembre de 2013 / Aceptado: 23 de enero de 2014

\section{Resumen.}

El presente artículo tiene como objetivo examinar a tres autores que desde sus propios campos disciplinarios académicos aportaron para el desarrollo de un saber educativo en América latina en los temas de cultura, comunicación y educación. Para ello y en su un primer momento, se entregará una reflexión histórica sobre la importancia que ha jugado la Industria Cultural en América Latina a partir de los aportes académico de Andrés Bello, cuyo accionar intelectual estuvo enfocado a cohesionar la unidad nacional de los recientes estados latinoamericanos del siglo XIX. Será a través del lenguaje escrito y oral, proveniente de la llamada cultura ilustrada, y con el apoyo de los medios de comunicación de la época en que el proyecto bellista se convertirá en la primera estrategia comunicativa y educativa que buscó plasmar las nuevas y variadas dimensiones de la naciente Cultura Sudamericana.

De igual manera, y en el mismo sentido, revisaremos las posiciones de los escritores y periodistas José Martí y Rubén Darío, quienes se ven confrontados con una Modernidad que comienza a reemplazar a la Cultura llustrada por la Cultura de Masas. Sus poemas y escritos en los periódicos de la época instalaron por vez primera, una impronta académica ligada a la crítica y la educación como es el cuestionamiento a la industria cultural y sus narrativas mediáticas que opera a fines del siglo XIX desde los diversos medios de comunicación.
Finalmente, se analizará cómo surge la crítica comunicativa en Latinoamérica frente a los procesos de dominación, que no solo provienen desde lo económico, sino también, desde las llamadas industrias culturales que emergen con mucha fuerza a mediados del siglo $X X$. Dichos medios de comunicación proyectan los procesos culturales como un producto mercantil, diluyendo con esta acción comunicativa y mediática, las auténticas dimensiones de la cultura.

Palabras clave: Lenguaje, cultura, medios de comunicación, critica comunicativa, industrias culturales, globalización, desterritorialización, hiperindustria cultural, mutación antropológica.

\section{Abstract}

The purpose of this article is to study three authors from different academic fields who have contributed to the development of educational knowledge systems in Latin America in the areas of culture, media communication, and education. In order to do so, I will first explore a historical study about the importance of the Cultural Industry in Latin America, based on academic contributions by Andres Bello, who focused intellectually to give cohesion to national unity in the recently-established XIX century Latin American states. Enlightened culture emerges from its written and spoken language, and with support of 
the media at the time, the "bellista project" would become the first media communication and educational strategy aimed at capturing the new and varied dimensions of a nascent South American Culture.

Similarly and in the same vein, I will look into the stance of writers and journalists, José Martí and Rubén Darío, who had to face Modernity as it began to replace the Enlightenment for a Culture for the Masses. Their poems and writings in newspapers back then, established an academic standpoint, for the first time, linked to media analysis and education, such as questioning the cultural industry and media narratives that were operating towards the end of the XIX century, in different media outlets.

Finally, I examine how media analysis in Latin America emerged in the face of processes of domination that came not only from the economic but the so called cultural industries that surfaced with so much power in the mid-twentieth century. These media outlets show cultural processes as a marketable product while diluting the true real dimensions of culture.

Keywords: Language, culture, media outlets, media analysis, cultural industries, globalization, deterritorialization, hyper industry, anthropological mutation.

Forma sugerida de citar:

Sandoval, S. (2013). La Industria Cultural y la crítica educativa en América Latina: Una Perspectiva Histórica. Alteridad, 8(2), pp. 155-161. Quito: Editorial Abya-Yala.

"Nuestra mirada se enmarca en aquello que difusamente podríamos llamar estudios en comunicación, parte de un dominio todavía más complejo que bajo la impronta de la interdisciplinariedad se inscribe en el campo de los estudios contemporáneo de las cultura". (Cuadra, 2012).

\section{Introducción}

¿Cómo debemos comprender la Industria Cultural y qué importancia tiene en la configuración de las identidades en América Latina?

Para entender la complejidad de la cultura y su adhesión a los medios de comunicación, es necesario, no sólo analizar, aspectos históricos y conceptuales que se enlazan y se localizan en los procesos de difusión y estrategias mediáticas, que apuntan fundamentalmente a buscar procesos de homogeneización y cosificación de las diversas culturas, sino más bien se intenta explicarla desde la industria cultural, tal como lo planteaban T. Adorno y M. Horkheimer en que la cultura expresada en el arte y transmitida través de los medios de comunicación convertirá a ésta en bienes producidos en serie.

Asimismo, para T. Adorno y E. Horkheimer (2004) dedujeron que el lenguaje es un instrumento o un soporte que colabora en la difusión de la industria cultural. Cabe señalar que el concepto acuñando por los representantes más emblemáticos de la Escuela de Frankfurt, ha sufrido las más variadas categorizaciones de análisis y estudios en el mundo de la educación y la comunicación, pero ésta no deja de ser importante para determinar ciertos rasgos que operaron en las sociedades a mediado del siglo XX.

Sin embargo, hoy se habla de una Hiperindustria Cultural ligadas a las nuevas tecnologías, donde no existen los llamados receptores pasivos, sino usuarios tecnológicos que acceden a nuevas narrativas en los tiempos de globalización económica situando nuevos fenómenos como son: la desterritorialización, la cultura internacional y las sociedades fragmentadas son motivos suficientes para nuevos análisis en el ámbito de la cultura, la educación y la comunicación. 


\section{Andrés Bello y la cultura illustrada}

“Todas las verdades se tocan" será el enunciado fundamental que hiciera Andrés Bello en su discurso el 17 de Septiembre de 1843 en la Universidad de Chile, fue "trascendental", como una condición a priori, capaz de concentrar o de resumir uno de los componentes esenciales de la política cultural y universitaria bellista. La ocasión en la cual se instala este "trascendental" no es irrelevante como tampoco lo es el escenario de "distinción" y de "representación" que lo acompañan. Esta expresión busca armonizar el cultivo de las ciencias y las letras con los puntos de vista de la moral y de la política. Bello señala, además, que los "adelantamientos" en todas estas líneas "se llaman unos a otros, se eslabonan, se empujan" no constituyen particularismos cerrados, aislados" (Ossandón, 2012: 8) ${ }^{1}$.

Sobre este tema, Bello comprendía que el paso de lo tradicional a lo moderno debía estar articulado a través de un cuerpo de intelectuales capaces de recibir y reflexionar la información y los saberes que provienen de la Europa del siglo XIX. "Todas las verdades se tocan", será para este autor una "alianza estrecha" entre la ciencia y la religión, acaso buscando acuerdos en el plano cultural necesario para el estado chileno y otras naciones sudamericanas.

En suposición a lo que Ossandón manifiesta "la línea de Michel Foucault, aquellos saberes no han alcanzado la "dignidad" de ser órdenes o de expresarse en "fórmulas generales" (que operan, en consecuencia, como "microsaberes" no hegemónicos ni sistematizados), irreconciliables por naturaleza: se podría decir, en lucha a muerte contra su coaptación por los grandes poderes o

Tomada del Texto de Estudios "Industria cultural y espacio público en América latina" . Universidad de Artes y Ciencias Sociales ARCIS. de Ossandón Carlos. Sin embargo se hace referencia también en el Link.http://patriciofloresgomez.blogspot. mx/2007/08/patricio-flores-gmez-doctorado-en.html (Consultada el 7 de febrero 2014). por dificultades propias de integración, no están invitados a formar parte de esa "alianza estrecha" incentivada por Bello” (Ossandón, 2012:8).

Para esto, Bello publica numerosos artículos en el periódico el "Araucano" 2 centrados básicamente en la filosofía y la educación convirtiéndose de esa manera en un gran formador de la opinión publica en la época poscolonial. Dicha estrategia, busca cohesionar la unidad nacional no sólo desde las perspectivas europeas, sino también desde las perspectivas locales y mestizas. El lenguaje y la gramática será su estrategia comunicativa en que los saberes educativos debían propagarse en dos dimensiones: la primera, debía ser horizontal estableciéndose un centro comunicativo con la academia y la segunda es de carácter multidireccional y tenía como función convertirse en un vaso comunicante entre la academia, los intelectuales y las diferentes clases sociales de la sociedad.

Se constituye de esta manera la relación Estado-Universidad y se instala en la esfera pública el debate de la importancia de la educación. La educación se convertiría entonces en un agente fundamental para el cambio social y un puente comunicativo para la configuración del o los Estados Naciones, siendo esta estrategia comunicativa la primera Industrial Cultural que busca desprenderse de la hegemonía española dando paso, a los llamados modernitas que irrumpen en América Latina y determinan que los rasgos más importantes de la Cultura de Masas en la primera década del siglo XX ya no sólo opera desde los

2 Andrés Bello fue también director y redactor de El Araucano, periódico ministerial fundado por Diego Portales en 1830, en el cual publicó numerosos artículos de educación, filosofía y teatro. En 1842 polemizó con el rioplatense Domingo Faustino Sarmiento sobre cuestiones de lengua, estética y políica. Se ocupó del lenguaje a través de numerosos estudios. Sobresale su Gramática de la Lengua Castellana (1847), que le valió ser designado miembro correspondiente de la Academia Española de la Lengua, y su Ortología y métrica, los dos trabajos más originales que se han realizado en nuestro idioma sobre esta materia. Escribió también un comentario a El Criterio de Balmes, y un estudio sobre El Cantar de Mío Cid. http://mww.biografiasyvidas. com/biografia/b/bello.htm 
textos convencionales sino también con la llegada masiva de los medios de comunicación y como ellos reformulan o alteran los vínculos cognitivos entre la esfera pública y privada "produciendo algunos casos de desequilibrios o integraciones entre estas dos esferas" que irán aumentando durante el transcurso del siglo XX. ${ }^{3}$

Sin embargo, estas esferas iniciaron con una transformación cultural "que se expresa en nuevas visibilidades o exterioridades sígnicas, en inéditas relaciones entre letra e imagen, y en la estimulación de unas sensibilidades que ya no tiene como fuente la cultura ilustrada y letrada del siglo XIX”. (Ossandón, 2013: 12).

Del mismo modo, son los medios de comunicación que ponen el concepto de la cultura al servicio del mercado y la estandarización de ésta, transformándose la cultura en mercancía y también en un proceso ideológico que está sustentado en la propia matriz del capitalismo, dicho de otro modo, esta Industrial Cultural estará ligada a los procesos de transformación de las sociedades latinoamericanas tendiendo a neutralizar las diferencias étnicas y sociales de las grandes masas asentadas en las principales ciudades de América Latina.

Sobre este tema, Rubén Darío ya en su texto "Azul", insinuará en su obra literaria el percance que estos "nuevos tiempos" trae a la cultura Ilustrada. El desencanto y la desilusión de los tiempos modernos estarán presentes en su texto. Asimismo, José Martí en el prólogo del "Poema del Niágara" escrito por Juan Antonio Pérez Bonalde (1882), advierte que "la extensión y re- significación que experimenta el campo de lo estético es uno de los rasgos esenciales del nuevo espacio público".

3 Hacia la segunda mitad del siglo $X X$, posiciones encontradas comienzan a debatir respecto a la aparición de multitudes en la vida social, lo cual a partir de las tecnologías de la comunicación, se transformó en un fenómeno evidente y perdurable. La industria cultural, irrumpe en el escenario con novedosas propuestas, por cierto, en muchos casos, más que cuestionables. http:// comunicacion.idoneos.com/index.php/336369.
De igual forma, Martí propugna en sus escritos periodísticos y ensayos el proyecto del latinoamericanismo que al final de cuentas, es una propuesta política; Modernismo v/s Modernistas, será un rasgo particular y fundamental en este periodo, en que Martí y Rubén Darío entregaron las bases conceptuales y epistémicos para enfrentar la creciente industria cultural que maniobraba desde los más diversos sectores de la sociedad latinoamericana, denunciando la creciente producción en serie del arte, apoyado por una educación influenciada por lo "moderno" y los medios de comunicación colocaron a la cultura bajo la creciente industria mediática. Sus críticas y aportes se centraron elementalmente en establecer las diferencias entre lo que realmente es la cultura ilustrada y la cultura de masas ¿Qué pasó entonces con la herencia académica de Bello, Martí y Darío en América Latina? o mejor dicho ¿La cultura de masas se impuso definitivamente en la región?

\section{La crítica educativa}

Es evidente que frente a estas preguntas habrá mucho debate; sin embargo se puede afirmar que en la segunda mitad del siglo XX se instaló en el continente americano la Crítica Comunicativa y Educativa produciendo un giro crítico hacia las Industrias Culturales mediáticas que se instalaron en la región a partir de los procesos descritos y que según, la especialista Libertad García (2013) esta crítica educativa y mediática estuvo "orientado a las formas comprensivas de conocimiento, se propuso superar los estudios positivistas de la comunicación social, creando nuevas formas metodológicas de tipo comprensivo basadas en la auto-reflexión, la consideración de la totalidad social e histórica, la especulación y el análisis comprensivo".

Dicho giro crítico y ruptura comenzará con los planteamientos conceptuales de la Escuela Culturalista latinoamericana en que textos como "Para leer al Pato Donald", de Ariel Dorfman y Armand Mattelart publicado en la década de los 
años setenta durante el Gobierno de la Unidad Popular en Chile causaría un gran impacto en los intelectuales provenientes desde las más diversas disciplinas.

En sus páginas se exponía que "detrás" de inocentes caricaturas como Hugo, Paco y Luis, se proyectaba la propaganda cultural e ideológica del capitalismo norteamericano es decir que la "historietas de Disney, más que un entretenimiento infantil, era un manual de instrucciones para los pueblos subdesarrollados sobre cómo han de ser sus relaciones con los centros del capitalismo internacional". Asevera el especialista Roberto Langella (2011).

De igual manera, este libro denunciaba abiertamente el comportamiento de los medios de comunicación, sus doctrinas y sus estrategias de manipulación y homogenización del pensamiento político a favor de las ideologías dominantes. Sus denuncias fueron tan polémicas en aquellas épocas que un periódico francés llegó a titular en su portada "El Pato Donad está en contra de Allende".

Por otra parte, en diversos centros de educación el texto de Dorfman y Mattelart motivaba a muchos lectores a educarse en destrezas técnicas y profesionales para comprender y develar que, las noticias o textos informativos siempre tenían un trasfondo político, social y cultural; y que, en la objetivad periodística expresada en caricaturas, artículos de opinión o titulares estarán presentes de forma explicita o implícita los intereses "oscuros" de quienes ostentan el poder.

La propuesta de Dorfman y Mattelart, busca analizar las significaciones que se desprenden de las prosografías o de los esparcimientos periodísticos de igual intención es la propuesta del giro crítico surgidos en los años 1970-1980, propuesta que tiene como impronta "mirar" la relación epistémico entre desarrollo, comunicación y tecnologías, ello significaría analizar los "bordes" de textos educativos y audiovisuales. De igual modo, los autores "Para leer al pato Donald", junto a Eliseo Verón proponen que la ideología

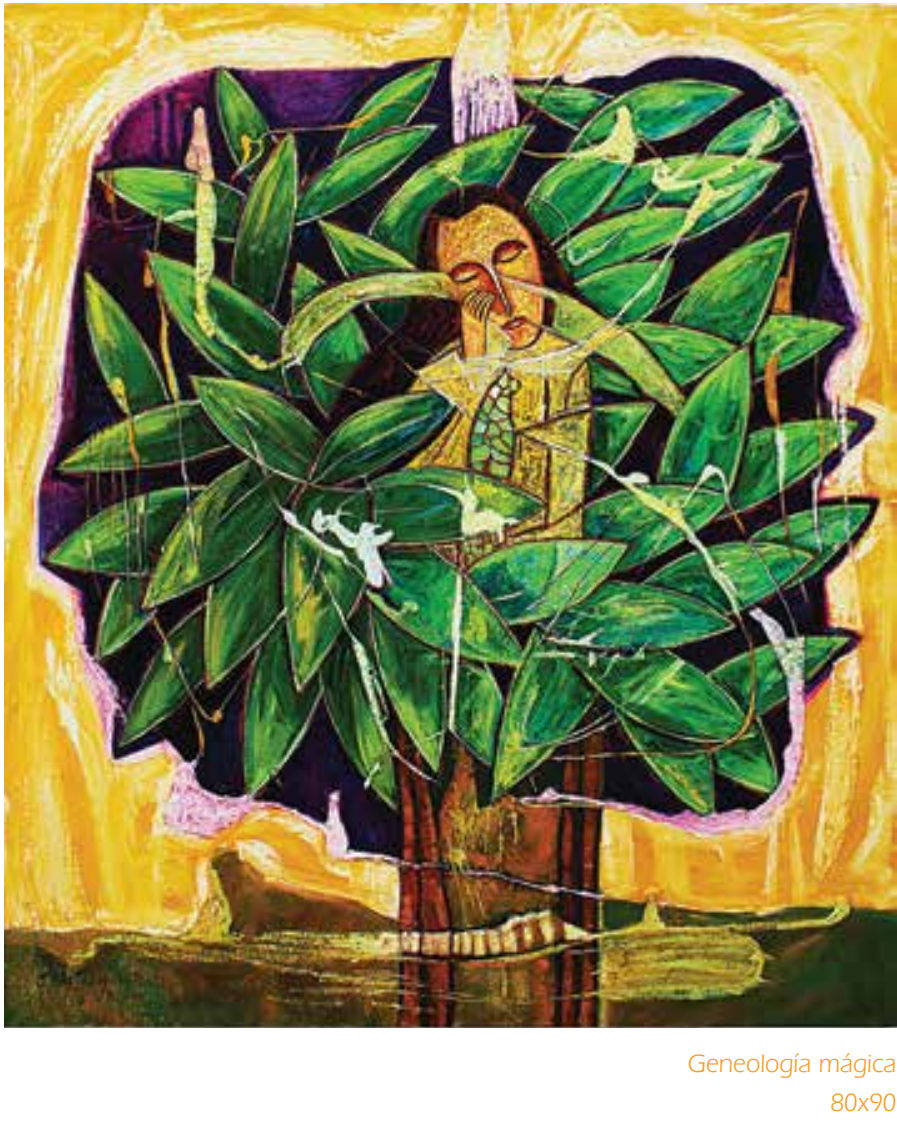

sigue estando presente no solo desde la escritura, sino que además, opera desde el lenguaje cotidiano y los centros educativos.

Será el momento en que Jesús Martín Barbero y Néstor García Canclini proponen estudiar la comunicación y la educación no solo desde los medios y la ideología dominante, sino también desde fisuras que produce el capitalismo mundial en la cultura popular.

Después de cruentas dictaduras en la mayoría de los países latinoamericanos en que la censura mediática fue el pan de cada día y las propuestas alternativas de educación y comunicación pasaron a la clandestinidad (panfletos, murales, periódicos, etc.) Se abocaron a retomar la lectura crítica con orientaciones hacia las temáticas de derechos humanos rompiendo de esa manera la censura y las Industrias Culturales que en mucho 
de los casos en América Latina recibía el 80\% de las agendas mediáticas norteamericanas. ¿Es posible romper las llamadas Industrias Culturales en el contexto de la Globalización y las Nuevas Tecnologías de la Información?

\section{Una mirada all presente}

En el mundo de las tecnologías, la desterritorialización y la des-nacionalización (Weber, 2000: 7), junto a la movilidad humana y las migraciones y las rupturas ligadas a las transformaciones económicas y políticas generan sensaciones de evanescencia que provocan sentimientos de desarraigo. Estos procesos llevan a una búsqueda intensa de las raíces culturales y también de nuevas percepciones. Es decir "que no sólo se trata de nuevas tecnologías y formatos comunicacionales, son las mediaciones, los modos de significación y de circulación de los signos lo que estaría provocando una transformación en la matrices cognitivas o de comprensión del mundo" (Ossandón, 2013: 13).

Por otra parte, citando a Pierre Bourdieu, la comunicación mediática se convierte en el mecanismo anónimo e invisible a través de la cual se ejercen censuras de todo orden y al mismo tiempo en instrumentos de nuevos órdenes simbólicos que casi siempre están ligados a los procesos de acumulación y consumismo.

En las sociedades mediatizadas y virtuales ${ }^{4}$, las prácticas sociales y culturales se articulan directamente con los medios y la sociedad, es decir los medios, y las NTCI (Nuevas tecnologías de la comunicación y la información) no son el objeto de la comunicación, su objeto es la vinculación con el ser humano (Nietzsche, 2000: 15), y posee dos sentidos: el de intercambio y el de la

4 Según Edgar Weber "lo virtual forma parte desde ahora de nuestro cotidiano hasta tal punto que a veces cuesta establecer una distensión entre lo real y lo virtual. El acceso tan masivo y directo a la información y el saber modifica y modificará profundamente nuestras culturas" en: Weber, Edgar, Las culturas en el proceso de la mundialización, 2000, pág.:7-10. participación y comprensión. El intercambio lo constituye el vínculo mediático, mientras que la participación y comprensión implica reconocer a los sujetos, capaces de comunicarse por medio de un lenguaje y de una acción.

Es decir, económicamente el mundo gira desde el capitalismo globalizado, pero la cultura ha desarrollado un sistema de símbolos y sensibilidades, generando un "imaginario colectivo internacional de des-territorialización" (Ortiz Renato, 1998: 37), trayendo consigo lo que Lipovetky (2006) insinúa una cierta "mutación antropológica", estableciéndose un nuevo diseño socio cultural en que, según Álvaro Cuadra (2012) se hallan en los distintos juegos del lenguaje, desplazando los grandes relatos y a los textos canónicos tradicionales. Son las consecuencias de las llamadas Hiper-industrias Culturales.

Por otra parte, en estos desórdenes planteados por Barbero desde las escenas del arte y la comunicación, se hace difícil establecer claramente las esferas de lo público y lo privado, muy por el contrario será este un campo de tensión en que Beatriz Sarlo en su texto "La Cultura de Zapping", recomendará "recomunicar tres lugares: la esfera académica, con la esfera pública y la esfera política"(Sarlo, Beatriz, 1987: 282) para poder entonces configurar una nueva dimensión política y educomunicativa. Indudablemente la Hiperindustria Cultural puso en acción un nuevo escenario en que los receptores pasivos dejaron de existir y hoy se da paso a los usuarios que ya no solo se conectan de forma vertical, sino además, lo hacen horizontalmente enfrentando de esa manera las tradicionales Industrias Culturales.

\section{Conclusiones}

Es a partir de estas reflexiones que se hace necesario e importante que se exploren nuevos modelos de educación que permitan a las personas en habilidades para lograr un consumo crítico de las nuevas narrativas mediáticas y desvelar los procesos de falseamiento de la realidad, evi- 
tando que los sistemas educativos se conviertan en instrumento al servicio de la intolerancia y la dominación.

También es importante tener en cuenta que la comunicación y las nuevas tecnologías en mucho de los casos producen efectos negativos en los sujetos configurando y justificando procesos cognitivos ajenos a los de los países o regiones en desarrollo.

\section{Referencias bibliográficas}

Adorno, T. \& Horkheimer, M. (2004). La industria cultural en Dialéctica de la Ilustración. Fragmentos filosóficos. Madrid: Tecnos.

Bourdieu, P. (1997). Sobre la televisión. Barcelona: Anagrama.

Brunner, J. (2003). Educación e internet ¿La próxima revolución?. Chile: Salesianos.

Cuadra A. (2012). Hiperindustria Cultural. Chile: Universidad ARCIS.

Eco, H. (1995). Apocalípticos e integrados. Barcelona: Tusquets Editores.

Eddine A. \& Mohammed N. (2000). La interculturalidad de Nc World en el paradigma globalitario.

Geertz, C. (1987). La interpretación de las culturas. México: GEDISA.
La comunicación y la educación deben generar una constante reflexión que permita buscar alternativas educomunicacionales en los cuales se promuevan los valores de la diversidad, el respeto por la democracia y los derechos humanos. Escuchar es la manera como se construye todo aquello que nosotros logramos interiorizar y establecer como verdadero. (Poulain: 2000:16).

Lipovetsky, G. (2006). Los tiempos hipermodernos. Barcelona: Anagrama.

Mattelart, A. (1995). La invención de la comunicación. México: Siglo XXI.

(1998). Pensar sobre los medios. Comunicación y crítica social. Buenos Aires: Paidós.

Ortiz, R. (1998). Los artífices de una cultura mundializada. Bogotá: Siglo del Hombre.

Ossandón, C. (2013). Industrial cultural y espacio público en América Latina. Universidad ARCIS.

Languella, Robert. (2011). "Para leer al Pato Donal". Consultada el 7 de febrero de 2014. Disponible en: http://robertolangella.blogspot.com/2011/11/para-leer-al-pato-donaldde-dorfman-y.html. 


\section{Apuntes para el debate ecuatoriano} sobre medios: Distribución de frecuencias, ¿posibilidades para la educomunicación?

\section{Notes on the Ecuadorian media debate: Distribution of broadcasting frequencies, possibilities for "educommunication"?}

Roberto Sánchez Montoya

Universidad Politécnica Salesiana rsanchezm@ups.edu.ec

Recibido: 07 de noviembre de 2013 / Aceptado: 23 de enero de 2014

\section{Resumen}

En los últimos años algunos países progresistas de América Latina han realizado cambios a sus leyes que regulan los medios de comunicación, con especial énfasis sobre los medios audiovisuales' que explotan el espacio radioeléctrico. Una cuestión que comparten estas nuevas leyes de comunicación es el criterio de reorganizar las concesiones de radio y televisión, con el compromiso de entregar un tercio de estas frecuencias a los medios constituidos por organizaciones sin fines de lucro, que son denominados medios comunitarios. Además, en varios casos, como el ecuatoriano, también se reserva otro tercio de las frecuencias para medios de organismos públicos. Estos cambios posibilitarían que en el mediano plazo el sector comunitario y público posean, en conjunto, la mayor parte de las frecuencias de los medios audiovisuales en varios países de la región. En teoría tendríamos un conjunto de espacios antes acaparados por el sector privado, que deben pasar a manos de sectores fuera de una

1 Cuando hablamos medios audiovisuales nos referimos a estaciones de radio y televisión. lógica estrictamente mercantil para la realización de sus producciones. En este marco nos preguntamos, ¿qué posibilidades existen para un relanzamiento de propuestas de comunicación orientadas, en un sentido amplio, hacia la educomunicación?2 Trataremos de ensayar respuestas a esta pregunta tomando como referencia el caso ecuatoriano y los desafíos, entendidos como logros y limitaciones, que plantea su nueva ley de comunicación.

Palabras clave: Comunicación, medios audiovisuales, democratización, Ecuador.

\section{Abstract}

In the last few years, some progressive countries in Latin America have made changes to laws that regulate media, with a particular emphasis on audiovisual media that make use of radio broadcast-

2 Educomunicación en el sentido de Mario Kaplún, quien explica que tanto los procesos educativos como los comunicativos implican aprendizaje a través de la mediación del lenguaje y que políticamente son la base para genera el diálogo para el cambio social. 
ing space. A key feature shared by these new media laws is the criteria for reallocating radio and TV concessions, with a compromise of assigning a third of these frequencies to non-governmental organizations, referred to as community media. Moreover, in several cases, as in Ecuador, another third of the frecuencias are reserved for public institutions. These changes would allow, in the medium term, for community and public groups to own most of the range of audiovisual media frequencies in several countries in the region. In theory, we would have spaces that had been previously hoarded by the private sector, now in the hands of groups outside of the strictly commercial rationality used for their own benefit. In this context, we ask, what possibilities are there for a relaunch of communication proposals oriented, in the general sense, to "educommunication" (educational communication)? We will attempt to provide answers by using Ecuador as a reference for both challenges, learned successes, and limitations under the new Law of Communication.

Keywords: Communication, audiovisual media, broadcasting media, democratization, Ecuador.

Forma sugerida de citar:

Sánchez, R. (2013). Apuntes para el debate ecuatoriano sobre medios: Distribución de frecuencias, ¿posibilidades para la educomunicación?. Alteridad, 8(2), pp. 162-170. Quito: Editorial Abya-Yala.

\section{Intro ducción}

En las últimas décadas, en el mundo, se observó una creciente importancia de los medios de comunicación audiovisuales sobre el campo de la política (Bourdieu, 1997; Sartori, 1998). Paralelamente a esta paulatina mediatización audiovisual de la política ocurrió un proceso de concentración de los principales medios de comunicación, en manos de grandes corporaciones privadas (Becerra \& Mastrini, 2001); de alguna manera en sintonía con las políticas económicas de corte neoliberal recomendadas por el Consenso de Washington para América Latina (Stiglitz, 2003). Como consecuencia de esta combinación de fenómenos, hacia finales del siglo $\mathrm{XX}$, los grupos privados más poderosos fueron acaparando cada vez más medios, audiencias y poder político.

Como respuesta, en los primeros años del siglo XXI, los estudios latinoamericanos de comunicación fueron retomando la centralidad de su reflexión sobre la política y economía de los medios, con autores como César Bolaño, Guillermo Mastrini, Martín Becerra y Enrique Sánchez, entre otros. Las propuestas teóricas recuperaron la tradición de los estudios críticos de los años 70 que sirvieron de base para elaborar el informe MacBride (1987) de la Unesco. Uno de los elementos centrales del mencionado informe fue la necesidad de construir un nuevo orden mundial de la comunicación para distribuir y balancear los flujos de información. Propuestas que en la década de los 90 estuvieron en un segundo plano en la producción intelectual de las academias latinoamericanas de comunicación, en las que se privilegió investigaciones de corte cultural (Follari, 2003).

Hacia finales de los 90 y comienzos del actual siglo la nueva línea de investigación de la economía política de la comunicación tuvo el espacio suficiente para denunciar la concentración mediática y propuso la urgente necesidad de desarrollar procesos de democratización de la comunicación bajo la perspectiva de la comunicación como derecho humano (Tuvilla, 1997). Estas propuestas se fueron consolidando a la par que, a mediados de la primera década del siglo XXI, en algunos países latinoamericanos, comenzaron a llegar al poder gobiernos de izquierda o centroizquierda con una agenda que retomaba propuestas posneoliberales y de democracia participativa.

Vale recordar que las políticas de privatización y desregulación colapsaron en varios países de la región, desde finales de los 90, produciendo severas crisis sociales y económicas (Stiglitz, 2003); en este contexto surgieron líderes políticos con discursos radicales. Siguiendo las aproxi- 
maciones de Laclau (2005) a la razón populista ${ }^{3}$ encontramos que, en los momentos de quiebre institucional, una cuestión fundamental en la constitución de una nueva identidad política tiene lugar cuando se produce una diferenciación dicotómica frente a la unidad que se busca interpelar. Este proceso de articulación social se concretará a través de un liderazgo que logre representar a las diferentes demandas de cambio institucional. Así un líder se convertirá en una figura clave para articular heterogéneas posiciones y dar cierta centralidad a un discurso antagónico para cambiar el status quo.

\section{Nuevos popullismos}

Cuando un proyecto político de corte populista triunfa democráticamente y accede al poder, tiene el desafío de transformar el Estado; es decir, buscará construir una nueva institucionalidad. En este marco los nuevos gobernantes ponen en marcha una serie de cambios institucionales que las políticas vigentes han sido incapaces de resolver. Sin embargo, todo gobierno que pretende crear instituciones nuevas es, a la vez, heredero de una institucionalidad producto de las relaciones políticas del pasado. Por tanto, funciona sobre las mismas bases de la administración pública que pretende transformar, situación que genera fuertes tensiones (Santos, 2007), porque tampoco rompe de cuajo con el sistema como lo hicieron las revoluciones del siglo XX, aunque los gobiernos de Ecuador, Venezuela y Bolivia se definan como revolucionarios (Stefanoni, 2012).

Las dificultades en los procesos de transformación institucional del sistema heredado se compensan con cambios progresivos en las estructuras de poder, pero estos cambios generan una fuerte resistencia por parte de las élites que

3 Las referencias al populismo no tienen una connotación negativa, sino que es visto como el resultado de una articulación de demandas populares que pueden resultar transformadoras $y$ emancipadoras. tratan de evitar la pérdida de sus posiciones de privilegio. Sin embargo, como hemos advertido, los gobiernos que buscan transformaciones importantes generalmente emergen de situaciones de crisis, por lo tanto los actores políticos tradicionales no suelen ser el mayor obstáculo para el proceso de cambio que se proponen; el principal motor de las críticas a un gobierno provendrá de quienes todavía sostienen posiciones de dominio para el debate público, como las corporaciones mediáticas privadas, generalmente vinculadas o financiadas por grandes grupos económicos.

En este contexto tienen lugar las confrontaciones entre los grandes medios privados y presidentes como Hugo Chávez [Nicolás Maduro], Rafael Correa, Evo Morales y Cristina Fernández que, en diferente grado, sindican a las corporaciones mediáticas de hacer política para atacar los procesos de cambio en sus respectivos países. Mientras tanto, los principales medios privados y sus gremios nacionales e internacionales denuncian que se atenta contra la libertad de expresión (SIP, 2013). Así tenemos que para los gobernantes populistas se vuelve una imperiosa necesidad política plantear una serie de acciones para limitar el poder de la prensa corporativa, que como se ha expuesto, en las últimas décadas adquirieron gran influencia sobre la vida política, social y económica de sus países (Bourdieu, 1997; Sartori, 1998; Becerra y Mastrini, 2001). Más aún si autores como Ramonet (1997) denuncian que las prácticas de las grandes corporaciones mediáticas amenazan a la misma democracia, por el sesgo ideológico uniforme que impregnan a la producción de sus contenidos.

Por último, más allá de las diferencias políticas en juego, el discurso que sostienen la mayoría de gobiernos progresistas está centrado en nociones de acción colectiva para implementar medidas que contribuyan a mejorar la igualdad de oportunidades en diferentes campos. Bajo este marco resulta fundamental regular y poner límites a la vinculación entre poder económico y medios de comunicación, con el objetivo de combatir el 
desigual acceso a la prensa, mejorar la difusión de información y generar una mayor diversidad de voces.

Los puntos mencionados, en el párrafo anterior, pueden resumirse como una necesidad de mayor pluralismo mediático y están relacionados con algunas propuestas del campo de la educomunicación, que aboga por diversificar las fuentes de información para ampliar el debate público, con sujetos críticos y creativos, frente a los medios de comunicación (de Fontcuberta, 2003).

\section{El caso ecuatoriano}

Desde la llegada a la presidencia de Rafael Correa, el gobierno ecuatoriano se define como el gobierno de la revolución ciudadana. El mandatario ecuatoriano se enfrenta confrontacionalmente a todos sus detractores, sosteniendo un discurso que dicotomiza el espacio público entre quienes están con la revolución ciudadana y los enemigos del cambio. Estos últimos responderían -en palabras del Presidente- a intereses que buscan regresar al pasado de la partidocracia, la corrupción y poner al país al servicio del capital como en el periodo de la larga noche neoliberal. En las intervenciones públicas del Primer Mandatarioecuatoriano tampoco se escapan críticas a los principales medios privados. Califica constantemente a un sector del periodismo como prensa corrupta, mediocre, mentirosa, entre otros adjetivos.

Correa ha sostenido una relación tirante con la gran prensa privada, no solo en el plano retórico, sino también ha impulsado una serie de acciones que han afectado a los propietarios de grandes medios de comunicación. Para comenzar el Estado a través un proceso judicial, por defraudación financiera al grupo Isaías, incautó dos canales de televisión de señal abierta (TC-Televisión y GamaTV) y dos canales de cable (CN3 y CD7), que pasaron a ser administrados por un fidecomiso de la Agencia de Garantía de Depósitos.

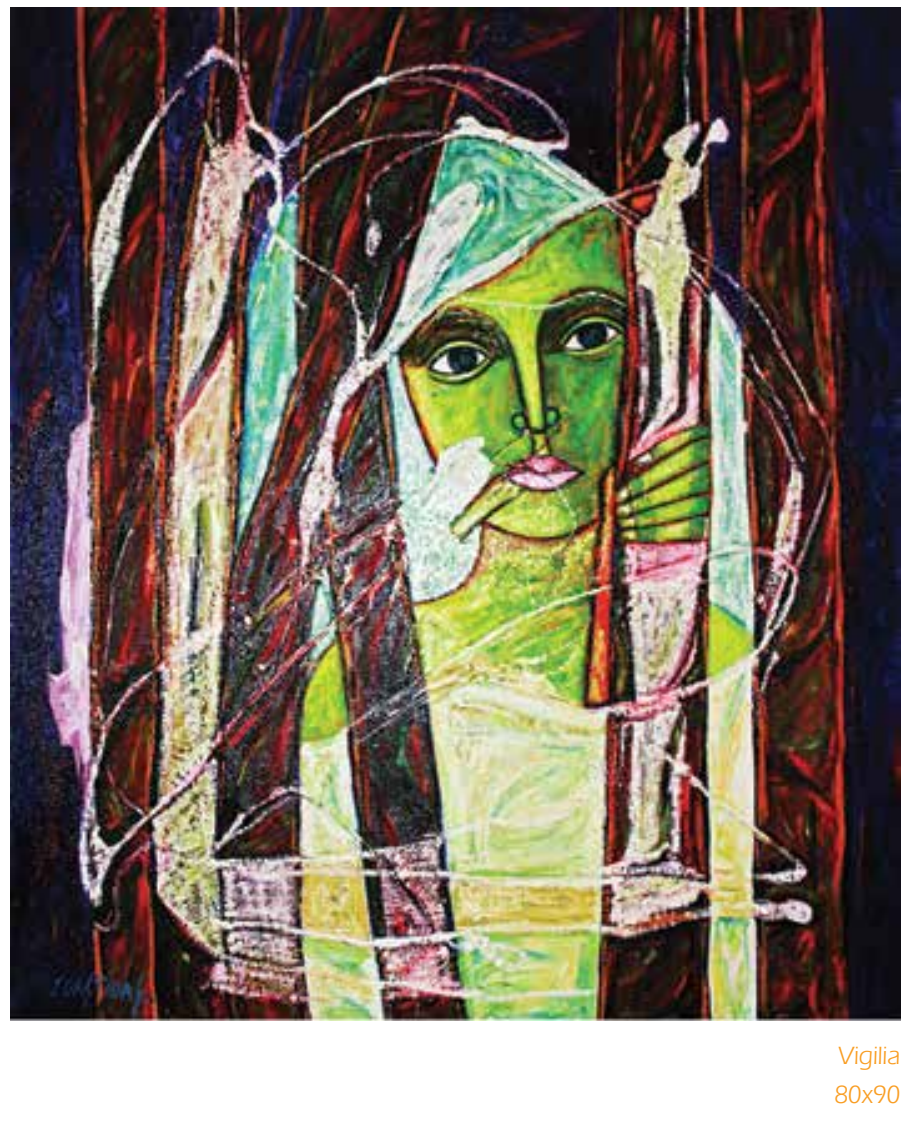

Con la nueva Constitución de 2008 se prohibió la inversión de los grupos financieros en medios de comunicación, tema que fue ratificado el 2011 con una consulta popular. De esta manera, un banquero que controlaba la propiedad de Teleamazonas se vio obligado a vender sus acciones de la televisora. Además, en este período entraron en funcionamiento los primeros medios públicos de la historia del Ecuador: una radio, un canal de televisión, un diario y una agencia de noticias, se han convertido en los principales voceros de la secretaría de comunicación del gobierno; situación inédita en el sistema de medios del país. Como observamos se trata de una significativa reconfiguración del espacio mediático ecuatoriano, a la que habría que agregar una serie de cadenas nacionales, informes semanales del Presidente y una intensa campaña publicitaria estatal. 
También debemos recordar que uno de los conflictos más sonados, entre gobierno y medios, ocurrió con el diario El Universo. El editor de opinión Emilio Palacio (2011) escribió un artículo titulado "No a las mentiras", en el que afirmaba que Rafael Correa podría ser enjuiciado en el futuro "por haber ordenado fuego a discreción y sin previo aviso contra un hospital lleno de civiles y gente inocente", por los sucesos del 30 de setiembre de 2010. Este artículo motivó una demanda de Correa contra Palacio y los directores del diario El Universo, a quienes acusó de faltar a la verdad y de no rectificar su información. En su defensa el Diario denunció una persecución contra la libertad de expresión y la manipulación política de la Corte Nacional de Justicia. Finalmente, los acusados por el Presidente fueron sentenciados a tres años de prisión junto con el pago de una indemnización de $\$ 40$ millones. Sin embargo, la sentencia fue perdonada por el agraviado bajo la figura de remisión, en un acto que sus seguidores calificaron como un gesto excepcional tras haber alcanzado los objetivos: búsqueda de la verdad, sentar un precedente judicial y sancionar moralmente a los difamadores (Patiño, 2012).

Un tema central en esta reconfiguración del sistema de medios fue la reciente aprobación de la nueva Ley Orgánica de Comunicación (LOC) en la Asamblea Nacional (2013). Esta propuesta legislativa estuvo bloqueada durante más de un año en la Asamblea Nacional porque el oficialismo carecía de los votos necesarios para su aprobación. Sin embargo, tras las últimas elecciones parlamentarias el Movimiento País alcanzó una mayoría abrumadora que le permitió aprobar la nueva LOC. Uno de los temas más relevantes que plantea la Ley es la redistribución de frecuencias del espacio radioeléctrico en tres grandes grupos: medios públicos, privados y comunitarios. Cabe mencionar que actualmente las concesiones de frecuencias están principalmente en manos privadas y en varios casos se han detectado que fueron entregadas de forma irregular, según un informe de la Comisión para la Auditoria de las Concesiones de las Frecuencias de Radio y Televisión (2009).

Esta propuesta, para redistribuir las frecuencias, se ha registrado previamente en otros países de América Latina y se argumenta que es necesario promover el pluralismo mediático, reivindicando el papel de los medios comunitarios. La primera iniciativa en esta línea proviene de una iniciativa legislativa uruguaya del año 2007 para reservar al menos un tercio de las frecuencias disponibles para la radiodifusión comunitaria, orientada a la difusión de organización sin fines de lucro (Kaplún, 2010). De forma similar, dos años después, la Ley de Servicios Audiovisuales de Argentina reservó el 33\% del espectro radioeléctrico a las organizaciones sin fines de lucro y en este caso también se reguló los límites al acaparamiento de frecuencias por los medios privados (Observatorio Social, 2011). Luego, en el año 2011, Bolivia incorporó en su legislación la figura del 33\% de la frecuencias para el sector privado, 33\% para los medios públicos y el 34\% restante se dividió en partes iguales, por un lado a las organizaciones sin fines de lucro y de otro lado a los pueblos originarios: campesinos $y$ afrodescendientes (AMARC, 2012). En el caso ecuatoriano se tomó el modelo boliviano del 34\% para la comunicación sin fines de lucro, pero sin incidir en la diferenciación entre organizaciones no gubernamentales y nacionalidades o pueblos originarios.

En todos los casos la aprobación de estas leyes tuvo una fuerte oposición de los grandes medios de comunicación a través de una serie de campañas para atacar la reconfiguración de las concesiones del espectro radioeléctrico y los debates parlamentarios fueron prolongados. Pero la respuesta, desde la otra orilla, la sintetizó muy bien el presidente ecuatoriano en la 42 Asamblea General de la OEA:

...lo que está en el centro del debate, queridas amigas y amigos, no es la libertad de expresión que todos defendemos, con la vida incluso, sino la contradicción ética y técnica de nego- 
cios privados con fines de lucro e intereses políticos y grupales, proveyendo un derecho indispensable para la sociedad; la información (Correa, 2012: 40).

Es decir, se denuncia la hegemonía del capital detrás de los negocios dedicados a la comunicación, que han monopolizado el debate sobre la libertad de expresión para defender sus propios intereses e incluso, algunos de ellos, han estado vinculados a intentos de desestabilización de la democracia en países como Venezuela, Ecuador y Bolivia, según el mandatario ecuatoriano. Desde esta perspectiva resulta clave que el Estado tenga un mayor protagonismo para garantizar el derecho a la comunicación, regular los excesos de los medios privados y fortalecer el poder ciudadano sobre el capital.

A pesar que estos cambios legislativos tienen algunos años en los primeros países que los implementaron, el proceso de otorgamiento de licencias a las organizaciones sin fines de lucro, ha resultado ser un asunto que avanza a ritmo pausado. Peor aún para los países que han aumentado las regulaciones a los medios privados y/o tienen que intervenir para reducir las frecuencias concesionadas. Por ejemplo, en el caso argentino el bloqueo judicial de la Ley, por parte del principal grupo mediático del país, estuvo varios años sin resolverse (Reporteplantese, 2013). Generalmente los medios privados recuren a sus gremios para denunciar, ante organismos judiciales nacionales e internacionales, aparentes violaciones a la libertad de expresión que estarían cometiendo autoritariamente los gobiernos democráticamente elegidos.

Estos cambios en la legislación sobre medios audiovisuales reivindican el derecho a la comunicación de sectores excluidos históricamente de las concesiones de frecuencias, y se apuesta la diversificación de voces con un acceso más plural a los medios. Pero también habría que preguntarse si estos procesos de cambio institucional que se realizan de forma confrontacional, tratando de someter la voluntad de cualquier adversario político, ha significado una profundización de la democracia.

El discurso antagónico contra la figura de los principales medios privados, convertidos en enemigos, parecería tener buenos resultados para la consolidación de un proyecto político populista, pero al mismo tiempo podría incurrir en formas de disciplinamiento vertical que reduzca el espacio para la disidencia, la protesta y el pluralismo.

Precisamente la crítica a los líderes de los países de la Alianza Bolivariana para los Pueblos de Nuestra América (ALBA) ${ }^{4}$ es que tienen en común, en mayor o menor medida, una concepción compartida de un enemigo interno y externo. Por ejemplo, para el caso de Venezuela, Jácome (2010) ha advertido que el enemigo externo al que se enfrenta la revolución bolivariana está relacionado con la denuncia del poder imperial de Estados Unidos y sus aliados, que constituirían el eje del capitalismo global. Mientras que el enemigo interno son los opositores al proceso de cambio, generalmente asociados a grupos de derecha o funcionales a ellos, y que a su vez estarían articulados a las políticas estadounidenses; es decir, agentes de poderes transnacionales. Estos aspectos son sumamente relevantes al trazar políticas de seguridad integral y soberanía nacional. Los miembros del ALBA se conciben como víctimas de la injerencia internacional que debe ser respondida con el fortalecimiento de sus políticas de securitización. De esta forma una cuestión central en estos países es pensar en políticas con estrategias de guerra asimétrica frente a un gran poder global. Asimismo, el socialismo del siglo XXI se concibe como proyecto regional que propone la articulación de un nuevo orden multipolar. Bajo esta perspectiva, este conjunto de naciones han desarrollado una estrategia de seguridad integral soberana, en diferentes áreas, que tienden hacia la securitización.

4 La ALBA está integrada por Cuba, Bolivia, Ecuador, Nicaragua, Venezuela, entre otros países caribeños. 


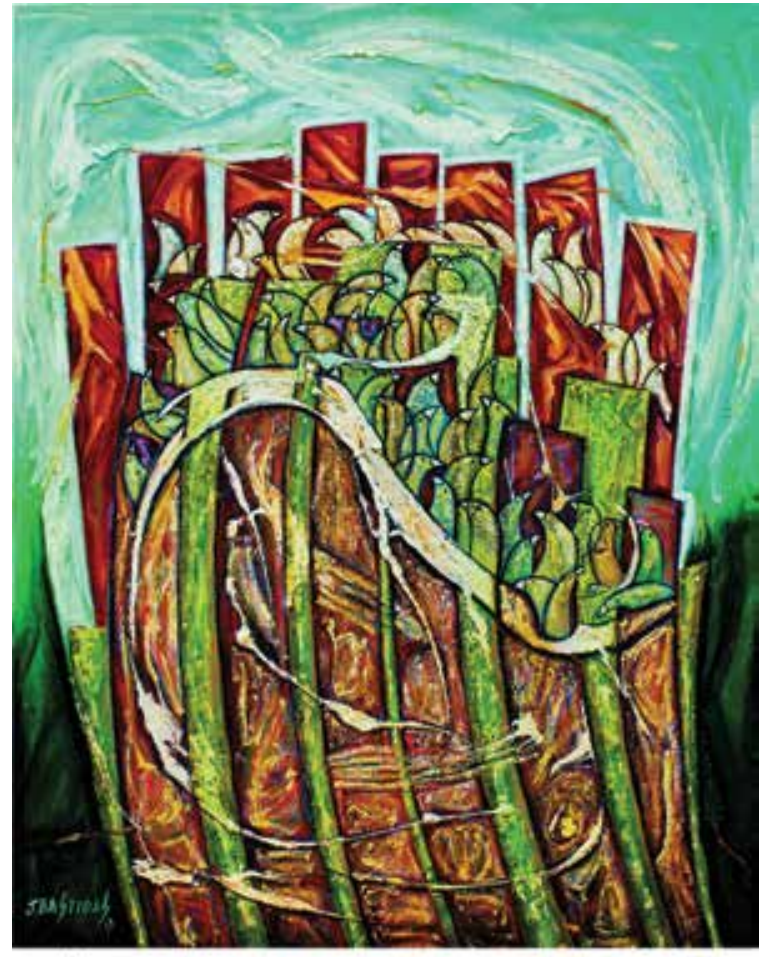

Juncos $70 \times 90$

Si tenemos en cuenta que la política es concebida como una permanente lucha por la construcción de sentido, resulta fundamental para los políticos tratar de controlar la construcción de la narrativa, de mejorar sus posibilidades de comunicación, con el objetivo de dominar la agenda y los debates, para persuadir a los similares y confrontar a los adversarios. En este punto es legítima la pregunta, ¿hasta qué punto la democratización de la comunicación puede caer en un juego que afecta la pluralidad de voces que busca promover?

Regresando al caso ecuatoriano, en este marco de confrontación, aún resulta complicado vislumbrar en el corto plazo de qué manera los cambios, que se han venido implementando, van a fortalecer concretamente procesos de educomunicación. Es más, la nueva institucionalidad todavía no termina de asentarse. Falta que transcurra el proceso de implementación de la LOC y la puesta en operación de los nuevos órganos y códigos reguladores.

En teoría estos primeros pasos para vigorizar estos nuevos medios audiovisuales deberían apuntar a mejorar la difusión de contenidos de mayor diversidad cultural y social. En la realidad, si bien los medios públicos del gobierno central han introducido algunos espacios de corte educativo y cultural, a su vez, el poder ejecutivo cuenta ahora con canales para expresar la línea editorial oficial sobre temas de debate nacional, muchas veces de forma confrontacional, hecho que es percibido como un exceso por parte de periodistas entrevistados sobre los espacios noticiosos de los medios públicos (Ordoñez, 2011). Añadiría que algo similar ocurre con los canales de televisión intervenidos por las acusaciones de defraudación fiscal al grupo Isaías.

Mientras tanto, sobre los medios comunitarios aún no se tiene indicios claros de qué línea vienen asumiendo, dado que es algo reciente la creación de las primeras radios locales vinculadas principalmente a comunidades indígenas; como señala Stiglitz (2003):

Si bien el gobierno tiene que aprobar, y hacer cumplir, leyes que garanticen la diversificación de los medios de difusión, también debe asegurarse de que por esos medios, se escuchen más voces, y para ello puede, por ejemplo, dar apoyo a las estaciones de radio comunitarias y a radios controladas por organizaciones no gubernamentales (p. 32).

\section{Conclusiones}

El propósito del presente ensayo fue plantear algunas dudas que nos ayuden a promover mayor debate sobre el marco en que se han venido produciendo los cambios en la legislación ecuatoriana de comunicación y cómo el mecanismo de redistribución de frecuencias podría favorecer a procesos de educomunicación en un sentido amplio del término: diversidad de voces y ciudadanos con reflexión crítica. 
Este análisis también apela a la comprensión del actual proyecto político que se concibe como transformador y que necesita una fuerte correlación de fuerzas para avanzar con los cambios institucionales que se han propuesto. Por ello, se considera difícil que el gobierno central abandone su lógica política dicotómica. Esta situación se puede apreciar en el funcionamiento de los medios públicos ecuatorianos donde existen serias interrogantes sobre su rol como promotor de un intercambio plural de ideas. Igualmente se aprecia una situación similar en los canales de televisión intervenidos, la publicidad estatal y las cadenas del Presidente.

Teóricamente, se viene un desafío para los investigadores de la comunicación sobre cómo introducir conceptos y metodologías que puedan

\section{Referencias bibliográficas}

AMARC ALC (2012). "De la legitimidad, legalidad: Ley de Telecomunicación de Bolivia”, en Cara y Señal, $N^{\circ}$ 15. Consultada en julio 2013. Disponible en: http://www.amarcalc.org/ caraysenial $/ 0$.php?cys $=15 \& s=4 \& n=5$

Asamblea Nacional (2013). "Ley orgánica de Comunicación", en Tercer Suplemento, Registro Oficial No22 - Año I, martes 25 de junio.

Comisión para la Auditoria de las Frecuencias de Radio y Televisión (2009). Informe definitivo y recomendaciones. Disponible en: http://www.ciespal.net/mediaciones/images/ informe\%20comisin.pdf (visitada diciembre 2012).

Correa, R. (2012). "Intervención en la 42 Asamblea General de la Organización de Estados Americanos. Consultada en setiembre 2013. Disponible en: http://www.presidencia.gob. ec/discursos/

Becerra, M. \& G. Mastrini (2001). "50 años de concentración de medios en América Latina: del patriarcado artesanal a la valorización en escala", en Quirós Fernández y Sierra Caballero, eds., pp. 179-208, Globalización, comunicación y democracia. Crítica de la eco- dar cuenta, de forma más sistemática, del estudio de esta nueva gobernanza de los medios de comunicación, dentro de un nuevo marco institucional.

Desde los activistas de la comunicación popular y alternativa, que apoyaron la aprobación de la nueva Ley Orgánica de Comunicación, se necesita avanzar en la comprensión sobre qué elementos relevantes del nuevo orden de la comunicación, son los centrales para alcanzar los objetivos democratizadores que inspiraron la norma. En caso contrario podría ocurrir una situación similar a las reformas agrarias que tuvieron lugar en algunos países de América Latina, que luego de ser implementadas sufrieron procesos de contrareforma o simplemente los nuevos pequeños propietarios fueron abandonados.

nomía política de la comunicación y la cultura. Sevilla: Comunicación Social Ediciones y Publicaciones.

Bourdieu, P. (1997). Sobre la Televisión. Barcelona: Anagrama.

De Fontcuberta, M. (2003). "Medios de comunicación y gestión del conocimiento", en Revista Iberoamericana de Educación, 32, MayoAgosto.

Jácome, F. (2010). "Venezuela: Defensa, seguridad, boliviarismo y socialismo del siglo XXI", en Hans Mathieu y Catalina Niño Guarnizo, eds., Anuario Seguridad Regional en América Latina y el Caribe. Bogotá: Friedrich Ebert Stifung.

Kaplún, G. (2010). "La nueva ley de Radiodifusión Comunitaria en Uruguay: el largo camino de la democratización de las comunicaciones". Consultada en julio 2013. Disponible en: http://www.unesco.org/new/fileadmin/ MULTIMEDIA/HQ/CI/CI/pdf/ipdc2010_ Uruguay_community_radio_law.pdf

Follari, R. (2003). "Los estudios culturales como teorías débiles", ponencia presentada al Congreso LASA, realizado en Dallas-Texas, 27-29 de marzo. 
Laclau, E. (2005). La razón populista. Buenos Aires: FCE. MacBride, S. (1987). Un solo mundo, voces múltiples: Comunicación e información en nuestro tiempo. México: FCE.

Palacio, E. (2011). "No a las mentiras", en Diario Universo, sección Opinión, sábado 5 de febrero. Disponible en: http://www.eluniverso. com/2011/02/06/1/1363/mentiras.html

Patiño, R. (2012). Canciller ecuatoriano Ricardo Patiño entrevistado por la cadena internacional NTN24. Consultada en septiembre 2013. Disponible en: http://www.youtube. $\mathrm{com} /$ watch?v=0Hkr6EAXPuQ

Observatorio Social (2011). "Los servicios de comunicación audiovisual y su trascendencia en América Latina", en Síntesis Clave $\mathrm{N}^{\circ} 70$, noviembre.

Ordoñez, R. (2011). Nacimiento de los medios públicos en el Ecuador: la (re)construcción de lo público. Tesis de maestría en Estudio Culturales. Quito: Universidad Andina Simón Bolívar.

Ramonet R. (1997). "Regímenes globalitarios", Le Monde Diplomatique, 15 de Enero.

Reporteplantense (2013). "La ley de servicios audiovisuales cuatro años mientras espera por su plena aplicación". Consultada en octubre 2013. Disponible en: http://reporte- platense.com.ar/index.php?option $=$ com content \&view $=$ article \&id $=4181$ :la-leyde-sevicios-audiovisuales-cumple-cuatro-anos-mientras-espera-por-su-plenaaplicacion \&catid=13: nota-de-tapa\&Itemid $=83$

Santos, B. (2007) "La reinvención del Estado y el Estado plurinacional”, en OSAL VIII, 22, septiembre.

Sartori, G. (1998). Homo Videns: La sociedad teledirigida. Madrid: Alianza Editorial.

Stefanoni, P (2012). "Posneoliberalismos cuesta arriba: Los modelos de Venezuela, Bolivia y Ecuador en debate", en Nueva Sociedad No 239, mayo-junio de 2012.

Stiglitz, J. (2003). "El rumbo de las reformas: Hacia una nueva agenda para América Latina", Revista CEPAL, 80, agosto.

SIP (2013). "SIP reitera advertencia por nuevos"delitos de prensa creados por el presidente Rafael Correa". Consultada en diciembre 2013. Disponible en: http://www.sipiapa.org/ sip-reitera-advertencia-por-nuevos-delitosde-prensa-creados-por-el-presidente-rafaelcorrea/

Tuvilla J. (1997). "Derechos Humanos y medios de comunicación”, en Comunicar 9, 77-86. 


\section{Contribuciones especiales}

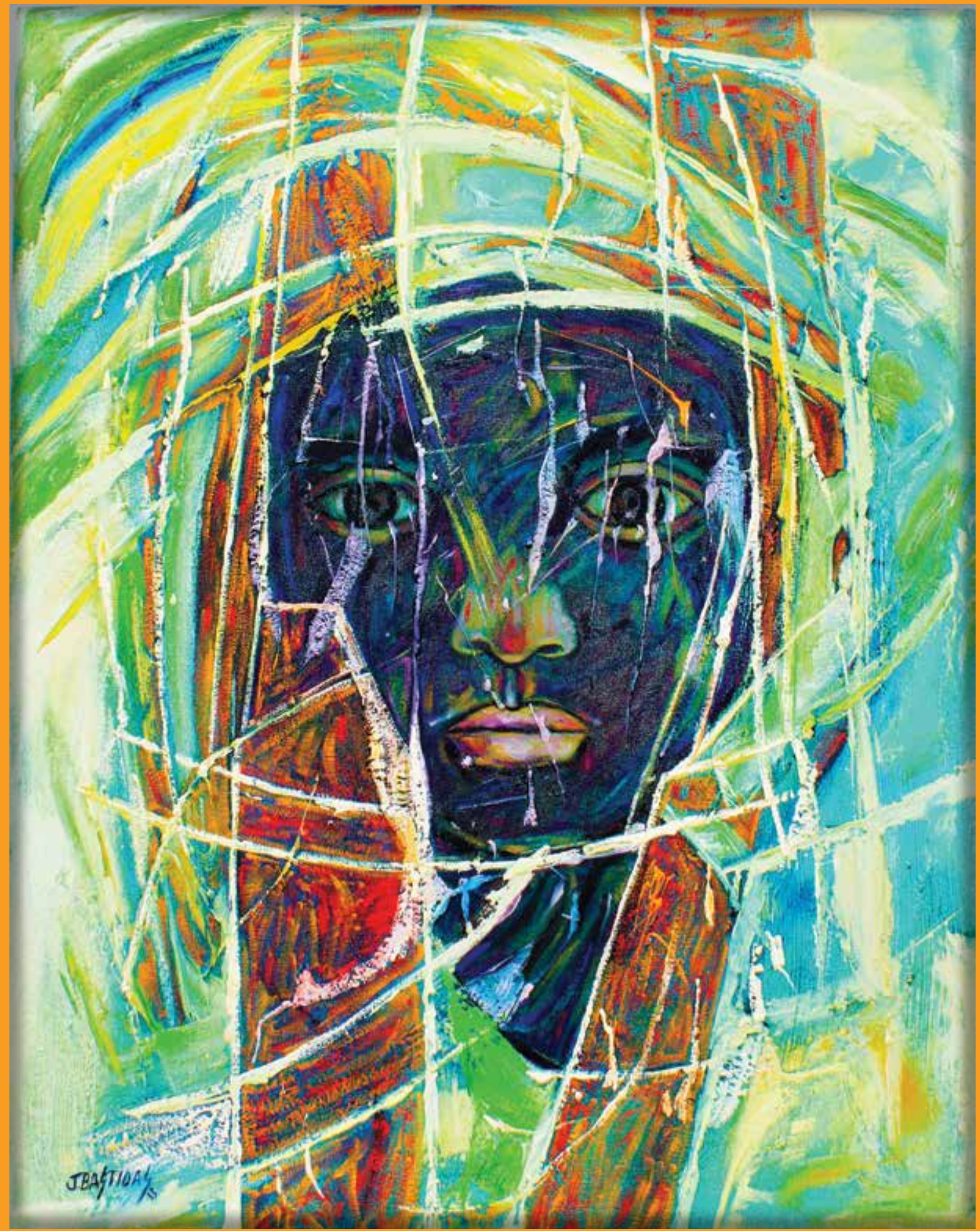




\title{
Currículo por competencias y la significatividad del proceso educativo salesiano
}

\section{Competency-based Curricula and the Significance of the Salesian Educational Process}

\author{
Gervásio Bassini Sobrinho \\ Universidade Federal de São João del-Rei \\ gbsob@ig.com.br
}

Recibido: 25 de agosto de 2013 / Aceptado: 23 de enero de 2014

\section{Resumen}

El presente documento discute el currículo por competencias y su pertinencia en las escuelas salesianas, analiza las limitaciones presentes en las escuelas en el desarrollo del proceso educativo salesiano y ofrece una propuesta de formación continua para los maestros y gestores de competencias curriculares.

Palabras clave: Educación salesiana-significatividad, constructivismo, protagonismo, gestor curricular, competencias, formación continua.

\begin{abstract}
This article examines competency-based curricula and its relevance in Salesian schools, by analyzing the limitations of the current Salesian educational development process and by offering a proposal for continuing education for competency-based teachers and administrators.

Keywords: Salesian education, significance, construcitivism, protagonism, curricula administration, competencies, continuing education.
\end{abstract}

Forma sugerida de citar:

Bassini, G. (2013). Currículo por competencias y la significatividad del proceso educativo salesiano. Alteridad, 8(2), pp. 172-191. Quito: Editorial Abya-Yala. 


\section{Introducción}

Este artículo se inspira en una disertación presentada para la obtención del título de Máster en Ciencias de la Educación, con mención en Gestión Educativa, en la Universidad Politécnica Salesiana, Unidad de Estudios de Postgrado, Quito - Ecuador, 17 de febrero de 2012.

La disertación en cuestión analizó el papel del gestor de competencias del currículo escolar, en la educación básica, en la Inspectoría São João Bosco.

La Inspectoría São João Bosco (ISJB) es una provincia que forma parte de la congregación salesiana y está localizada en la región sureste y oeste de Brasil, donde mantiene 16 escuelas de Educación Básica y dos Escuelas de Educación Superior. Es una de las instituciones mantenedoras de la Universidad Católica de Brasilia y del Centro Universitario de Leste de Minas Gerais (UNILESTE), localizado en la región de Vale do Aço, en Minas Gerais.

La investigación usada en la disertación de maestría se efectuó en 16 escuelas de la ISJB, en el 2009, involucrando a 281 de los 856 profesores y gestores de las escuelas, escogidas aleatoriamente, de acuerdo con el modelo estadístico usual. Las escuelas de la ISJB sumaban más de 10.000 alumnos matriculados.

Para analizar la situación-problema de las escuelas de educación básica de la Inspectoría São João Bosco, no habían datos científicos que demostraran la existencia o no de la situación problemática del significado del contenido curricular ministrado, que parecía presentarse de forma descontextualizada, fragmentada y carente de sentido, calcado sobre la práctica de enseñanza que enfatiza la transmisión de la información. En este contexto, los responsables por la gestión de competencias curriculares demostraban vivir una situación de tensión entre la práctica educativa reinante y las orientaciones de educación en Brasil y la propia intelección del criterio preventivo, como eje conductor del sistema educativo salesiano y de los trazos característicos de la metodología salesiana.
La disertación presentada se desarrolló de forma que construya un modelo de formación y actualización permanente para los gestores de competencias curriculares y educadores de las escuelas de educación básica de la Inspectoría São João Bosco. Con eso, las escuelas podrían responder con calidad y significatividad a las nuevas necesidades de la formación y aprendizaje de las y los estudiantes.

Los datos defendidos en la disertación permiten, con aproximación, hacer una generalización para las escuelas salesianas en general, dando origen a este artículo, que lleva el nombre de "Currículo por competencias y la significatividad del proceso educativo salesiano".

\section{Currículo por competencias}

El propósito de la educación, según Adorno (2000: 121), es conducir a la autorreflexión crítica, provocando la emancipación. Es justamente esta autorreflexión crítica la que da sentido a la implementación del currículo por competencias. De hecho, el enfoque por competencias tiene como objetivo desarrollar la capacidad crítica, de modo que los alumnos sepan analizar, decidir, planear, exponer sus propias ideas, escuchar las opiniones de las otras personas. Para Roegiers \& De Ketele (2004: 35), esto, dando sentido al aprendizaje, lo vuelve eficaz y crea la base para aprendizajes posteriores. Con la autonomía provocada por el aprendizaje por competencias, se espera que los alumnos sean capaces de ejercer la ciudadanía, como instrumento para posicionarse bien en el mundo. Según Soares (1998: 3) "solamente individuos autónomos consiguen manejar herramientas dinámicas, como el conocimiento, la creatividad, la toma de decisiones y la comunicación".

La implementación de un currículo por competencias se traduce en oferta de nuevas herramientas que ayudan al proceso educativo a posicionarse eficazmente frente a los cambios socio-culturales globales y a responder a los nue- 
vos desafíos de la educación para el siglo XXI, con enfoques y paradigmas curriculares capaces de construir una nueva educación; es también una respuesta a las pretensiones del Proyecto Educativo Pastoral Salesiano (PEPS). Esta implementación no puede ser entendida como un modismo educacional más; el enfoque por competencias señala cambios efectivos en las prácticas pedagógicas, de modo que permita a quien aprende volverse sujeto activo dentro del proceso de enseñanza aprendizaje, capaz de ejercer colaboración, relacionamiento y complicidad en la búsqueda del aprendizaje.

Existen críticas fundamentadas contra la adopción de este nuevo paradigma. Algunas nacen en la sociología del trabajo y sugieren que se quiere preparar al educando para la realidad del mercado. Otras nacen del contexto didácticopedagógico y son generadas a partir de la imprecisión del concepto de competencia y de la propia falta de preparación de los profesores. En este sentido, Sacristán, en su libro "Educar por competencias: ¿qué tiene de nuevo?” (2011), discute al respecto de la falta de acuerdos en cuanto a educar por competencias, mostrando que, para algunos, las competencias son útiles para mover al mundo productivo; para otros, el concepto es un modismo en la enseñanza que tiene una finalidad de adiestramiento social; algunos incluso, el concepto de competencias surge como una oportunidad de reformulación de los sistemas educativos tradicionales, buscando superar a la escuela que está enfrascada en contenidos poco funcionales.

Durante las décadas de los 80 y 90, varios autores como Isambert-Jamati (1997), Maranduba (1981), Perrenoud (1999), Ropé \& Tanguy (1997), Séron (1998) hicieron sus consideraciones al respecto de la polisemia que la noción de competencia involucra. De hecho, el uso del término, diseminado por las más diversas áreas, como educación, administración, marketing, economía, derecho, trabajo y otras, han provocado las más variadas concepciones. Con respecto a la polisemia reinante, Therrien \&Loiola, citando a Perrenoud, puntúan que:
El enfoque por competencias está entendido de formas muy diversas $y$, a veces, llega a ser mal entendido. Se manejan expresiones polisémicas, conceptos poco estabilizados y se ataca un enorme problema: las finalidades y los contenidos de la enseñanza. No es nada anormal, pues, se confronta una inmensa diversidad de concepciones de cultura y de escuela, unas explícitas y construidas, otras intuitivas y esbozadas (...) Therrien \& Loiola, 2001: 84).

Sin duda, existe una necesidad de recontextualización en la noción de competencia en la educación. Aliás, Bernstein (1998) llama la atención para esto.

Tanto provocando muchas discusiones en cuanto a la conceptualización, el enfoque curricular por competencias se viene afirmando en los medios educacionales como un nuevo paradigma, en el contexto en el que es presentado en los Cuatro Pilares de la Educación (Delors, 2001).

Para aquellos que están preocupados con la reestructuración de los sistemas educativos, el enfoque por competencias apunta al cuestionamiento de los saberes escolares y la finalidad de la escuela. Tal visión pone en juego la transposición didáctica ${ }^{1}$ y la necesidad de colocar a la escuela en situación proyectual, de forma que, según Chevallard (1991, p. 18), el saber resultante de transposición didáctica sea legitimado "en un saber enseñado como algo que no es de ningún tiempo ni de ningún lugar y no se legitima mediante el recurso de la autoridad de un productor, cualquiera que sea”. Así, mirando el enfoque curricular con el prisma de la transposición didáctica, las competencias surgen como un instrumento que propicia el análisis de lo que la escuela ofrece y de las opciones didácticas de los profesores, cuestionando contenidos enseñados y aprendizajes descontextualizados.

La implementación del enfoque por competencias en la educación escolar en el proceso

1 Según Yves Chevallard el término transposición didáctica tiene su origen con Michel Verret (VERRET, M.. Le temps des études. Paris: Honoré Champion. 1975). 
educativo salesiano debe buscar dar otro significado a la escuela, de modo que pueda volverla cuestionadora de los saberes escolares y de su finalidad, flexible, abierta, creativa, capaz de superar la pura reproducción de conocimientos, posicionando al alumno en el centro de la construcción de su conocimiento, principalmente "de los conocimientos que estén a servicio de las competencias" (Perrenoud, 2005: 74). Y, en esta línea también, deben ser estructurados los proyectos que se relacionan con la formación de profesores.

En medio de las dificultades de comprensión, el enfoque curricular por competencias, al ser introducido, exige que los cambios ocurran en el sistema educacional de forma que la escuela y los profesionales de la educación interioricen libremente su concepción. Tomando en consideración que el profesor tiene un papel relevante en el proceso, el acompañamiento de estos profesionales, con la conquista de su adición, se torna fundamental para el éxito del proceso educativo. Así, en el proceso de formación continua, es importante que se trabaje la concepción de competencias, de forma que haya unidad de concepto en la elaboración de la propuesta pedagógica, para que la escuela pueda planearse de forma clara, evidenciando objetivos comunes y viables.

\section{Pertinencia de la implementación del currículo por competencia}

Vimos que, según Adorno (2000: 121), la educación debe conducir a la autorreflexión crítica, capaz de provocar la emancipación, dando significado a la ejecución del currículo por competencia. Pero, para las escuelas salesianas, ¿es pertinente la implementación del currículo por competencia?

Con la autonomía que el aprendizaje por competencias provoca, se espera que los alumnos sean capaces de ejercer la ciudadanía, como quería
Don Bosco (Bosco, 2005), según su tradicional: buenos cristianos y honestos ciudadanos.

El cumplimiento del currículo por competencias responde a los nuevos desafíos de la Educación para el Siglo XXI, con enfoques y paradigmas curriculares capaces de fundamentar una nueva educación (Delors, 2001); explora los nuevos ángulos directores de la educación de este milenio, capaces de presentar un nuevo aliento a la lucha por un desarrollo humano sustentable, dentro de la perspectiva de la complejidad contemporánea señalada por Morín (2003); responde a las pretensiones del Proyecto Educativo Pastoral Salesiano (PEPS) en la formación de buenos cristianos y honestos ciudadanos, dentro de las características de la prevención del sistema preventivo.

El hecho de dar respuesta a las pretensiones del PEPS es justificativa capaz de garantizar la pertinencia de la implementación de un enfoque curricular por competencia en las escuelas salesianas. Es probable que los educadores salesianos no tengan la percepción de esta realidad, por causa del desconocimiento que demuestran en relación a propio sistema preventivo. Además, esto ya fue denunciado por el Capítulo General 21 (CG21) de los Salesianos:

Una generalizada ignorancia del significado histórico y científico del sistema; falta adaptación a la variedad de las situaciones; falta de actualización y de contacto con las contribuciones más seguras de las ciencias modernas del hombre; una crítica adición a los métodos educativos y pastorales incompatibles con las finalidades y características del servicio apostólico salesiano (Capítulo General 21, 98).

El Capítulo general 21 continúa:

Pero en el fondo, se puede encontrar, todavía la decadencia de la identidad y vitalidad religiosa salesiana, que no podría dejar de involucrar también al Sistema Preventivo, si es verdad que en él Don Bosco "condensó toda la espiritualidad de acción apostólica para sus hijos" (Capítulo General 21: 99). 


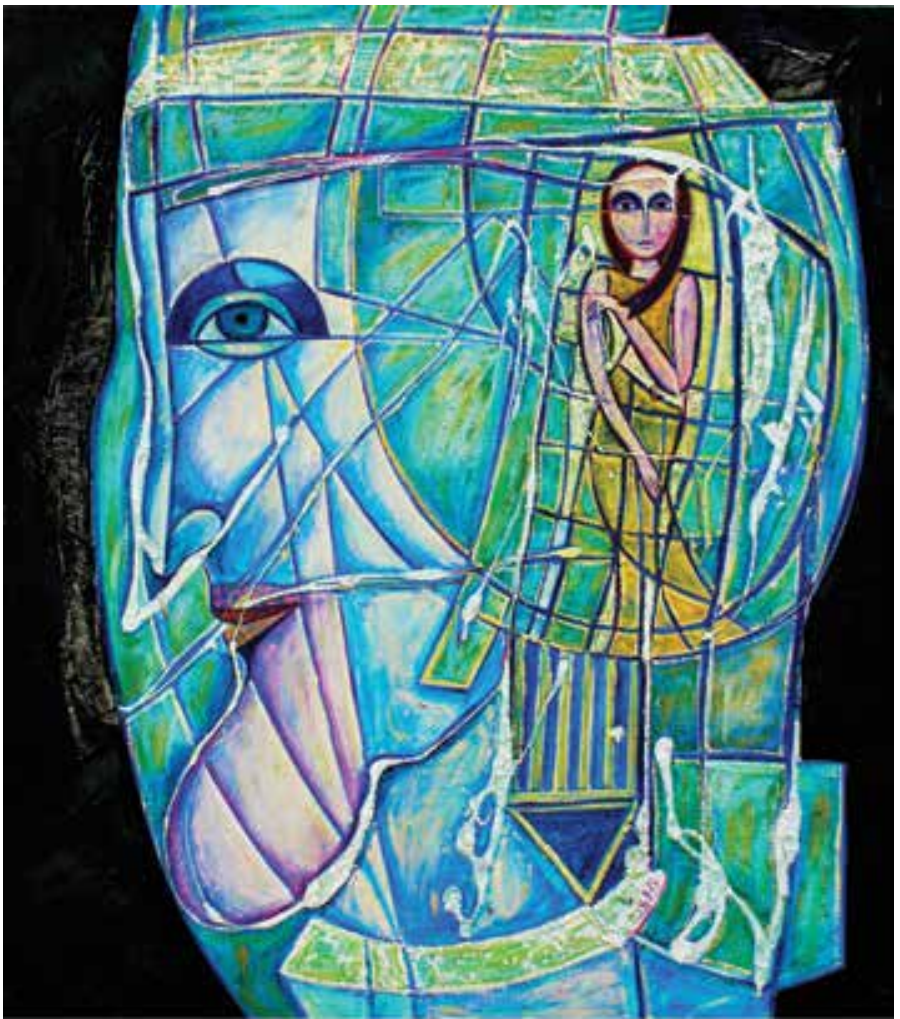

Griego $0 \times 90$ criterio preventivo, como moldeador del proceso educativo salesiano, orienta la propuesta de educación, en función del futuro del educando, con ejercicio gradual y madurador de la libertad y posibilitando experiencias positivas como prevención de las experiencias deformantes (pp. 27, 43-47). El ambiente educativo es iluminado por la participación y por las relaciones humanas que se desarrollan en él y debe ser marcado por el acogimiento, riqueza de propuestas, espíritu de familia, simplicidad, optimismo, serenidad, creatividad, protagonismo, flexibilidad, presencia educativa amorosa, solidaria y estimulante (p. 27, 95). Las Fuerzas Interiores, configuradas en la Razón, Religión y "Amorevolezza” (Amor Educativo), garantizan el buen sentido, la flexibilidad, la persuasión, el sentido de Dios inherente a cada persona insertada en el proceso educativo, la cordialidad que hace crecer y crea responsabilidad (p. 27). La Presencia Animadora abre a los educadores al conocimiento del mundo de los educandos y a la solidaridad con ellos en todos los aspectos legítimos de su dinamismo, con la participación en sus vidas, atención con sus exigencias, creación de relaciones personales, personalización de las propuestas (p. 27). La Relación Personal reconoce el carácter único y la historia particular de cada individuo, valora el patrimonio que cada uno tiene en sí, acoge de forma incondicional, con diálogo incansable, familiaridad, confianza, oferta de propuesta personalizada (p. 27). La Dimensión educativo-cultural procura responder a los desafíos complejos de la sociedad de hoy, favoreciendo un proceso de crecimiento personal y social, preocupándose por la asimilación crítica y creativa de la cultura, de modo que desarrolle una pedagogía de valores y el crecimiento del compromiso por la justicia y por la paz. Ella desarrolla también una metodología preocupada por la personalización de las propuestas, con la actuación a través de experiencias educativas, con una educación que socializa, con la convergencia de todas las intervenciones educacionales (pp. 47 - 48). La Propuesta educativo-cultural privilegia el aspecto educativo sobre la simple instrucción; 
tiene una organización pedagógica y metodología que favorece la interacción educativa, buscando superar las organizaciones didácticas repetitivas; coloca a los educandos como centro y sus cuestionamientos como referencia; ofrece una visión humana y evangélica del trabajo; promueve una calificación profesional y de la identidad salesiana ( pp. $88-89$ ).

Frente a los puntos colocados, es posible juzgar como pertinente la implementación de un enfoque curricular por competencia en las escuelas salesianas; sin embargo, esto exigirá que reformulen sus prácticas y sus políticas, en términos educacionales. Nada sucederá mágicamente. Hay un camino a seguir para asegurar la calidad de la escuela en su respuesta coherente con el Sistema Preventivo.

Ante lo expuesto, un proceso de educación continua y actualización para educadores y gestores debe ser estructurado para atender a las pretensiones del Proyecto Educativo Pastoral Salesiano (PEPS), avalando la pertinencia de la implementación de un enfoque curricular por competencias. El proceso de formación continua y de actualización tiene que preocuparse de algunos puntos que son base en la propuesta educativa salesiana: la centralidad del educando; la metodología pedagógica salesiana; los trazos característicos del Sistema Preventivo; la Dimensión Educativo-cultural.

\section{Proceso Educativo Salesiano (PES)}

El Proceso Educativo Salesiano se configura en el Sistema Preventivo de Don Bosco. El Sistema Preventivo es una estrategia educativa-pastoral de tipo preventivo y promocional, teniendo como destinatarios preferenciales a los jóvenes más necesitados y que viven en situaciones de riesgo, conforme a las Constituciones y Regulaciones de la Sociedad de San Francisco de Sales, en su artículo 20; no consiste en estructuras y procesos represivos.
Como propuesta colectiva, el Sistema Preventivo educa socializando, de forma que organiza al proceso educativo como proceso de relación y comunicación, trabajo de colaboración y experiencia social creadora de actitudes y capacidades de convivencia y participación. Como propuesta individual, el Sistema Preventivo reconoce el carácter único y la historia particular de cada educando, valorando el patrimonio que cada individuo tiene en sí.

De acuerdo al Cuadro de Referencia de Pastoral Juvenil Salesiana (Dicasterio para la Pastoral Juvenil, 2005:26), el Sistema Preventivo se demuestra como "una rica síntesis de experiencia espiritual, propuesta de evangelización juvenil y metodología pedagógica".

Las "Constituciones y Reglamentos de la Sociedad de San Francisco de Sales", en su artículo 20, hablan que el Sistema Preventivo tiene su fuente en la experiencia de la caridad de Dios. El Cuadro de Referencia de la Pastoral Juvenil Salesiana (Dicasterio para la Pastoral Juvenil, 2005:27), citando el Capítulo General 23 (CG23) de los Salesianos de Don Bosco, dice que "Esa experiencia nos dispone a acoger a Dios en los jóvenes convencidos de que en ellos Dios nos ofrece la gracia del encuentro con Él y nos llama a servirlo en ellos, reconociendo su dignidad, renovando la confianza en sus recursos de bondad y educándolos a la plenitud de la vida".

Como propuesta de evangelización juvenil, el Dicasterio para la Pastoral Juvenil (2005: 27) presenta una síntesis muy pertinente, a partir del CG23:

La propuesta original de evangelización juvenil parte del encuentro con los jóvenes ahí donde ellos se encuentran, valorando el patrimonio natural y sobrenatural que todo joven trae consigo, en un ambiente educativo lleno de vida y rico de propuestas; es hecho a través del camino educativo, que privilegia a los últimos y los más pobres; promueve el desarrollo de los recursos que ellos tienen, y propone una forma peculiar de vida cristiana y de santidad juvenil (cf. CG23:97 - 115). 
El proyecto original de vida Cristiana está organizado en torno de algunas experiencias de fe, de opciones de valores y de actitudes evangélicas, que constituyen la Espiritualidad Juvenil Salesiana (EJS), como estilo de santidad educativa propuesta a todo joven para crecer en Cristo, hombre perfecto, desarrollando sus dinamismos interiores para la maduración de la fe (cf. CG23: 158-180).

Como metodología pedagógica, el Dicasterio para la Pastoral Juvenil (Proyecto educativo-pastoral salesiano: elementos y líneas fundamentales, 1981) sistematiza los trazos característicos del Sistema Preventivo como se explica más adelante

Al discutir el sentido del significado del proceso educativo salesiano, el foco de las atenciones se vuelve para la metodología pedagógica del Sistema Preventivo, analizando los trazos característicos que lo componen.

\section{Significado del proceso educativo sale- siano}

El significado del proceso educativo salesiano está ligado a la relevancia de su preocupación para el mejoramiento y desarrollo humano y la calidad de vida de los individuos y grupos que participan del sistema educacional.

El Sistema Preventivo procura desarrollar su significado a partir de los trazos que caracterizan su metodología pedagógica: a) criterio preventivo; b) ambiente educativo; c) fuerzas interiores; d) presencia animadora; e) relación personal.

A partir de las Constituciones y de las Regulaciones (Sociedad de San Francisco de Sales, 2003), del Capítulo General 21 (Capítulo General 21, 1978), del Capítulo General 23 (Capítulo General 23, 1990), del Cuadro de Referencia de la Pastoral Juvenil Salesiana (Dicasterio para la Pastoral Juvenil, 2005), del Proyecto Educativo Pastoral Salesiano (Proyecto educativo-pastoral salesiano: elementos y líneas fundamentales, 1981), podemos describir los trazos que caracterizan al Sistema Preventivo en la forma que sigue:

\section{a) Criterio Preventivo}

El Criterio Preventivo (CP) es el elemento que guía todo el proceso educativo salesiano. En su radicalidad, pretende ofrecer al individuo una propuesta de educación que privilegia la construcción de un futuro promisorio, mediante el ejercicio gradual y esmerado de la libertad.

En este proceso, las orientaciones del Sistema se empeñan en proporcionar todas las posibilidades al educando para que viva experiencias positivas, previniendo, de esta forma, las situaciones deformantes y superando positivamente los riesgos y las dificultades del camino.

A partir de los elementos de acogida y presencia, el CP orienta al educando para que se sitúe en su realidad concreta, acompañando su capacitación e inserción en el mundo de trabajo. El Criterio Preventivo exige una fuerza representativa y pública a favor de políticas, legislaciones y recursos al servicio de los excluidos y necesitados y señala la necesidad de un ambiente educativo incluyente y solidario, abierto a la realidad sociopolítica del entorno del educando.

Así, el criterio preventivo (CP) orienta la educación para que el individuo sea capaz de encontrar una motivación para sus decisiones y acciones, de modo que ellas den un sentido efectivo a su existencia. El CP, sin embargo, pretende que la persona viva en plenitud de sus aspiraciones, sus dinamismos e impulsos.

\section{b) Ambiente Educativo}

El Sistema Preventivo requiere un ambiente educativo acogedor, iluminado por la participación de la comunidad educativa, favoreciendo el buen desarrollo de las relaciones humanas, el espíritu de familia, la simplicidad en el reaccionar, el optimismo, la serenidad en las relaciones y toma de decisiones, la creatividad, el protagonismo, la flexibilidad, la riqueza de propuestas que busquen el progreso del educando. Todo este proceso debe 
ser envuelto por la presencia educadora amorosa, solidaria y estimulante.

Es imprescindible que en este ambiente los educandos puedan encontrarse como amigos, en relacionamientos marcados por la confianza, el vivir con alegría. De la misma forma, es esencial que los educadores sepan hacer propuestas para responder a los intereses de los educandos, y así bien sugieran opciones de valores y de fe.

En la conducción del proceso educativo, la adición a los valores propuestos por la escuela debe ser estimulada por las vías de persuasión y de amor educativo, jamás por la imposición forzada.

Todo este proceso exige el fortalecimiento de la comunidad educativa a través de un estilo de gestión participativa y democrática, a partir de la vivencia de la reciprocidad.

\section{c) Fuerzas Interiores}

Las fuerzas interiores configuradas en la Razón, Religión y Amorevolezza (Amor Educativo) constituyen el trinomio sintetizador de la experiencia educativa salesiana. Ellas impregnan todo el rico patrimonio de valores que garantizan el genuino desarrollo humano, religioso y cristiano de cada participante del Proyecto Educativo Salesiano. Como síntesis de la experiencia educativa salesiana, la Razón se manifiesta en el buen sentido, en la flexibilidad, en la persuasión; la Religión es entendida como el sentido de Dios inherente a cada persona dentro del proceso educativo; la Amorevolezza (Amor Educativo) es percibida como la cordialidad que hace crecer y crea responsabilidad.

\section{d) Presencia Animadora}

La presencia animadora en medio de los educandos abre a los educadores al conocimiento del mundo de cada individuo y a la solidaridad con él en todos los aspectos legítimos de su dinamismo. Así, los Educadores tienen posibilidades de vivir su misión educadora no solamente en medio de los educandos, pero, también, con ellos y por medio de ellos.
Ir al encuentro de los educandos, acogerlos desinteresadamente y con empeño, colocarse en escucha atenta de sus pedidos y aspiraciones son, para los educadores salesianos, actitudes fundamentales que preceden cualquier otro paso educativo.

Adquieren fundamental importancia, en el proceso educativo salesiano, la participación en la vida del educando, la forma simpática que se tiene para mirar su mundo, la atención con sus necesidades, la creación de relaciones personales.

El Sistema Preventivo exige un intenso y luminoso ambiente de participación, vivificado por la presencia amorosa, animadora y activadora, capaz de favorecer todas las formas constructivas, propositivas y responsablemente libertadoras.

\section{e) Relación Personal}

La propuesta educativa salesiana no sólo se basa en propuestas colectivas o generales, sino también reconoce el carácter único y la historia particular de cada educando. Esta relación se basa e la familiaridad y en la confianza. El camino educativo comienza con la valorización del patrimonio que cada educando tiene en sí y que cada educador, con inteligencia y paciencia, va descubriendo.

La relación personal puede generar una circulación de amistad recíproca, estima y responsabilidad, al punto de suscitar en el educando la convicción de que su persona tiene un valor y un significado que sobrepasar cuanto él mismo podría imaginar. Es esto lo que acaba por hacer que en el educando desencadenen sus mejores energías. En la relación personal, el camino educativo comienza con la valorización del patrimonio que cada educando tiene en sí y que cada educador va descubriendo a través de la acogida incondicional, del diálogo incansable, de la familiaridad, de la confianza, de la oferta de propuesta personalizada.

De hecho, el Proyecto Educativo Salesiano, en términos metodológicos, busca la personalización de las propuestas, según la originalidad personal e histórica de cada educando, apelando a 
sus fuerzas internas, más que a condicionamientos exteriores. Procede a través de experiencias educativas que favorezcan el contacto directo y activo con la realidad, las actitudes y el proceso de búsqueda, la capacidad de enfrentar la realidad a partir de diversos puntos de vista y con diversas formas de aproximación. Educa socializando, organizando la educación como proceso de relación y comunicación, como trabajo de colaboración y experiencia social que crea actitudes de convivencia y participación. Cuida de la convergencia de todas las intervenciones educativas para la formación de una personalidad unitaria, en que todos los aspectos se funden, fortificándose recíprocamente.

Frente a lo presentado, ¡cómo se muestra, en general, el escenario de las escuelas salesianas?

Como la vivencia de la Metodología Pedagógica Salesiana es fundamental para la significatividad del Sistema Preventivo, los educadores parecen no estar presentando una gran sintonía e identificación con el Sistema Preventivo. Esto señala que las escuelas necesitan trabajar con más atención la vivencia de la metodología pedagógica salesiana, una vez que tal vivencia puede ser considerada como una flaqueza del ambiente interno, reflejándose, entonces, en una debilidad que debe ser superada.

La vivencia de la metodología pedagógica salesiana pone en juego el sentido del proceso educativo salesiano, preocupado de forma relevante con la mejoría del desarrollo humano y la calidad de vida de los individuos y grupos que participan del sistema educacional.

\section{Resignificación de las experiencias de formación y aprendizaje}

La implementación de un enfoque curricular por competencias se topa con proyectos educativos que aún privilegian la enseñanza centrada en el profesor, con la consecuente valoración del conocimiento, autonomía de enseñanza y relego del aprendizaje a segundo plano. Es primordial, para una efectividad en la implementación de un currículo por competencias, que en la escuela haya un cambio de visión con resignificación del aprendizaje y de la enseñanza.

La Congregación Salesiana, de la cual las escuelas salesianas forman parte, se inserta "en el movimiento que educa y evangeliza a través de la escuela, contribuyendo con el patrimonio pedagógico heredado de San Juan Bosco y acrecentado por la tradición posterior" Capítulo General 21 (1978: 130).

El Cuadro de Referencia de la Pastoral Juvenil Salesiana, solventa la necesidad de manutención de la capacitación profesional educativa a través de una formación permanente cuidadosa, armonizándose con el estilo salesiano, cuyos trazos metodológicos fueron presentados anteriormente.

¿Cómo se muestran frente a eso las escuelas salesianas?

Los educadores de las escuelas salesianas han demostrado limitaciones en el conocimiento del Sistema Preventivo. Tales limitaciones comprometen la identificación y sintonía, perjudicando el sentido propio del Proyecto Educativo Salesiano, una vez que están en juego las experiencias de formación y aprendizaje que deben responder por la calidad del sentido del proceso educativo salesiano, dentro de lo que se propone la metodología pedagógica salesiana. Así, las escuelas necesitan trabajar, en su proceso de formación continua y de actualización, una nueva construcción de las experiencias de formación y aprendizaje, involucrando el criterio preventivo, el ambiente educativo, las fuerzas interiores, la presencia animadora, la relación personal. Esta reformulación tiene influencia capital en el proceso educativo salesiano, una vez que éste se preocupa, conforme al Dicasterio para la Pastoral Juvenil (2005, p. 62), en "colaborar en la promoción y evangelización de la sociedad de la cultura, a través de una calificada presencia educativa". 


\section{Gestión de competencias curriculares y el papel de su gestor}

Toda propuesta de educación expresa un proyecto social. Es dentro de esta visión que el papel de la escuela, del conocimiento y del currículo, debe ser colocado.

La propuesta de educación salesiana, encarnando el Sistema Preventivo, está consolidada en el Proyecto Educativo Pastoral Salesiano (PEPS). El Dicasterio para la Pastoral Juvenil (2005: 39), al hablar sobre el PEPS, expresa que " es un instrumento operativo que orienta la realización de la Pastoral Juvenil Salesiana según las diversas situaciones y contextos en los cuales los jóvenes viven y orienta toda iniciativa y recurso en vista de evangelización". El PEPS tiene como finalidad ser "la mediación histórica y el instrumento operativo en todas las latitudes y en todas las culturas; es el elemento de inculturación del carisma", (Dicasterio para la Pastoral Juvenil, 2005: 39).

El Cuadro de Referencia de la Pastoral Juvenil Salesiana (Dicasterio para la Pastoral Juvenil, 2005: 42) señala que el PEPS debe integrar "los diversos aspectos y elementos de la pastoral salesiana en un proceso único que tienda a una única finalidad". Según el Dicasterio (2005: 42), ese proceso se articula en cuatro aspectos fundamentales llamados las cuatro dimensiones del PEPS. Tales dimensiones son: dimensión educativo-cultural, dimensión de evangelización y catequesis, dimensión vocacional, dimensión de experiencia asociativa. El Cuadro de Referencia de la Pastoral Juvenil Salesiana (Dicasterio para la Pastoral Juvenil, 2005: 42) coloca como finalidad de la dimensión educativo-cultural el desarrollo de la persona en su realidad de ser humano. Ya como finalidad de la dimensión de la evangelización y catequesis, el desarrollo de la persona debe involucrar su vocación para lo trascendente. Con relación a la dimensión vocacional, la persona debe ser preparada para dar respuesta al proyecto de Dios con opción responsable de vida. En la dimensión de la

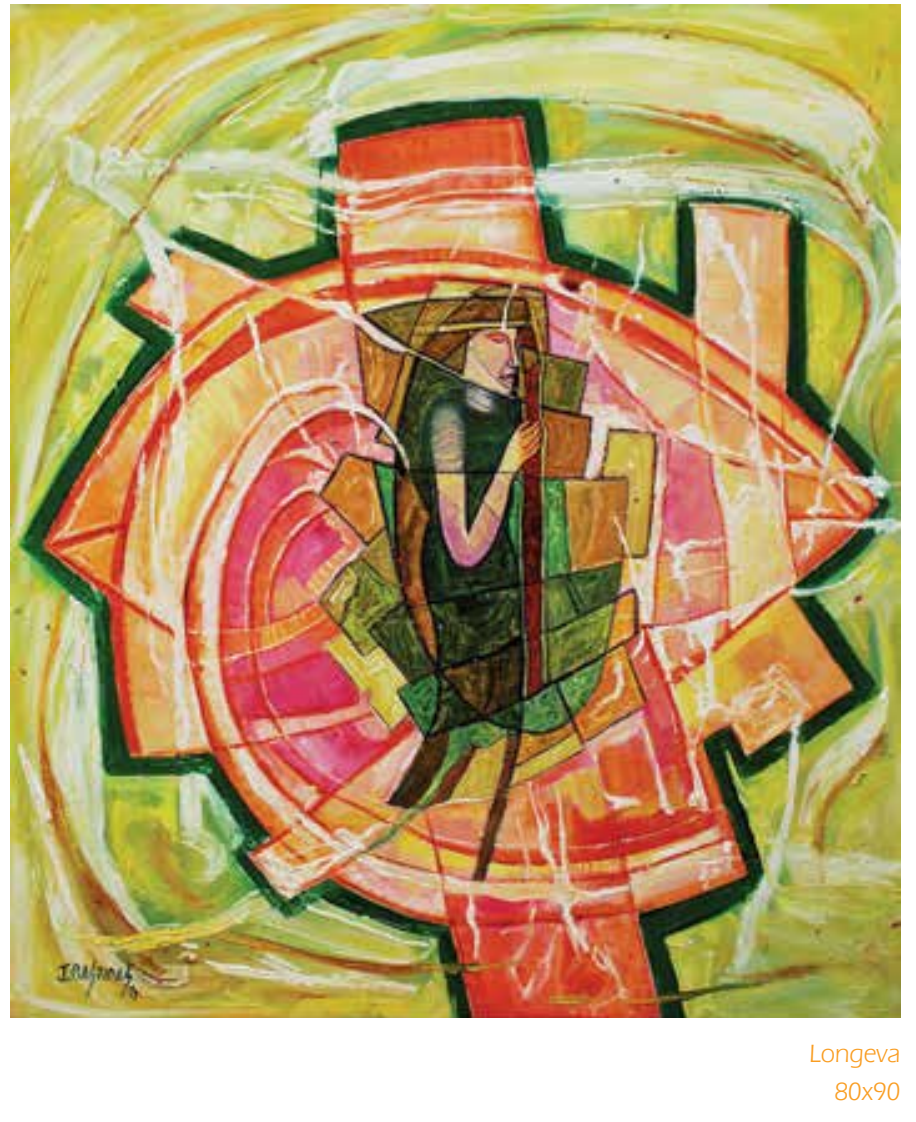

experiencia asociativa, el desarrollo apunta para el valor del otro y de la comunidad, la maduración para la participación e intervención en el propio ambiente, la iniciación en el empeño social, la profundización de la experiencia de Iglesia, el descubrimiento y maduración de la propia decisión vocacional en términos sociales y eclesiásticos.

Analizándose las cuatro dimensiones del PEPS a la luz de lo que propone Jacques Delors (Delors, 2001), podemos relacionarlas con los cuatro saberes esenciales de Delors: la dimensión educativo-cultural puede ser relacionada con el "aprender a CONOCER"; la dimensión de evangelización y catequesis con "aprender a SER"; la dimensión vocacional con "aprender a HACER"; la dimensión de la experiencia asociativa con “aprender a CONVIVIR". 
Es en este contexto que el papel del gestor de competencias curriculares de las escuelas salesianas necesita ser promovido.

En el PEPS, "el coordinador pastoral, con un equipo, anima la acción evangelizadora, cuidando de su profunda integración en el proceso didáctico y educativo" (Dicasterio para la Pastoral Juvenil, 2005: 93).

En el contexto de las escuelas salesianas, el coordinador pastoral ha recibido nombres variados como vice-director, coordinador pedagógico, supervisor y otros más, dependiendo de la escuela en la que esté actuando.

El coordinador pastoral es el gestor de competencias curriculares que anima las escuelas salesianas. Es quien posee la responsabilidad (Dicasterio para la Pastoral Juvenil, 2005: 93-98), de supervisar la propuesta educativo-pastoral en las escuelas. Como gestor de competencias curriculares, le compete a él, con su equipo manejar: la dimensión educativo-cultural de la escuela, las prioridades de la función educativo-cultural salesiana, el trabajo educativo-cultural en perspectiva evangelizadora, las principales intervenciones de la propuesta educativo-cultural salesiana.

El gestor de competencias curriculares, al moverse dentro de la propuesta educativa salesiana, tiene que estar atento a los nuevos desafíos de la educación para el Siglo XXI (Delors, 2001), a la complejidad contemporánea conforme a la propuesta de Morín (2003) y a las señalizaciones sugeridas por las respectivas determinaciones oficiales locales.

Para que el gestor de competencias curriculares de las escuelas salesianas pueda desarrollar su trabajo, dentro de la propuesta salesiana, un proceso de formación continua y actualización debe ser desencadenado en las escuelas salesianas. En ese proceso, algunos puntos importantes en el manejo de competencias curriculares y en el buen desempeño del papel de su gestor deben ser trabajados. Así, el proceso de formación continua debe perfeccionar las formas en las que los gestores presenten la importancia de las directrices curriculares presentes en las orientaciones oficiales.
Las prácticas curriculares de los gestores deben ser reformuladas con acciones interdisciplinarias. Es necesario que los gestores democraticen las actividades pedagógicas y didácticas, de forma que sean menos limitadas. El aval continuo de las prácticas curriculares debe ser continuamente practicado. La resolución de problemas debe privilegiar la objetividad. Los gestores deben trabajar de modo convincente a la pertinencia de la sensibilización curricular. Deben estudiar formas de gerenciamiento de los profesores como comunidad educativa. Las acciones interdisciplinarias deben ser propuestas de forma cristalina, con la finalidad de provocar cambios en las prácticas educativas. Nuevas formas de manejo de los profesores deben ser implementadas. Estrategias capaces de suscitar y animar las etapas de trabajo deben ser revistas, así como la capacidad de los gestores de ayudar a identificar y modificar lo que influencia el sentido de los saberes y de las actividades escolares. Los gestores deben, incluso, rever la creación y la manejo de situaciones problemas, identificar obstáculos y ayudar en el análisis y reordenamiento de las tareas. Es necesario que desarrollen estrategias más convincentes en cuanto a la observación de los profesores y alumnos en los trabajos, que busquen mayor objetividad en la ponderación de las competencias en construcción, así como que desarrollen con claridad parámetros para el análisis de las prácticas educativas.

\section{Los procesos de formación en las escue- las salesianas}

Analizando el Cuadro de Referencia de la Pastoral Juvenil Salesiana (Dicasterio para la Pastoral Juvenil, 2005: 64-65), algunos elementos son indicativos del grado de vitalidad de la Comunidad Educativo Pastoral y también son indicativos del camino de crecimiento de la Comunidad. Tal vitalidad se manifiesta en la calidad de las relaciones humanas, en la madurez del sentido de pertenencia, en la calidad de adecuación de 
los procesos informativos y comunicativos, en el desarrollo de la identidad educativo-pastoral.

La calidad de las relaciones humanas apunta a la necesidad de trascender las puras relaciones funcionales, las relaciones esencialmente de amistad y la colaboración basada en una voluntad empírica. Señala el respeto e interés que debe ser desarrollado en la relación con las personas. La necesidad de compartir los valores que están en la base de la misión salesiana y en su estilo de actuación. La calidad de las relaciones humanas evidencia que debe ser establecido, de forma clara, el grado de responsabilidad y de funciones compartidas.

La madurez del sentido de pertenencia es caracterizada por la forma como ocurre la participación en los objetivos, en los criterios y en las responsabilidades educativas y pastorales que involucran al Proyecto Educativo Pastoral Salesiano.

La calidad y adecuación de los procesos informativos y comunicativos señalan la necesidad de que la comunicación e información fluyan adecuadamente para que la comunidad educativa se mantenga motivada e informada y alcance los fines que se propone, sin comprometer la calidad de sus servicios.

El desarrollo de la identidad educativopastoral se enfoca en la preocupación con el educador, para que él comparta los valores que son el objetivo de la propuesta educativa y pastoral salesiana. Para que esto suceda, el es instado a empeñarse en el propio proceso de formación continua; a esforzarse para alcanzar una calidad profesional, educativa y cristiana, en el desarrollo de su trabajo; a sintonizarse, dialogar y ser presencia en medio de los jóvenes.

Partiendo del panorama antes presentado y considerando que, según Imbernón (2001: 42) se vuelve incuestionable una nueva manera sobre la cual la institución educativa debe ser vista, con nuevas formas de ver al docente, con nuevos paradigmas para la cultura profesional, con nuevo posicionamiento y participación de los profesionales involucrados en la educación.
Las escuelas salesianas, en general, desarrollan una serie considerable de procesos de formación para sus profesionales de la educación. Sin embargo, tales procesos presentan limitaciones en la práctica de los profesionales de las escuelas. En términos de proceso de formación continua y actualización, la aplicación de contenidos subyacentes a ellos necesita ser vista en función: (1) de mayor vivencia de la misión, de la metodología pedagógica salesiana y de su aplicación en las experiencias de formación y aprendizaje; (2) del planteamiento de contenidos curriculares y sus prácticas educativas; (3) de la necesidad de trascendencia del puro contenido; (4) de la creación de un ambiente educativo que favorezca formas constructivas, propositivas y responsables; (5) de la superación de las limitaciones de las actividades didácticas y pedagógicas por los órganos gestores; (6) de mayor participación de los profesores, con buen diálogo y relación entre ellos.

\section{Competencias que los gestores curricu- lares deben desarrollar}

El gestor de competencias curriculares, según el Cuadro de Referencia de la Pastoral Juvenil Salesiana (Dicasterio para la Pastoral Juvenil, 2005: 93), identificado como coordinador pastoral, tiene la responsabilidad de animar la acción evangelizadora, administrando la dimensión educativo-cultural de la escuela, las prioridades de la función educativo-cultural salesiana, el trabajo educativo-cultural en perspectiva evangelizadora, las principales intervenciones de la propuesta educativo-cultural salesiana. En este manejo, el gestor promueve "la organización y coordinación de los diversos equipos", cuida "la calidad de orientación educativa" y profundiza "la formación educativa espiritual, cristiana y salesiana" de las escuelas. (Dicasterio para la Pastoral Juvenil, 2005: 66) .

Moviéndose dentro del Proyecto Educativo Pastoral Salesiano, el gestor de competencias curriculares tiene también la responsabilidad de 


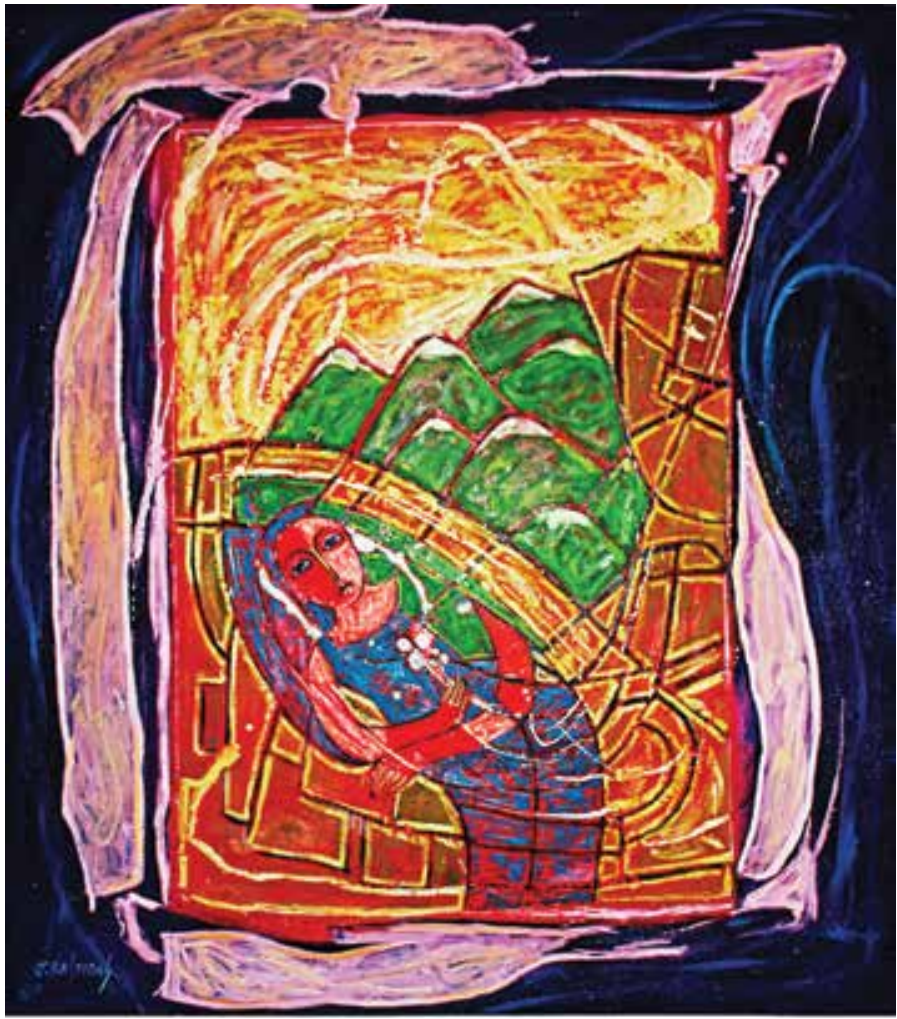

Ternura $80 \times 90$ capacidad de interpretar comunitariamente la realidad social, para garantizar a los profesores una reflexión sobre su práctica docente. Esto ayudará a mantener un proceso constante de auto-validación que oriente el trabajo educativo; creará el compromiso de los gestores en la colaboración de búsqueda de soluciones para los problemas y prácticas con las cuales los profesores se encuentran; desarrollará instrumentos que faciliten la práctica reflexiva docente, para que éstos aprendan a interpretar, comprender y reflexionar sobre la educación y la realidad de forma comunitaria; y dará mayor participación de los gestores en la ayuda a los docentes en la valoración de la necesidad potencial y en la calidad de innovación que debe ser incorporada en el trabajo educativo.

- Desarrollar la competencia que involucra el diagnóstico con objetividad y la eficacia del significado de los procesos de aprendizaje. Esto propiciará a que los gestores ayuden a los profesores a: (1) percibir el modo institucional de conocer y de querer ser; (2) percibir la señal de vida transversal de la institución; (3) analizar la calidad de sus alumnos por medio de sus contribuciones a la sociedad; (4) captar la calidad de lo que está siendo aprendido por los alumnos y de la forma como el educando está aprendiendo.

Enfrentar la incertidumbre con pensamiento multidimensional; potenciar la actitud de actualización y autonomía profesional; identificar en los alumnos el "punto sensible para el bien"; acoger con amabilidad y sin preferencias a los alumnos, y establecer consenso y aplicación de normas que permitan una convivencia constructiva. Con eso, los gestores podrán acompañar a los profesores: (1) en el dominio de métodos y técnicas que involucren los pilares de la educación para el siglo XXI; (2) en el desarrollo de la capacidad de aprendizaje, de relación, 
de convivencia, de cultura, de contexto y de interacción con las personas, con los grupos y con la comunidad que envuelve a la educación; (3) en el desarrollo de una sociedad en cambio e incertidumbre; (4) en la oferta de caminos para el desarrollo de nuevas prácticas educativas, con abertura y autonomía profesional compartida.

- Contextualizar permanentemente el currículo y su significado con los contenidos y elaborar y desarrollar en equipos de proyectos y materiales. Esto permitirá a que los gestores ayuden a los profesores y se transformen en agentes dinámicos culturales, sociales y curriculares, de forma que se conviertan en profesionales participativos, activos y críticos en la innovación del propio contexto, en un proceso flexible.

- Aplicar estrategias para formar el pensamiento autónomo y crítico. Con esto los gestores podrán auxiliar a los profesores a trascender la enseñanza como mera actualización científica, pedagógica y didáctica, abriendo posibilidades para que ellos creen modelos de relación y de trabajo, superando los modelos burocratizadores, formalistas e intervencionistas, de modo que favorezcan la autonomía en la vivencia de una democracia real y en la superación de los obstáculos de los procesos educativos de formación.

- Impulsar el protagonismo en las experiencias de formación y aprendizaje y en la motivación de corresponsabilidad con actitud de participación. Con esto los gestores podrán trabajar con los profesores en el desarrollo de prácticas alternativas, teniendo como base la autonomía y la colegialidad como mecanismo de participación. Así, los profesores vislumbrarán nuevas formas de entender la profesión docente y establecerán estrategias de pensamiento, de percepción, de estímulo y de concentración en la toma de decisiones para procesar, sistematizar y comunicar la información, volviéndose facilitadores del aprendizaje, capaces de provocar la cooperación y la participación activa de los alumnos.

\section{Propuesta de formación continua}

\section{Consideraciones iniciales}

La mejoría de la calidad de enseñanza, según algunos estudiosos (Nóvoa, Maldaner, Zeichner, Rodríguez, Schön), sólo es posible que suceda si los profesionales de la enseñanza que actúan en las escuelas se abran para el proceso de formación continua. Esto les permitirá percibirse en el epicentro del conocimiento para elucidar el proceso enseñanza-aprendizaje.

Los cambios sociales, económicos y culturales han exigido análisis constantes en la educación, desencadenando reformas educacionales en grande número de países. Por esto, la formación continua es una exigencia del mundo actual.

Según Sacristán (1990), "la formación continua puede ser considerada como una de las piedras angulares imprescindibles a cualquier intento de renovación del sistema educativo”. En este contexto, el papel de los profesionales de la educación asume importancia capital en el proceso renovador de los sistemas educativos, comprometidos con la ciudadanía. Demo posiciona bien este sentimiento:

Para encarar las competencias modernas, innovadoras y humanizadoras (el educador) debe irremediablemente saber reconstruir conocimientos y colocarlos al servicio de la ciudadanía. Así, profesor será quien, sabiendo reconstruir conocimiento con calidad formal y política, orienta al alumno en el mismo camino (Demo, 1996: 273).

La práctica reflexiva ha aflorado como orientación fundamental en el proceso de formación continua de los profesionales de la educación. Al respecto, Imbernón esclarece: 
La formación tendrá como base una reflexión de los sujetos sobre su práctica docente, de modo que permita que examinen sus teorías implícitas, sus esquemas de funcionamiento, sus actitudes, etc., realizando un proceso constante de autovalidación que oriente su trabajo. La orientación para ese proceso de reflexión exige una propuesta crítica de la intervención educativa, un análisis de la práctica del punto de vista de las presuposiciones ideológicas y comportamientos subyacentes (Imbernón, 2001:48-49).

A partir de esta visión, el concepto de formación continua de los educadores trasciende los puros procesos de actualización. Dado que la actualización implica adquisición de informaciones pedagógicas, didácticas y científicas, fuera del contexto de las prácticas educativas, la formación continua implica reflexión crítica para la construcción de conocimientos y teorías sobre la práctica educativa.

La reflexión crítica implicada en la formación continua, según estudios de Schön (1992; 2000) y Alarcão (2003), involucra el conocimiento en la acción, la reflexión en la acción, la reflexión sobre la acción, la reflexión para la acción, entendiéndose por acción a toda actividad profesional de la educación.

En el proceso reflexivo, el profesional de la educación se torna sujeto de sus actos, valorando sus experiencias personales, sus reflexiones teóricas, sus saberes de la práctica. Con eso, nuevos significados se van desabrochando y siendo comprendidos, posibilitando el enfrentamiento de las dificultades con las cuales él se va encontrando en el día a día, con el conocimiento escolar siendo construido, a partir de la transposición para la forma didáctica de conocimiento científicamente producido. Es claro, en este proceso, no se puede olvidar la articulación entre la formación y la profesionalización.

Pues bien. En el contexto de la formación continua, el Dicasterio para la Pastoral Juvenil (2005: 91), focalizando el Proyecto Educativo Pastoral Salesiano (PEPS), compromete a la
Comunidad Educativo-Pastoral (CEP) de las escuelas salesianas como "nuevo sujeto de la responsabilidad educativa". Compete al CEP la responsabilidad de "cuidar de la capacidad profesional educativa con una cuidadosa formación permanente". Este cuidadoso proceso de formación permanente implica:

- Promover entre todos sus componentes la participación en los valores educativos expresados en el PEPS; proceder, a partir del consenso sobre los valores humanos de base, por el camino de profundización, en miras de valores y objetivos cristianos.

- Garantizar un proyecto sistemático de formación permanente de todos los miembros del CEP para actualizar sus competencias educativas, didácticas y salesianas y desarrollar su vocación educativa y cristiana.

- Asegurar un buen funcionamiento de los diversos organismos, determinando las tareas específicas y el espacio de las intervenciones de decisiones de los diversos componentes de la comunidad educativa, preocupándose de la validación y el respeto de las diversas competencias y funciones. (Dicasterio para a Pastoral Juvenil, 2005: 91).

Así pues, la formación continua, más allá de ser una exigencia del mundo actual, para las escuelas salesianas pasa a ser un imperativo de la Congregación Salesiana, consolidado en el Cuadro de Referencia de la Pastoral Juvenil.

\section{Puntos críticos}

Para trazar una propuesta de formación continua y actualización, es necesario un conocimiento de las vulnerabilidades presentadas por la institución: Las vulnerabilidades de las escuelas, así como las potencialidades, pueden ser identificadas a partir de un diagnóstico estratégico.

Un diagnóstico estratégico, en las escuelas salesianas, de forma general, suele revelar tres puntos que se constituyen en puntos críticos. Tales puntos pueden ser sistemati- 
zados así: Formación, Animación y Gestión, Comunicación.

\section{Formación}

El problema central de este punto crítico reside en el hecho de la formación de los gestores y profesores que no respondan a las exigencias del Proceso Educativo Salesiano (PES) y a las orientaciones educativas en vigor.

Las causas de eso se localizan en los procesos formativos que no están respondiendo satisfactoriamente a las propuestas salesianas de educación y a las políticas educacionales oficiales. Los gestores, a su vez, tampoco se encuentran perfectamente sintonizados con la propuesta salesiana de educación. Los efectos de este panorama se hacen sentir tanto en los profesores como en los gestores. Tales efectos se presentan: (1) con una visión reduccionista de la pedagogía salesiana y del sentido y enfoque curricular vigente; (2) con la descontextualización e ineficacia del proceso de formación continua de los docentes y gestores, (3) con el predominio del programa tradicional de formación de gestores y profesores y la inexistencia de una oferta de programas de calificación para la formación y capacitación.

\section{Animación y Gestión}

El núcleo de este punto crítico reside en la desarticulación de la animación y gestión sistemática de las escuelas, conforme al Proyecto Educativo Salesiano (PES).

La causa de la desarticulación se localiza en la insuficiente preparación y en la insuficiente sintonía de los equipos gestores para asumir la propuesta salesiana de educación y las orientaciones oficiales de educación. Los efectos del comportamiento presentado se localizan en la ineficiencia y desconocimiento del proceso de gestión curricular.

\section{Comunicación}

El problema central de este punto crítico reside en el hecho de que la comunicación institucional no consiga crear la articulación de la animación y gestión de los procesos propuestos por la educación salesiana y por las orientaciones oficiales de educación.

La causa de este problema es el insuficiente conocimiento del proceso educativo salesiano y la carencia de una cultura de comunicación institucional. Los efectos de eso son encontrados en la desarticulación de los actores sociales en la construcción de la propuesta curricular y en la falta apurada de conciencia sobre el valor de la educación.

\section{Objetivo estratégico}

De una forma general, a partir de un diagnóstico estratégico, las escuelas suelen presentar muchos elementos positivos que se constituyen en sus potencialidades. Las potencialidades levantadas pueden ayudar a hacer frente a las vulnerabilidades reveladas. El buen balance de las fuerzas y oportunidades permite trazar un objetivo estratégico para sanar los puntos críticos presentados por las escuelas. Esto ayuda a las escuelas a desarrollar estrategias y actividades de formación, de animación, gestión y comunicación para, en un plazo determinado, capacitar a sus profesionales de la educación para que los gestores puedan desempeñar con eficiencia, eficacia y calidad el papel de gestor de competencias del currículo escolar.

\section{Estrategias claves}

Partiendo de los puntos críticos, como referencias de guía, y del objetivo estratégico, las escuelas pueden trazar decisiones claves, viables y eficaces para satisfacer las necesidades o resolver los problemas presentados. Tales decisiones claves se constituyen en estrategias, líneas de acción (procesos esenciales) y actividades indispensables en la mejoría de la calidad de enseñanza en las escuelas.

Como estrategias claves, las escuelas deben prestar su atención hacia:

- El desarrollo de un proceso de formación de gestores y profesores que responda satisfactoriamente a las exigencias del Proceso 
Educativo Salesiano y a las exigencias de las orientaciones educativas en vigor.

- La articulación sinérgica de los procesos de animación y gestión de las escuelas según las directrices establecidas en el Proyecto Educativo Salesiano.

- La optimización del uso de todos los medios de comunicación disponibles en la institución en función de la animación y gestión del proyecto educativo pastoral salesiano.

\section{Líneas de acción}

A partir de las estrategias claves presentadas, las escuelas pueden desarrollar algunas líneas de acción.

En función de la Formación:

Ampliar la formación continua y la actualización para profesores y gestores curriculares.

Socializar las experiencias de formación continua y actualización.

Involucrar al sector de Tecnología de la Información en el proceso de formación continua y actualización de gestores y profesores.

Involucrar Instituciones de Educación Superior en el proceso de formación continua y actualización de gestores y profesores.

Calificar las experiencias de capacitación.

En función de la Animación y Gestión:

Elaborar y sistematizar de manera conjunta los procesos de animación y gestión. Potencializar y calificar los procesos de animación y gestión.

Comprometer al sector de Tecnología de la Información en el proceso de animación y gestión.

En función de la Comunicación:

Comprometer a toda la comunidad educativa en el proceso de formación y actualización.

Elaborar un plan de comunicación y marketing.

Optimizar los recursos tecnológicos existentes para una comunicación efectiva.

\section{Objetivos operativos y actividades}

Basadas en las líneas de acción, las escuelas deben trazar sus objetivos operacionales, con las respectivas actividades, de acuerdo con sus necesidades y disponibilidades de recursos, dentro de un plan operativo que contemple las actividades, los responsables y el cronograma de desarrollo.

\section{Conclusiones}

La propuesta de este artículo fue discutir el "currículo por competencia" y el significado del "Proceso Educativo Salesiano", a partir de una investigación hecha en las escuelas de la Inspectoría São João Bosco. De acuerdo a los datos recolectados, se volvió importante hacer una llamada de atención a las escuelas para un proceso de formación continua de sus educadores, de modo que las escuelas puedan responder con calidad y sentido a las nuevas necesidades de formación y aprendizaje de los alumnos. Frente a lo presentado, surgen algunas conclusiones que involucran, de forma general, a las escuelas salesianas:

- Los responsables por la gestión de competencias curriculares necesitan estar atentos, en los procesos formativos, a la intelección del Criterio Preventivo, como eje del sistema Educativo Salesiano y de los trazos característicos de la metodología salesiana, pues existe un conocimiento precario del asunto, conforme a los visto en el punto 4 de este trabajo.

- Una propuesta de formación continua y actualización puede interferir en la práctica de enseñanza de los educadores y hacer que los profesores que están arraigados al modelo tradicional y resistentes a las orientaciones de un currículo por competencias puedan rever sus posiciones y ofrece al gestor de competencias curriculares elementos para que pueda aplicar parámetros confiables que orienten el manejo de las competencias curriculares. 
- El Papel del Gestor de Competencias del Currículo es promover la superación de las vulnerabilidades encontradas a partir de un diagnóstico estratégico, usando estrategias y líneas de acción que permitan: (1) superar la visión reduccionista de la Metodología Pedagógica Salesiana y la visión reduccionista del sentido y enfoque curricular vigente; (2) calificar con eficiencia el conocimiento los procesos de gestión curricular; (3) contextualizar y volver eficiente el proceso de formación permanente de los docentes; (4) vincular a los actores sociales de la construcción de la propuesta curricular; (5) buscar equilibrio entre responsabilidades y remuneración; (6) buscar ofertas de programas de calidad para formación y capacitación; (7) reformular los programas de formación y capacitación; (7) reformular los programas de formación para que el predominio del programa tradicional de formación de profesores sea superado.

- De forma general analizándose las vulnerabilidades de las escuelas salesianas, tres puntos surgen como críticos: la formación, la animación y gestión, la comunicación. Tales puntos señalan que hay necesidades que deben ser solventadas y problemas que deben ser resueltos. En la formación, el proceso formativo de los gestores y profesores no está respondiendo a las exigencias del Proceso Educativo Salesiano (PES) y a las orientaciones educativas en vigor. Con relación a la animación y gestión, existe una desarticulación de la animación y gestión sistemática de las escuelas, dentro de lo que el Proyecto Educativo Salesiano prevé. En cuanto a la comunicación, no ha conseguido crear la articulación entre la animación y la gestión de procesos propuestos por la educación salesiana y por las orientaciones oficiales de la educación. Si tantos puntos críticos no son resueltos, el proceso educativo salesiano queda comprometido. Un

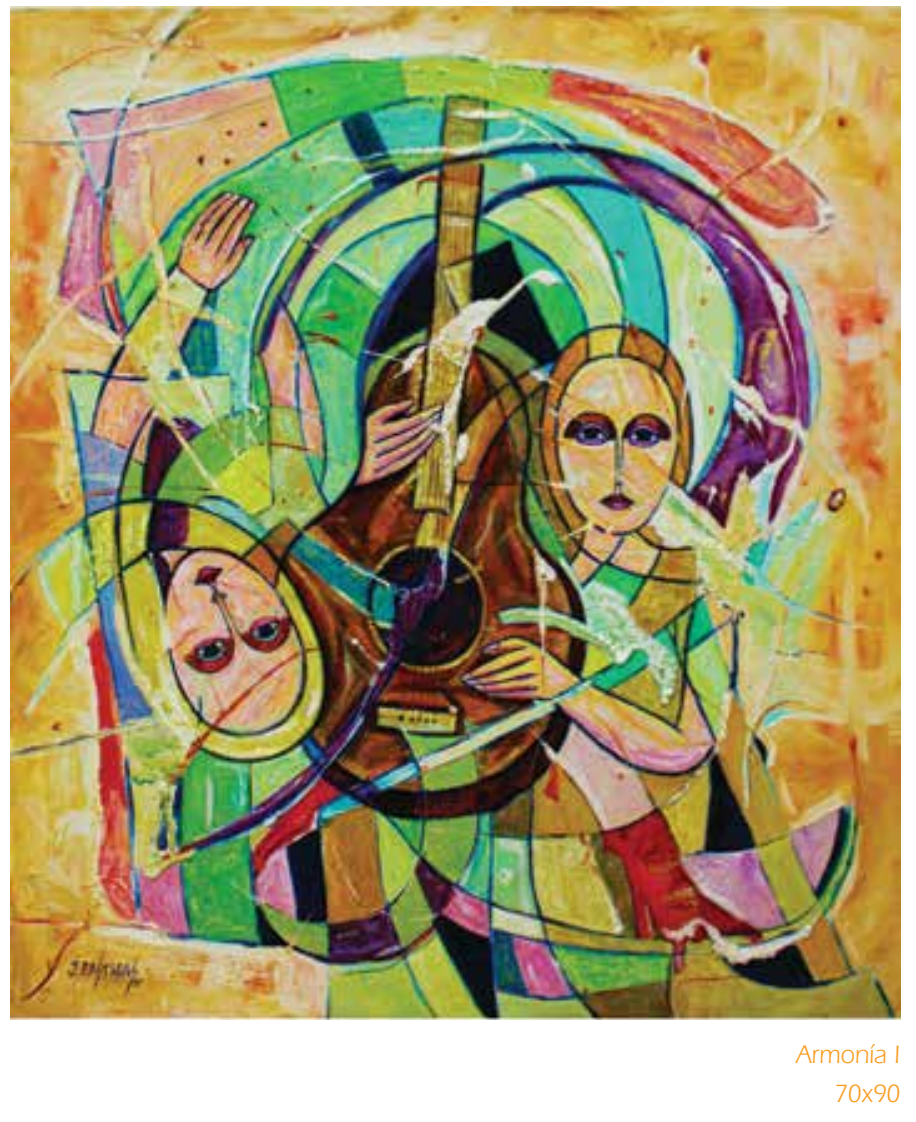

proceso de formación continua y actualización para gestores y profesores puede ofrecer elementos para superar los problemas o necesidades que los puntos críticos señalan.

\section{Recomendaciones}

Para que una propuesta de Formación Continua y Actualización para Gestores y Profesores pueda llegar al objetivo que se propone en las escuelas salesianas, algunas recomendaciones se hacen necesarias en términos de organización, implementación, ejecución y contenido de la propuesta:

- En términos de organización, es necesario: (1) planear los pasos que se darán; (2) sea escogida una metodología de trabajo; (3) exista un buen proceso de comunicación; 
(4) sea conformado y se conozca el equipo involucrado en el trabajo; (5) se desarrolle un cronograma de trabajo con el equipo; (6) el trabajo sea hecho de forma proactiva; (7) sea formalizado el inicio del trabajo.

- En términos de implementación, es necesario: (1) conseguir el compromiso de todos los directores y gestores de las escuelas; (2) diseminar las informaciones; (3) hacer levantamientos de requisitos; (4) identificar las oportunidades; (5) evaluar los riesgos; (6) crear estrategias para involucrar a las personas; (7) hacer una validación económica; (8) identificar los recursos; (9) establecer formas de actuación; (10) establecer indicadores para acompañamiento.

- En términos de ejecución, es necesario: (1) involucrar a los equipos del proyecto; (2) planear la ejecución de las tareas, ordenando las actividades, estableciendo la duración; (3) atribuir responsabilidades; (4) garantizar recursos; (5) elaborar un cronograma de trabajo; (6) elaborar informes;
(7) difundir el trabajo; (8) supervisar la ejecución; (9) acompañar la calidad de los servicios; (10) avalar sistemáticamente las tareas realizadas.

- En términos de contenido, sobre el pilar aprender a conocer, en el trabajo de formación y actualización de los educadores, las escuelas salesianas pueden trabajar la visión presentada por la dimensión educativo-cultural, que forma parte del Proyecto Educativo Pastoral Salesiano (PEPS); sobre el pilar aprender a vivir juntos, en el trabajo de formación y actualización de los educadores, las escuelas pueden trabajar la visión presentada por la dimensión de la experiencia asociativa, conforme al Proyecto Educativo Pastoral Salesiano (PEPS); sobre el pilar aprender a ser, en el trabajo de formación y actualización de los educadores, las escuelas pueden trabajar la visión desarrollada por la dimensión de la evangelización y catequesis, conforme a la propuesta del Proyecto Educativo Pastoral Salesiano.

\section{Referencias bibliográficas}

Adorno, T. W. (2000). Educação e Emancipação (2a ed.). Rio de Janeiro: Paz e Terra.

Alarcão, I. (2003). Professores reflexivos em uma escola reflexiva. São Paulo: Cortez.

Bassini Sobrinho, G. (2012). O papel do gestor de competências do currículo escolar da educação básica na Inspetoria São João Bosco. Dissertação de Mestrado, Universidad Politécnica Salesiana, Quito, Ecuador.

Bernstein, B. (1998). Pedagogía, Control Simbólico e Identidad. Madrid: Morata.

Bosco, S. J. (2005). Memórias do Oratório de São Francisco de Sales 1815-1855. (3a ed., F. S. Catarina, Trad.). São Paulo: Editora Salesiana.

Canen, A. \& Moreira, A. F. B. (orgs.). (2001). Enfases e omissões no currículo. Campinas:Papirus.

Capítulo General 21. (1978). Documentos capitulares. São Paulo: Escolas Profissionais Salesianas.
Capítulo General 23. (1990). Educar os jovens na fé: documentos capitulares. Roma: [s. n.].

Chevallard, Y. (1991). La transposición didáctica. Buenos Aires: Aique Grupo Editor.

Delors, J. (org.) (2001). Educação: um tesouro a descobrir. Relatório para a Unesco da Comissão Internacional sobre a Educação para o século XXI. São Paulo: Cortez; Brasília, DF: MEC.

Dicastério para a Pastoral Juvenil. (2005). Quadro de referência da Pastoral Juvenil Salesiana. (2a ed., J. A. Velho, Trad.). São Paulo: Editora Salesiana.

Imbernón, F. (2001). Formação docente e profissional: formar-se para a mudança e a incerteza. (7a Ed.). São Paulo: Cortez.

Isambert-Jamati, V. (1997). O apelo à noção de competência. L'Orientation Scolaire et Professionalle. In: Ropé, F. \& Tanguy, L. (orgs.). Campinas: Papirus. 
Kramer, Sonia. (2001). Propostas pedagógicas ou curriculares: subsídios para uma leitura crítica. In: Moreira, Antonio Flavio. (Org.). Currículo: políticas e práticas. Campinas: Papirus.

Maldaner, O. A. (1995). A formação continuada de professores: ensino-pesquisa na escola - professores de Química produzem seu programa de ensino e se constituem pesquisadores de sua prática. Projeto de tese de doutorado em Educação, apresentado para qualificação na Faculdade de Educação da Unicamp. Campinas, SP: Unicamp.

Maranduba, R. G. B. (1981). Competências essenciais ao professor de $1^{\circ}$ grau, no Brasil. Rio de Janeiro: UFRJ.FE. 109 p. Dissertação de Mestrado (Mestrado em Educação).

Demo, Pedro. (1996). Formação Permanente de Professores: educar pela pesquisa. In Menezes, L.C. (org) Professores: Formação e Profissão. Campinas, S.P: Autores Associados.

Morin, E. (2002). Os sete saberes necessários à educação do futuro (5a. ed.). São Paulo: Cortez; Brasília: UNESCO.

Morin, E. (2003). Introdução ao pensamento complexo. Lisboa: Instituto Piaget.

Nóvoa. A. (1991). Formação contínua de professores: realidades e perspectivas. Aveiro: Universidade de Aveiro.

Nóvoa, A., Gómez, A. P., Schön D. A. (1992). Os professores e a sua formação, Nóvoa (org.), Lisboa, Dom Quixote.

Perrenoud, P. (1999). Construir as competências desde a escola. Porto Alegre: ARTMED.

Perrenoud, P. (2002). A prática reflexiva no ofício do professor: profissionalização e razão pedagógica. Porto Alegre: Artmed.

Perrenoud, P. (2005). Escola e cidadania. Porto Alegre: ARTMED.

Proyecto educativo-pastoral salesiano: elementos $y$ lineas fundamentales. (1981). Jesús Mairal (Trad.), (Vector, 2). Madrid: Centro Salesiano de Pastoral Juvenil.

Rodríguez, J. M. (1995). Formación de profesores y prácticas de enseñanza: un estudio de caso. Huelva: Universidad.
Roegiers, X. \& De Ketele, J.-M. (2004). Uma pedagogia da integração. Competências e aquisições no ensino. Porto Alegre: Artes Médicas.

Ropé, F. \& Tanguy, L. (1997). Saberes e Competências: o uso de tais noções na escola e na empresa. Campinas: Papirus.

Sacristán, J. G. (1990). Conciencia y acción sobre la práctica como liberación profesional de los profesores. Barcelona: Universidade de Barcelona.

Sacristán, J. Gimeno. (2000). O currículo: uma reflexão sobre a prática. 3. ed. Porto Alegre: ArtMed.

Sacristán, J. G, et all. (2011). Educar por competências: O que há de novo? Porto Alegre: Artmed.

Schön, D. (1992). Formar professores como profissionais reflexivos. In: Nóvoa, A. (org.) Os professores e sua formação. Lisboa: Dom Quixote.

Schön, D. (2000). Educando o profissional reflexivo: $u m$ novo design para o ensino e a aprendizagem. Porto Alegre: Artes Médicas.

Séron, A. G. (1998). Del trabajo estable al trabajador empleable: el enfoque de las competencias profesionales y la crisis del empleo. Caderno de Educação, Pelotas, FaE/UFPel, jul./dez.

Shimidt, Elizabeth Silveira. (2003). Currículo: uma abordagem conceitual e histórica. Dissertação de Mestrado. Universidade Estadual de Ponta Grossa, PR.

Silva, Tomaz Tadeu. (2005). Documentos de Identidade: uma introdução às teorias do currículo. Belo Horizonte: Autêntica.

Soares, H. (1998). A Importância da Autonomia. A Razão (jun.). Santa Maria: RS.

Sociedade de São Francisco de Sales (2003). Constituições e Regulamentos. (2a. Ed.) São Paulo: Editora Salesiana.

Therrien J. \& Loiola, F. (2001). Experiência e competência no ensino: pistas de reflexões sobre a natureza do saber-ensinar na perspectiva da ergonomia do trabalho docente. Educação \& Sociedade. Ano 22, n. 74, abr.

Zeichner, K. (1993). A formação reflexiva de professores: idéias e práticas. Lisboa: Educa. 


\title{
"Impacto de los estilos de liderazgo en el clima institucional del Bachillerato de la Unidad Educativa María Auxiliadora de Riobamba"
}

\author{
Impact of leadership styles on the institutional \\ climate of the Unidad María Auxiliadora High \\ School in Riobamba
}

Luisa Lozado

Unidad Educativa María Auxiliadora luisa_lozada@hotmail.com

Recibido: 13 de mayo de 2013 / Aceptado: 23 de enero de 2014

\section{Resumen}

El presente trabajo describe dos variables que son claves en toda organización: estilos de liderazgo y clima institucional. Se analizan los factores que intervienen y el impacto del liderazgo que ejercen los miembros de la comunidad educativa en el clima institucional. Para este propósito, se revisan diferentes teorías de liderazgo de varios autores que ponen en evidencia la calidad y calidez del clima percibido por sus miembros, teorías que reflejan la conducta de las personas, manifestadas a través de la diversidad de estilos, los mismos que han sido seleccionados según la clasificación propuesta por Bass y Avolio en: transformacional, transaccional y laissez-faire. (dejar hacer, dejar pasar).

El enfoque mixto cualitativo y cuantitativo con un alcance de tipo descriptivo correlacional hace ver que los estilos de liderazgo que se practican en el establecimiento, inciden en el clima institucional provocando un ambiente agradable, motivador, alegre, familiar con sentido de pertenencia; o negativo, desmotivador e indiferente. Cuanto más democrático, participativo y transformacional es el estilo de liderazgo; más cálido, familiar y de confianza es el ambiente en la institución.

Palabras clave: Liderazgo, clima organizacional, clima institucional, percepción, motivación, participación, transformacional, transaccional y laissez-faire.

\begin{abstract}
This article describes two variables that are key in any organization: leadership styles and institutional climate. I analyze different key factors that come into play: the influence that institutional climate and leadership has over members in an educational community. For this purpose, I examine various leadership theories by different authors that highlight the warmth and quality perceived by its members, theories that reflect people's behavior, manifested in a diversity of styles, which have been selected based on the classification proposed by Bass and Avolio in "Transformational, transactional, and laissez-faire leadership styles" (Estilos de liderazgo transformacionales, transaccionaes y de laissez-faire).

The mixed qualitative and quantitative focus with a correlational descriptive reach, shows that leadership styles put into practice in an institution have an impact on its climate, generating a pleasant, motivating, happy, familiar environment with a sense of belonging; or a negative, discouraging, and indifferent one. The more democratic, participatory, and transformational the leadership style is, the warmer, more familiar, and trustworthy the institutional climate becomes.
\end{abstract}

Keywords: Leadership, organizational climate, institutional climate, perception, motivation, participation, transformational, transactional, laissez-faire. 


\section{Introducción}

El propósito de este trabajo es determinar el impacto que tienen los estilos de liderazgo en el clima institucional percibido en el Bachillerato de la Unidad Educativa María Auxiliadora de Riobamba.

El tema en mención constituye el ambiente interno o la atmósfera laboral del lugar de trabajo; desde esta perspectiva, Chiavenato (1999) infiere que la actitud de las personas con respecto al clima institucional depende de factores físicos, ambientales, personales, funcionales que hacen un clima agradable o no.

En el lenguaje salesiano, el clima se sitúa como mediación entre los valores inspirados en el Evangelio y el contexto sociocultural; es el ambiente donde es posible experimentar relaciones ricas de valores caracterizadas por la confianza, familiaridad, empoderamiento, diálogo, entre otros: un lugar donde la alegría, constituya la atmósfera de fondo de la familiaridad entre jóvenes y adultos. De acuerdo al legado de Don Bosco y María Mazzarello, las obras salesianas son "casas" que acogen, lugares de encuentro para que quien llegue se sienta en "familia" (Hijas de María Auxiliadora, 2005: 149).

$\mathrm{Al}$ referirnos al clima institucional, no existe un consenso claro sobre su conceptualización; es necesario tomar en cuenta algunos elementos señalados por ciertos teóricos.

Autores como Davis, citado en Mellado (2005), se refiere al clima institucional como el representante del completo sistema social generado por el trabajo en grupo. Desde esta óptica, el ambiente laboral que se vive al interior de una organización revela gran parte de su funcionamiento relacional, pudiendo influir tanto en el estado perceptual, como en el comportamiento y satisfacción de sus miembros.

García (2009: 46) pone en juego sus dotes administrativos y apuesta por las personas, en primer lugar y luego, el trabajo; sin lugar a dudas, la percepción del clima mejora considerablemente reflejándose en el aprendi-

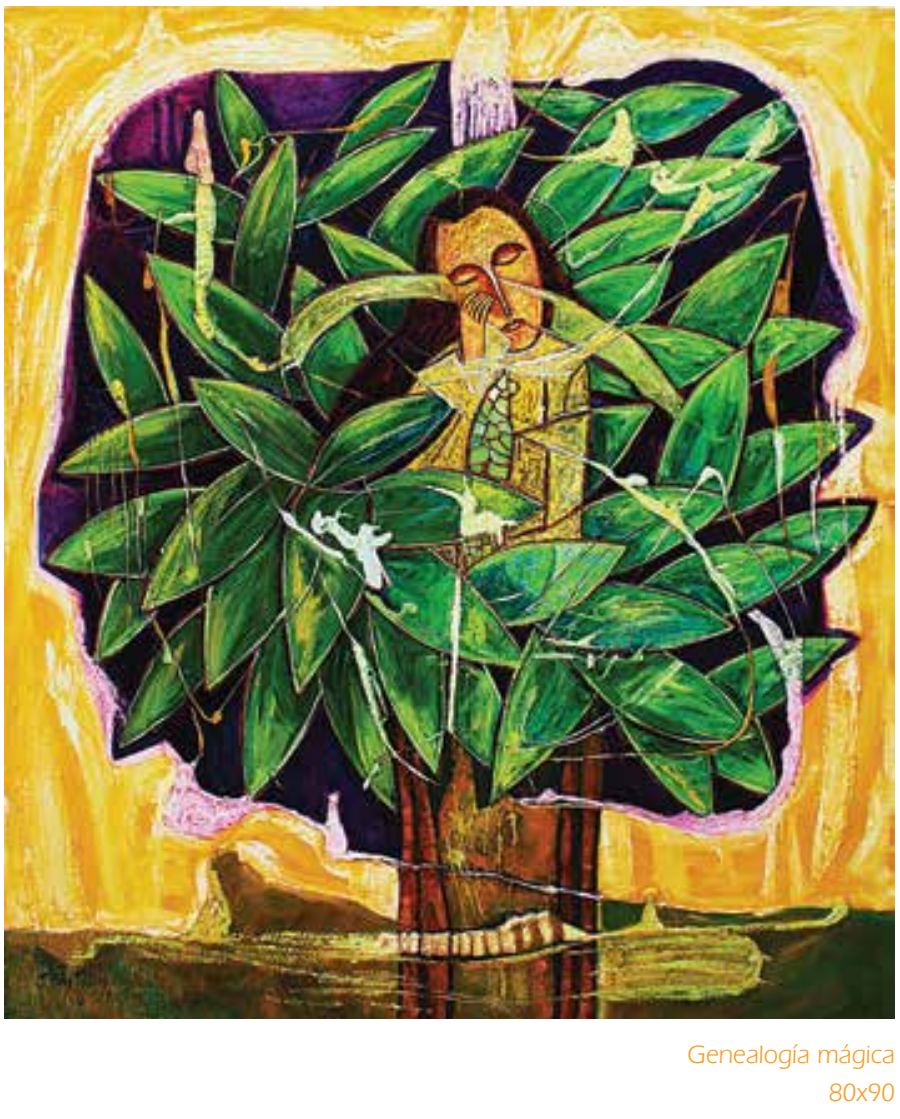

zaje (rendimiento) y se optimiza la productividad de todos.

La siguiente variable aborda los diferentes estilos de liderazgo los mismos que influyen con genuinos comportamientos e impactan sobre los individuos según su percepción y los múltiples agentes que convergen (Likert, citado en Morales, 2009:16).

Si partimos del hecho de que una organización es viva, formada por personas que revelan su funcionamiento relacional: liderazgo y clima están íntimamente asociados y el liderazgo es de tal relevancia que es el aspecto que más incide en el clima y, a su vez, está sobre la creatividad y productividad de las personas (Cuadra \& Veloso 2010: 17).

Al hacer una primera aproximación, se realiza una breve descripción de las teorías que permiten identificar características y fac- 


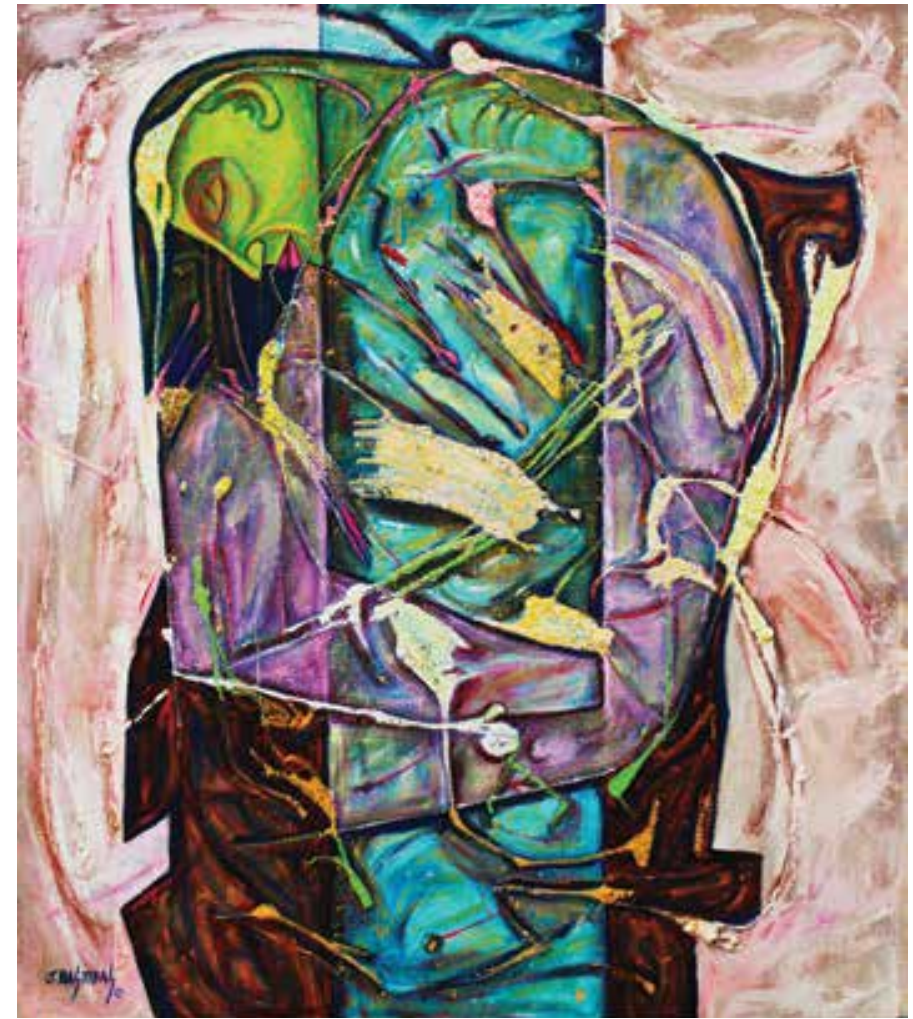

Protectora II.

$70 \times 90$ dianas de sus miembros. Al hablar de clima, nos referimos a una cultura ya que no se puede entender por separado. La cultura describe la forma de vida de la organización en todos sus aspectos; constituye la manera institucionalizada de pensar y de actuar que existe en una organización; representa, la identidad y la misión que hace que se distinga una institución de otra (Chiavenato, 2009: 176).

El concepto de clima organizacional, según Chiavenato (1999), fue introducido por primera vez en psicología industrial/organizacional por Gellerman en 1960. Su definición se basa en el enfoque objetivo de Forehand y Gilmer (1964), quien define el clima como el conjunto de características permanentes que describen una organización, la distinguen de otra, e influyen en el comportamiento de las personas que la forman. Para Anderson (1982), el clima es entendido como "calidad de vida".

Este depende de la percepción directa o indirecta del individuo y se refleja en su productividad, rendimiento y satisfacción. En este sentido, Méndez (2005) identifica como el resultado de la forma en que las personas establecen procesos de interacción social. Es una percepción predominante, de tal forma que los psicólogos hacen una analogía con el concepto de personalidad. Halpin (citado en Fernández, 2004) expresa que la personalidad es para el individuo lo que el clima organizacional para la institución. Según Pérez (2011), es el ambiente donde encuentra su punto de equilibrio y se define el comportamiento humano.

La diversidad de criterios es, tal vez, la razón para que no exista una unificación de definiciones y metodologías que permitan elaborar un claro concepto al respecto (García, 2009b: 55).

Los autores Bris y García subrayan algunos elementos organizacionales y lo definen como "el ambiente total de un centro educativo determinado por los factores físicos, elementos estructurales, personales, funcionales y culturales de la 
institución que, integrados, confieren un estilo propio a la misma" (Bris, 2000: 107).

Otro autor, Gonçalves (1997) relaciona el clima organizacional con las condiciones y características del ambiente laboral, las cuales generan diferentes percepciones en los empleados y afecta directamente a su comportamiento. Este concepto evoca un sin número de elementos que hacen que Likert califique como multidimensional, compuesto por ocho dimensiones: los métodos de mando, las fuerzas de motivación, los procesos de comunicación, la influencia, la toma de decisiones, la planificación, el control y los objetivos de rendimiento y perfeccionamiento (García, 2009). El ambiente institucional está influenciado por factores internos y externos, Álvarez (citado en García, 2009) plantea muchos otros como: comportamiento, relación simbiótica, liderazgo, consenso, trabajo gratificante, relaciones interpersonales, estabilidad laboral, valoración, salario, entre otras (García, 2009: 53).

Después de conocer el criterio de varios autores, considero que la propuesta más importante es la de Likert (citado en Cruz, 2009). Su objeto es identificar sistemas de organización, uno de cuyos componentes, es el clima. La fuente son las percepciones de los miembros respecto a las ocho dimensiones mencionadas; las mismas que generan cuatro tipos de clima: el sistema I: autoritario explotador; el sistema II: autoritario paternalista; el sistema III: consultivo y; el sistema IV: participación en grupo.

Estos factores caracterizan al clima organizacional perfilando algunas teorías:

Desde el enfoque administrativo, la teoría clásica de la administración, liderada por Taylor (1891) se centra en el trabajo y la persona como pieza de un proceso mecánico. Esta teoría se apoya en tres pilares: elevada productividad, altos incentivos y eficacia.

Por otro lado, la teoría de Elton Mayo (1880) hace énfasis en las relaciones humanas, que motiva a las personas, de allí que se habla del hombre social.
El enfoque motivacional, propuesto por Maslow (1943), "el hombre es un ser con deseos y su conducta está dirigida a la consecución de objetivos, que atañen a todo individuo".

Idalberto Chiavenato toma el modelo motivacional de Maslow para explicar que el clima organizacional depende del grado de motivación de los empleados. A medida que crece la motivación, la persona se siente auto realizada y las relaciones interpersonales son satisfactorias.

Las teorías analizadas anteriormente confluyen en tres elementos fundamentales: la percepción, los factores organizacionales y el comportamiento organizacional.

\section{Elementos relevantes del clima organizacional}

Igual que Likert, Bris subraya una serie de elementos relevantes sin los cuales no puede desarrollarse en positivo ninguna organización, basada en relaciones humanas y necesitada de un orden y una estructura organizativa formal y funcional (Bris, 2000). Expresa que para reconocer el tipo de clima de una organización, debemos valorar los siguientes parámetros: comunicación, participación, motivación, confianza, planificación, liderazgo y creatividad. Los autores Likert, Hernández y Bris (mencionados por Méndez, 2005) coinciden al señalar la motivación, el liderazgo y la comunicación como elementos imprescindibles que construyen un clima entre los cuales, el liderazgo es determinante en el ambiente laboral con su capacidad de influir en el comportamiento de un grupo y motivarlo hacia objetivos comunes (Gómez, 2008: 162).

\section{El liderazgo}

Conjunto de componentes que tiene una persona para conducir a un grupo: conocimientos, habilidades y hasta condiciones innatas, como el carisma (Krause, 1998; citado por Salcedo \& Romero, 2006: 93). 
En la antigua filosofía China el liderazgo se lo entiende como "la voluntad de controlar los sucesos, la comprensión necesaria para marcar un rumbo y el poder para llevar a cabo una tarea, utilizando cooperativamente las habilidades y las capacidades de otras personas" (Salcedo, 2006: 93).

El liderazgo "es cualquier tentativa para influenciar en el comportamiento de un individuo o de un grupo" (Kotter, citado por Gómez, 2008). Lo corrobora Estrada, al afirmar que liderazgo es "influenciar en la gente para que se empeñe voluntariamente en el logro de los objetivos del grupo" (Estrada, 2007: 287).

Liderazgo "es levantar la visión de una persona a vistas más altas” Drucker (1996). Es la "capacidad de influir en el comportamiento de un grupo (seguidores) y motivarlo hacia objetivos comunes" (Mejía, Estrella, Zea \& Pérez 2004: 14). "Liderar es ir más lejos, implica crear colaboración, buscar la satisfacción de los miembros, innovar y mejorar continuamente" (Delgado, 2004: 195).

El "liderazgo" es el arte de influir, dirigir y guiar a las personas para que potencien sus talentos, motivados en la consecución de los objetivos hacia el bien común" (Alfaro, 2010).

Por su parte, Marín (1998, referido por Vargas 2010: 60) en su definición, recoge los elementos de los autores mencionados y dice que liderazgo, es el desarrollo de un sistema completo de expectativas, capacidades y habilidades que permiten identificar, descubrir, utilizar, potenciar y estimular al máximo las fortalezas y la energía de todos los recursos humanos de la organización.

Las teorías que plantean varios autores se derivan de los principios de las teorías psicológicas de la personalidad. A pesar de no existir una teoría universal de liderazgo, hay un acuerdo en el que, para considerar el concepto de líder, es necesario pensar simultáneamente en la interacción de tres variables:

- El líder con su personalidad;

- Los seguidores con su personalidad; y,

- El contexto relacional en el que sucede el liderazgo.
Las cualidades más sobresalientes de un líder se demuestran en el arte de ser innovador, creativo y visionario. Las diferentes teorías ponen en evidencia algunas características.

Teoría de los rasgos: Asegura que el liderazgo es innato y que se nace líder. Stogdill expresa que existen tres rasgos asociados a los líderes: inteligencia, estatura física y personalidad (Beraun, 2011: 17). Su propuesta es que el líder nace con cualidades que lo diferencian.

Teoría del gen del liderazgo: Cyril Levicki (citado por Gómez, 2008: 172) sostiene que las personas nacen con cierta predisposición para ser líderes.

A las características de los líderes, los autores en mención, identifican como la teoría del "Gran Hombre" en referencia a los rasgos de los grandes líderes que han marcado la historia (Contreras \& Sáez, 2008).

Teoría transformacional: se caracteriza por elevar el interés y desarrollar las capacidades de sus seguidores. Los líderes transforman a los seguidores haciéndoles más conscientes de la importancia y el valor de los resultados del trabajo, activando sus necesidades superiores, como diría Maslow, e induciéndoles a superar su propio interés en beneficio de la organización (Álvarez, Castillo \& Coral, 2010: 220).

Dentro de esta teoría, se resaltan algunos estilos:

El liderazgo transaccional: "una relación de influencia de tipo económico". El líder transaccional intercambia premios y promesas por el esfuerzo y responde a los intereses inmediatos de sus seguidores por contingencia (Cardona, 2000).

El liderazgo transformacional: su objetivo consiste en entregar al personal las herramientas necesarias para exceder su potencial. Feiner (2003 citado por Cuadra) basa su efecto en la motivación, la satisfacción y el logro del seguidor.

Se preocupa por el bienestar de sus seguidores y, a su vez, les desafía a desarrollar sus fortalezas y superar debilidades con el objeto de conseguir un ambiente laboral favorable de trabajo en equipo (Contreras \& Sáez, 2008). 
Se caracteriza por buscar una vida de calidad, anteponiendo a la persona; con una actitud proactiva busca siempre la solución para una convivencia armoniosa (Martínez, Vásquez \& Granados, 2001).

El liderazgo trascendente: según Cardona (2000) expande la teoría transformacional, ya que aparte de las relaciones de intercambio económico (transaccional) o el intercambio social (transformacional), agrega el tipo de intercambio por contribución, y al conjunto de estas tres clases llama "liderazgo relacional".

El liderazgo laissez-faire: denominado política de no intervención, es la ausencia o evitación del liderazgo (Bass, referido por Rodríguez, 2007).

La teoría conductual: se centra en el comportamiento. Se fundamenta en la conducta de la persona y hace referencia a tres estilos tradicionales de liderazgo, que en estudios realizados por Lewin, Lippit y White (1939, referido por Ayoub, 2009: 6) identifican como diferentes estilos directivos:

- El liderazgo autoritario

- El liderazgo democrático

- El liderazgo "laissez faire"

Rensis Likert (2009) propuso un modelo para estudiar la conducta del líder basado en "Sistemas de Administración". Señala dos tipos básicos: uno centrado en la tarea y el otro centrado en las personas.

El liderazgo centrado en la tarea se interesa por la ejecución de tareas y por los resultados; en el liderazgo centrado en la persona, la preocupación principal es la persona y su bienestar.

Basado en la teoría de McGregor, Likert cita cuatro sistemas para explicar los estilos de liderazgo: 1) autoritario explotador, 2) autoritario paternal, 3) consultivo; y, 4) participativo - democrático. Cada uno de los estilos con sus características propias.

Por los efectos de cada sistema, Likert (2009) y su grupo de colaboradores, llegaron a la conclusión de que el sistema más eficiente era el cuarto: participativo-democrático.

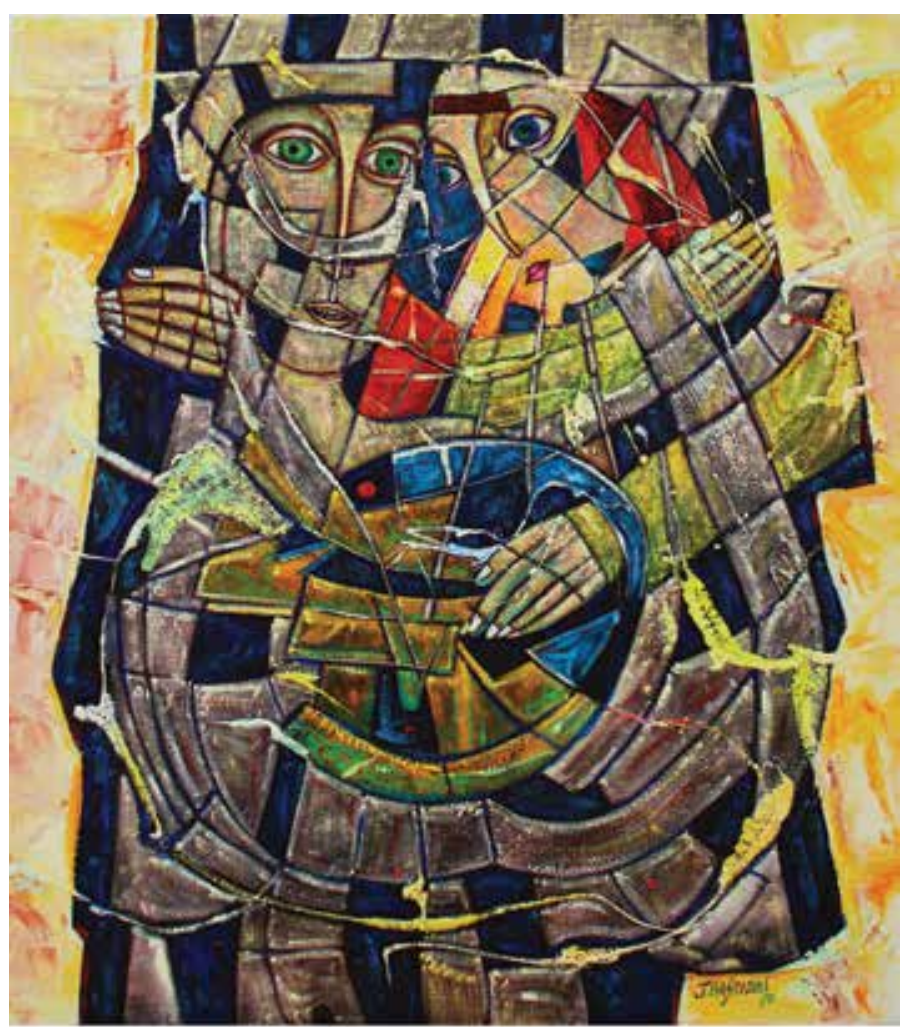

De esta manera, hablar de estilos de liderazgo, es referirse al patrón de conducta. Todos los estilos varían según la motivación, el poder o la orientación que tenga el líder hacia la tarea o las personas (Mitzberg 1980, citado por Gómez, 2008: 175).

En este artículo abordaremos el liderazgo transformacional porque responde a las nuevas realidades organizativas y sociales; atiende a la persona en todas sus dimensiones.

\section{Características del liderazgo transformacional}

Según Bass (1985) el líder transformacional se distingue por cinco características básicas: la influencia idealizada, es el carisma, los seguidores le admiran y le quieren imitar; la motivación inspiradora sabe comunicar su visión de modo 
convincente con palabras y ejemplo; el estímulo intelectual promueve a sus colaboradores a ser críticos, a buscar el por qué de las cosas; la consideración individual hace que el líder tome en cuenta las necesidades de cada persona para guiarlos según lo requiera; la tolerancia psicológi$\mathrm{ca}$, como proceso de aprender a tolerar los errores de los demás y a utilizar los propios para mejorar.

La paciencia, la amabilidad y el sentido de humor crean una atmósfera de trabajo adecuado para solucionar los problemas que se presentan (González, 2008: 42).

El clima siempre estará en función del estilo de gestión de los líderes; por ello, un buen liderazgo es garantía de un clima de familiaridad, armonía, trabajo y satisfacción. "El jefe ideal es aquel que alcanza las metas y mantiene un buen clima empresarial" ( Delgado, 2003: 77).

En conclusión, los estilos de liderazgo, en interacción con otros aspectos organizacionales, determinan el clima institucional y la calidad de vida de la misma. Cuanto más democráticoparticipativo y transformacional es el estilo de liderazgo, más alto es el nivel de familiaridad y confianza en la institución.

\section{Metodología}

\section{Participantes y procedimiento}

El trabajo desarrollado con las estudiantes del Bachillerato de la UEMAR requirió de una investigación de campo en la que predomina el método de inferencia inductiva con un enfoque de investigación mixto, cuantitativo-cualitativo (Hernández, 2003: 5).

Se fundamenta en la medición numérica, el conteo y el uso de la estadística para establecer patrones de comportamiento de las estudiantes, para lo cual semaneja la técnica de la encuesta a través de un cuestionario.

En el enfoque cualitativo, se utilizan técnicas como la observación con estudiantes y docentes; el grupo focal con el Consejo Estudiantil y el Comité de Padres de Familia; entrevistas a administrativos y personal de apoyo; luego se analiza la percepción de la comunidad educativa sobre el clima institucional.

El alcance de la investigación es de tipo descriptivo y correlacional porque pretende evaluar, medir y analizar la relación que existe entre "estilos de liderazgo" y "clima institucional".

En la elaboración del instrumento, se recoge la información utilizando la escala de Likert, con rango desde 1 (insuficiente) hasta 5 (sobresaliente).

Se aplican 46 indicadores para las estudiantes; 27 para los docentes; 17 para los padres de familia; 13 para el personal de apoyo y administrativos, dentro de los cuales se evalúa las variables: estilos de liderazgo (Bass \& Avolio, 1995) y clima institucional. Los informantes, personal de apoyo y administrativo, solo responden a clima institucional.

La tabulación y el análisis de la información, se realiza a través de cuadros estadísticos y gráficos que permite evidenciar las fortalezas y debilidades sobre los estilos de liderazgo y su impacto en el clima institucional.

\section{Análisis y resultados}

Una vez obtenidos los resultados, se procede a analizar los estilos de liderazgo presentes en la Unidad Educativa María Auxiliadora de Riobamba.

En la tabla $\mathrm{N}^{\circ} 1$ se evidencian las respuestas de los informantes en relación a los estilos de liderazgo y al clima institucional. 
Tabla 1: Estilos de liderazgo y clima institucional

\begin{tabular}{|c|c|c|c|c|c|c|}
\hline & Valoración & Administrativos & Profesores & Padres F. & $\begin{array}{c}\text { P. } \\
\text { Apoyo }\end{array}$ & Estudiantes \\
\hline \multirow{6}{*}{$\begin{array}{c}\text { Clima } \\
\text { institucional }\end{array}$} & Insuficiente & 0 & 1 & 2 & 2 & 5 \\
\hline & Regular & 0 & 3 & 4 & 0 & 10 \\
\hline & Bueno & 6 & 14 & 18 & 14 & 22 \\
\hline & M. Bueno & 64 & 37 & 45 & 40 & 26 \\
\hline & Sobresaliente & 34 & 46 & 31 & 44 & 37 \\
\hline & Valoración & Administrativos & Profesores & Padres F. & $\begin{array}{c}\text { P. } \\
\text { Apoyo }\end{array}$ & Estudiantes \\
\hline \multirow{6}{*}{$\begin{array}{c}\text { Liderazgo } \\
\text { transformacional }\end{array}$} & Insuficiente & 0 & 1 & 4 & 0 & 3 \\
\hline & Regular & 0 & 6 & 8 & 0 & 10 \\
\hline & Bueno & 0 & 22 & 19 & 0 & 27 \\
\hline & M. Bueno & 0 & 26 & 37 & 0 & 32 \\
\hline & Sobresaliente & 0 & 35 & 32 & 0 & 27 \\
\hline & Valoración & Administrativos & Profesores & Padres F. & $\begin{array}{c}\text { P. } \\
\text { Apoyo }\end{array}$ & Estudiantes \\
\hline \multirow{6}{*}{$\begin{array}{c}\text { Liderazgo } \\
\text { transaccional }\end{array}$} & Insuficiente & 0 & 9 & 0 & 0 & 3 \\
\hline & Regular & 0 & 17 & 0 & 0 & 32 \\
\hline & Bueno & 0 & 32 & 0 & 0 & 36 \\
\hline & M. Bueno & 0 & 30 & 0 & 0 & 20 \\
\hline & Sobresaliente & 0 & 12 & 0 & 0 & 8 \\
\hline & Valoración & Administrativos & Profesores & Padres F. & $\begin{array}{c}\text { P. } \\
\text { Apoyo }\end{array}$ & Estudiantes \\
\hline \multirow{5}{*}{ No liderazgo } & Insuficiente & 0 & 18 & 0 & 0 & 50 \\
\hline & Regular & 0 & 18 & 0 & 0 & 18 \\
\hline & Bueno & 0 & 26 & 0 & 0 & 20 \\
\hline & M. Bueno & 0 & 25 & 0 & 0 & 8 \\
\hline & Sobresaliente & 0 & 13 & 0 & 0 & 3 \\
\hline
\end{tabular}

Elaborado por: Sor Luisa Lozado León 


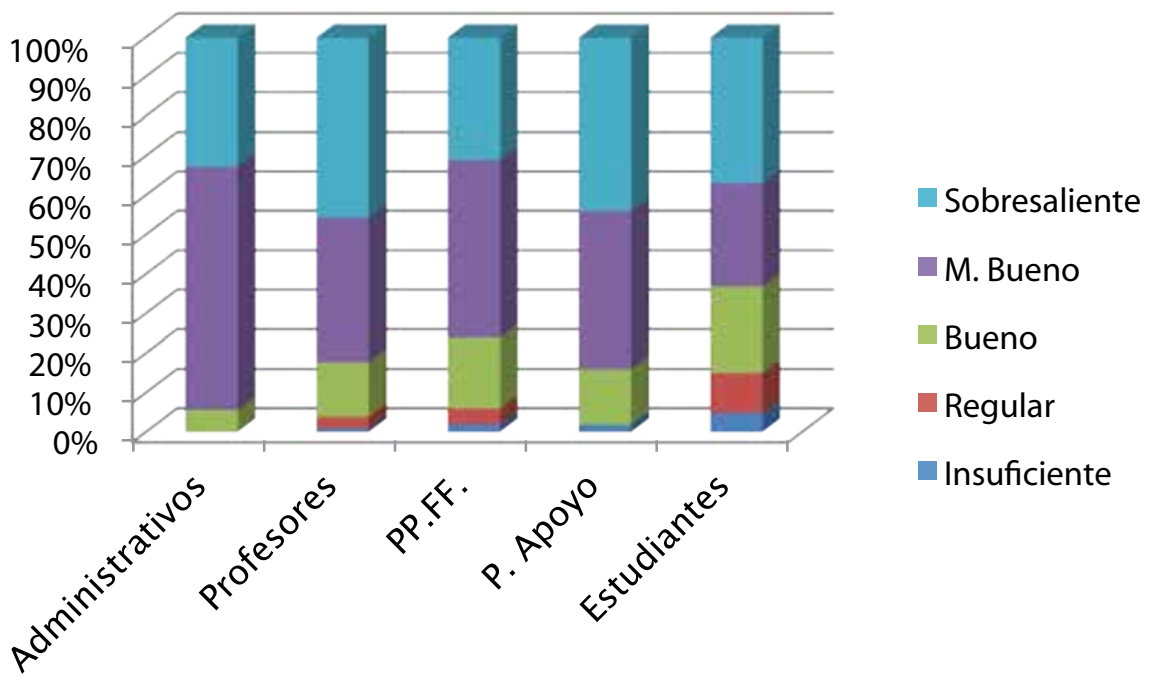

Elaborado por: Sor Luisa Lozado León

\section{El clima institucional}

Al comparar las respuestas proporcionadas por los informantes, se demuestra una diferencia marcada entre las valoraciones con el porcentaje más alto de muy bueno y sobresaliente; mientras que, entre bueno, regular e insuficiente es mínimo.

Partiendo de las respuestas de las estudiantes, se comprueba que la fortaleza en la percepción del clima institucional, se encuentra entre muy bueno y sobresaliente; el 63\% demuestra que las estudiantes del Bachillerato se sienten motivadas, aman a su colegio, mantienen buenas relaciones con los docentes y directivos, representan al colegio en diferentes eventos y eso hace que el mayor porcentaje perciba un clima óptimo, lo que constituye una gran fortaleza de la institución.

El 37\% demuestra la existencia de algunos puntos débiles como mayor escucha, diálogo, apertura y sobre todo, la participación a través del Consejo Estudiantil, a quienes reconocen como sus representantes.

Para los docentes el clima de la institución también constituye una gran fortaleza ya que mantienen relaciones fraternas, solidarias y respetuosas, se sienten motivados a dar lo mejor de sí y afirman ser parte de la misma. Dentro de las debilidades, se evidencia cierta desmotivación debido a las nuevas exigencias ministeriales que influyen en su percepción del clima.

Los padres de familia tienen una percepción positiva, muy cercana a la de los docentes. Ellos manifiestan deseos de una mayor participación en las actividades que programa la institución.

Para el personal de apoyo y administrativos, el clima de la institución es óptimo, con una necesidad de mejorar el trabajo en equipo entre sus miembros. 
Gráfico $\mathbf{N}^{\circ}$ 2. Liderazgo transformacional

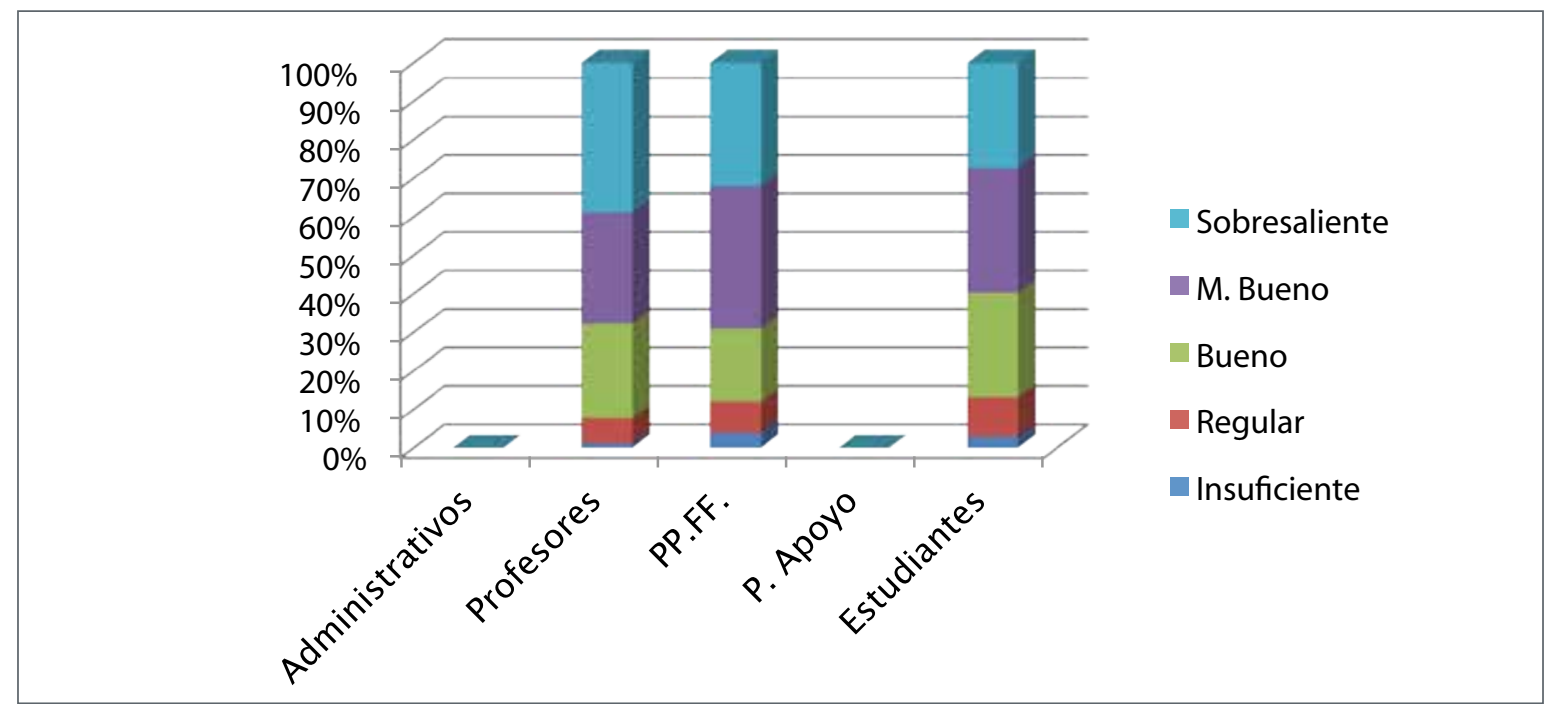

Elaborado por: Sor Luisa Lozado León

Los porcentajes del liderazgo transformacional, en los informantes, se ubican entre sobresaliente, muy bueno y en menor proporción en bueno.
Por las respuestas proporcionadas, se infiere que los informantes sienten que sus autoridades los valoran como personas, los motivan, a ser mejores cada día y les forman permanentemente en un $86 \%$.

Gráfico No 3: Liderazgo transaccional

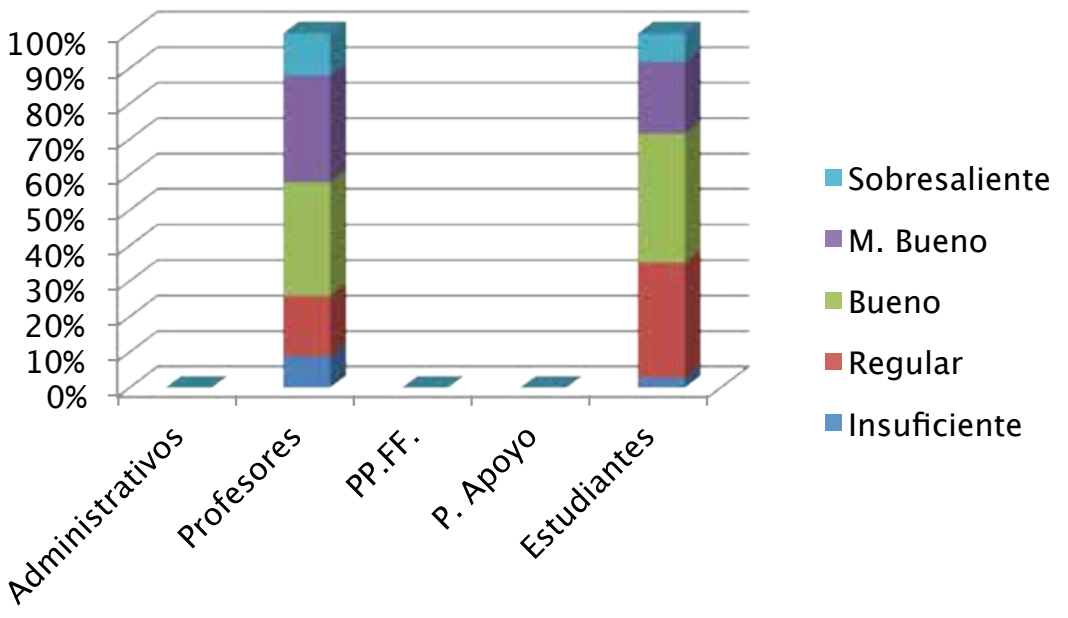

Elaborado por: Sor Luisa Lozado León 
Se ubica en un término medio entre regular, bueno y muy bueno (88\%); con mayor puntuación en bueno. Este resultado evidencia en docentes y estudiantes una relación de interacción con una motivación externa que satisface las necesidades del momento; sin importar la persona, se da un intercambio de intereses en el grupo; esto indica que en la institución, el liderazgo transaccional se practica en un promedio de bueno, según manifiestan los actores. Los resultados indican la existencia de este liderazgo aunque no en alto porcentaje; sin embargo, es pertinente tomar en cuenta nuestras actitudes de transacción para una mejor formación de la persona.

\section{Gráfico No 4: No liderazgo}

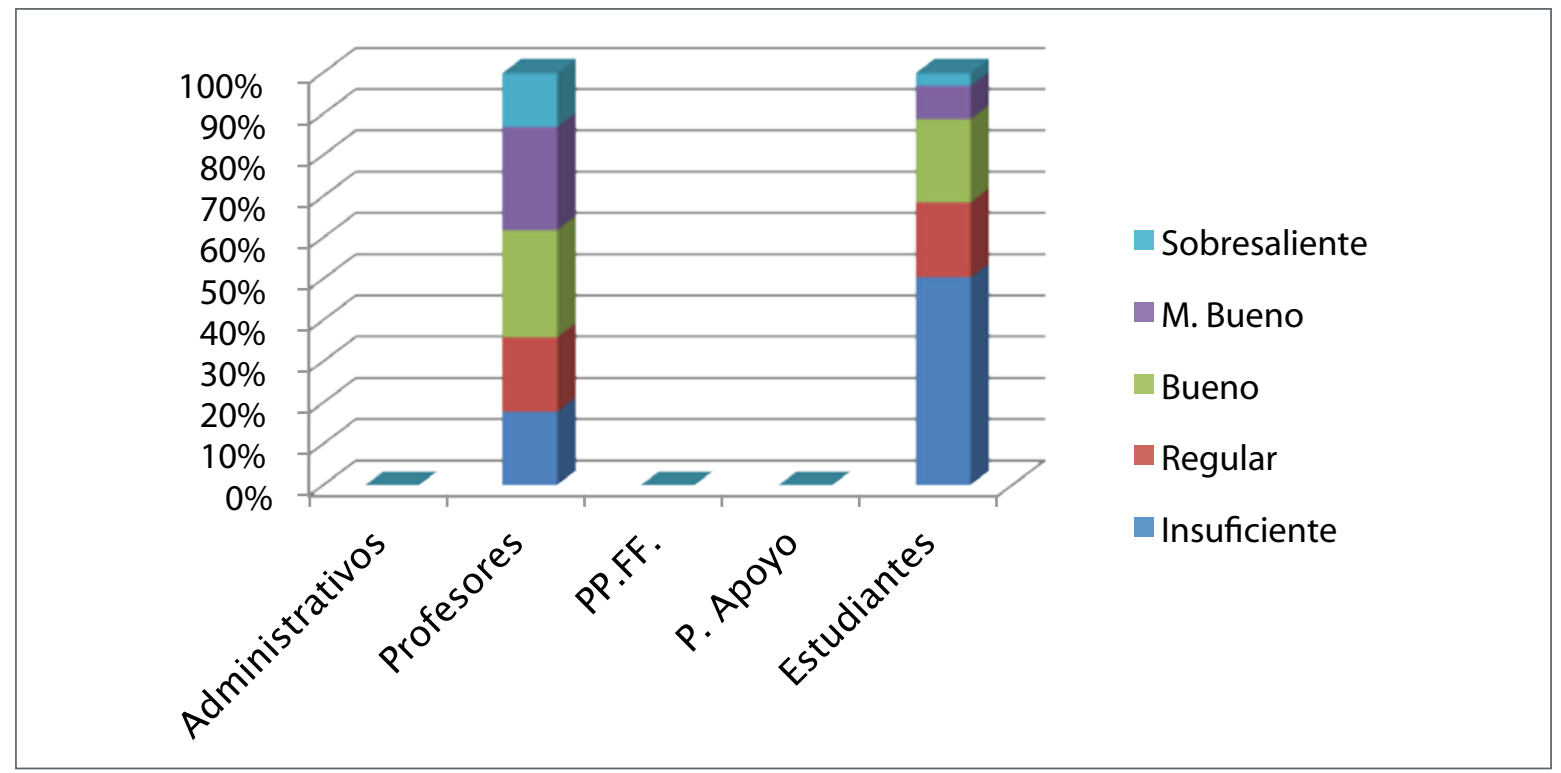

\section{Elaborado por: Sor Luisa Lozado León}

El no liderazgo es puntuado por las estudiantes como insuficiente en un 50\%, dando a entender la no vivencia de este; un bajo porcentaje señala como regular y bueno, indicando que se evidencian algunos rasgos de no liderazgo como en la capacidad de tomar decisiones, que se resalta como debilidad; en tanto que los docentes califican en igual proporción, dando a entender que este liderazgo está presente en algunos momentos.

El dato de bajo liderazgo laissez-faire para las estudiantes es una fortaleza para la institución; no así para los docentes, puesto que hace falta un buen liderazgo para intervenir oportunamente ante problemas suscitados.

\section{Relación entre estilos de liderazgo y clima institucional}

El estilo de liderazgo es el que provee el ambiente propicio para la actuación de la persona. El comportamiento de las mismas está condicionado a la percepción del clima que se vive.

En los gráficos se evidencian dos puntuaciones más altas, las que corresponden a un clima institucional muy bueno (64\%), percibido por los administrativos y la insuficiencia del estilo laissez-faire, percibido por las estudiantes. En los cinco grupos de informantes sobre el clima institucional, existe mayor puntuación entre muy bueno y sobresaliente. Consecuentemente, se evidencia un buen clima. 
De los tres estilos de liderazgo sobresale el liderazgo transformacional, entre muy bueno y sobresaliente. En tanto que el liderazgo transaccional demuestra una ubicación media, esto es que la institución tiene características de este liderazgo pero en menor escala (entre regular y bueno).

En el laissez-faire, salta a la vista la valoración de insuficiente que dan las estudiantes; esto demuestra que realmente este estilo está ausente en la institución; sin embargo, no es así para los docentes, probablemente porque tienen otro criterio de valoración y lo ubican en forma proporcionada demostrando que, aunque en menor escala, hace falta un liderazgo más asertivo; se debe evitar la evasión de responsabilidades y la permisividad entre el personal.

Visto de esta manera, el liderazgo transformacional está en armonía con la percepción del clima institucional, el mayor porcentaje se ubica entre muy bueno y sobresaliente en las dos variables; esto demuestra que un liderazgo transformacional produce un buen clima institucional.

Con el fin de afirmar la percepción del clima institucional en la UEMAR y captar más información, se aplica la técnica de la observación directa: a las estudiantes se evalúa su participación en las diferentes actividades institucionales; a los docentes, en el ambiente de trabajo, se enfatiza el sentido de pertenencia; al grupo de padres de familia, su participación y colaboración con la institución; al Consejo Estudiantil, el liderazgo que ejercen entre las compañeras. En general, se observa un ambiente de alegría, espontaneidad y confianza, sobre todo, entre docentes y estudiantes, creando un buen clima en la Institución.

También se aplica la técnica del grupo focal al Comité de Padres de Familia y al Consejo Estudiantil con la pregunta: ¿cómo perciben el ambiente general de la institución y cómo se sienten cuando llegan al colegio? Se puede inferir que existe un gran aprecio por la educación salesiana, sobre todo la educación en valores como el respeto, la solidaridad, la justicia, el orden y la paz, puesto que son valores agregados que tienen las estudiantes y ello favorece a la identificación y al sentido de pertenencia.

Según los gráficos, los grupos de estudiantes, docentes y padres de familia, califican al liderazgo transformacional como óptimo en la Institución, de igual forma al clima institucional.

Los padres de familia perciben al liderazgo transformacional entre muy bueno y sobresaliente; el liderazgo transaccional y el no liderazgo no aparecen en este grupo.

Según los docentes, el liderazgo transformacional es excelente, se encuentra entre sobresaliente y muy buena por lo que constituye una fortaleza; el liderazgo transaccional se ubica en nivel medio y el no liderazgo tiene la misma proporción entre sobresaliente, muy bueno, bueno y regular.

De estos resultados podemos inferir que, para las estudiantes, el liderazgo transformacional es óptimo, el transaccional se practica en menor escala y el no liderazgo se ve muy poco.

En conclusión, predomina el liderazgo transformacional en los tres grupos de informantes entre muy buena y sobresaliente. Las estudiantes se sienten tomadas en cuenta, perciben el interés por ayudarlas a ser mejores en todo momento, son motivadas a enfrentar retos y desarrollar todo su talento; el liderazgo transaccional se ubica en segundo lugar lo que sigue siendo positivo para la Institución; sin embargo, hace falta identificar rasgos más definidos de liderazgo en las autoridades. El no liderazgo se califica de insuficiente; es decir, positivo para la Institución ya que los actores perciben que las decisiones se toman oportunamente y los procedimientos, en cada situación, se manejan con claridad.

El clima institucional percibido por todos los informantes es excelente; el mayor porcentaje está ubicado entre muy bueno y sobresaliente. Esto constituye una fortaleza para la Institución, las estudiantes del Bachillerato y todo el personal percibe un ambiente sereno, participativo, de ayuda, de trabajo y respeto. 
Al relacionar las variables, comprobamos que el impacto de los estilos de liderazgo es determinante para el clima institucional. Tomando en cuenta que éste es el ambiente que perciben las personas por las relaciones entre los miembros y el trabajo en equipo o, como expresa Mellado (2005); es el estilo de dirección que influye, tanto en el estado perceptual como en el comportamiento, y la satisfacción de los miembros motivando o desmotivándolos.

Las respuestas obtenidas ratifican el gran impacto de los estilos de liderazgo en el clima institucional de la Unidad Educativa María Auxiliadora de Riobamba.

\section{Reflexiones}

El objetivo de este estudio fue determinar el impacto que tienen los estilos de liderazgo en el clima institucional del Bachillerato de la UEMAR; para lograrlo, se analizaron en qué medida impactan los estilos de liderazgo en el clima institucional. Se observó que son determinantes ya que sus efectos se evidencian de manera coherente así:

- El liderazgo transformacional, motivador, comunicativo y estimulador produce un clima agradable, participativo y deseable en donde cada persona se siente realizada, valorada y rinde lo mejor de sí.

- Se pone a prueba y se evidencia la hipótesis: cuanto más participativo, democrático y transformacional es el liderazgo, mayor familiaridad y confianza se vive en la Institución; entendiéndose por participación ser parte de las decisiones de la institución para que vivan el sentido de pertenencia.

- Se realiza una comparación entre clima institucional y estilos de liderazgo y se comprueba que un estilo transformacional, que se preocupa por la formación de la persona, produce un clima sereno, armonioso y de satisfacción de todos los miembros.

- Mellado (2005) expresa que el estilo de dirección influye tanto en el estado per- ceptual, como en el comportamiento y la satisfacción de los miembros.

\section{Conclusiones}

- Realizado el diagnóstico con sus respectivos instrumentos, se constata que en la UEMAR se actúa con los tres estilos de liderazgo: transformacional, transaccional y laissez-faire, prevaleciendo el estilo transformacional que está íntimamente relacionado con el clima institucional.

- Un buen clima institucional es índice de un liderazgo motivante y persuasivo que se traduce en un rendimiento eficiente $y$ en notoria satisfacción de los empleados. Un clima armonioso potencia relaciones personales sanas y éstas retroalimentan el clima e influye en el rendimiento de todos. Los estilos de liderazgo están íntimamente unidos al clima institucional puesto que el comportamiento del ser humano depende de la percepción que tenga del ambiente que le rodea.

- Una de las implicaciones más relevantes que se desprende de este estudio es que si se ejerce el liderazgo transformacional las consecuencias positivas de este estilo se ven reflejadas en todo el personal, ya que prioriza a la persona, motiva para actuar con visión de futuro, valora sus fortalezas y desarrolla sus potencialidades. En el liderazgo transaccional no se desconoce la actitud de transacción que surge eventualmente de las autoridades para una mejor formación de las personas. Si bien el no liderazgo se ubica en un promedio medio bajo por parte de los docentes, probablemente es un llamado a las autoridades para tomar una actitud más asertiva en la institución.

- El estilo de liderazgo actúa en el clima institucional como la melodía de la música en el ser humano: creando un ambiente rítmico y armonioso que incentiva al desempeño 
de la persona en un clima de calidad y calidez.

- Como educadores salesianos seguimos a Bass y Avolio (1990), fortaleciendo el liderazgo transformacional, pues necesitamos contar con personal motivado, satisfecho, valorado, proactivo y decidido a enfrentar retos que la sociedad requiere para avanzar humanamente en un clima de confianza que, en el lenguaje salesiano,

\section{Referencias bibliográficas}

Álvarez, O.; Castillo, I. \& Coral, F. (2010). Estilos de liderazgo en la selección española de Taekwondo. Universitat de les Illes Balears, 19 (n.2): 219-230. Recuperado de: http://www. redalyc.org/redalyc/pdf/

Ayoub, J.L. (2009). Enfoque conductista del liderazgo. Revisión del marco teórico a través del análisis del enfoque conductista del liderazgo. Universidad Autónoma de Madrid. Recuperado en: http://portal.uam.es/portal/page/portal/UAM_ ORGANIZATIVO/Departamentos/ CienciaPoliticaRelacionesInternacionales/ doctorado/Seminario de Investigación.

Bass, B. \& Avolio, B. (1990). Desarrollo del liderazgo transformacional: Manual para el cuestionario de liderazgo multifactorial. Universidad Estatal de Nueva York.

Beraun, L. (2011). Teoría de los rasgos por liderazgo para generar capacidades. Recuperado de: http://www.scribd.com/doc/56014709/ Liderazgo-Para-Generar-Capacidades.

Bris, M. (2000). Clima de trabajo y organizaciones que aprenden. Educar.(27): 103-117. Recuperado de: http://ddd.uab.cat/pub/ educar/0211819Xn27p103.pdf.

Burns, McG. (2011). Modelos de liderazgo. Recuperado de: http://www.slideshare.net/habilidades22/ modelos-de-liderazgo.

Contreras, F. \& Sáez, C. (2008). Estilos de liderazgo en honorables diputados. Congreso Nacional de Chile. Espacio Abierto, (001): 53-72, se denomina "familiaridad", característica que debe identificar a toda obra impulsada desde el espíritu salesiano. Se demuestra, por tanto, que la calidad del clima institucional depende del estilo de liderazgo que se aplique en el grupo; puesto que actúa como la melodía en el ser humano creando un ambiente rítmico y armonioso que incentiva al desempeño de la persona, en un clima de calidad y calidez.

Maracaibo, Venezuela. Recuperado de: http:// redalyc.uaemex.mx/pdf/

Cuadra, A. \& Veloso, C. (2007). Liderazgo, Clima y Satisfacción Laboral en las Organizaciones. Universum Talca,(2.22) Recuperado de:http:// www.scielo.cl/scielo.php?pid=S07183762007000200004\&script=sci_arttext

Cuadrado, I. \& Molero,F. (2002). Liderazgo transformacional y género: autoevaluaciones de directivos y directivas españoles. Revista de Psicología del Trabajo y de las Organizaciones: 39-55. Recuperado de: http://redalyc.uaemex. $\mathrm{mx} /$ redalyc/pdf/2313/231317661002.pdf.

Chiavenato, I. (2009). Gestión del talento humano. Editorial Mc Graw Hill, Reg. (736):176-180. México

Delgado, M. (2004). La función de liderazgo de la dirección escolar: una competencia transversal. Recuperado de: http://pedagogia.fcep. urv.cat/revistaut/revistes/ferreres/capitol4article2.pdf

Fernández, A. (2004). Clima organizacional en las escuelas: Un enfoque comparativo para México y Uruguay. Recuperado de:http:// redalyc.uaemex.mx/src/inicio/ArtPdfRed. jsp?iCve $=55120205$

García, M. (2009a). Clima Organizacional y su Diagnóstico: Una aproximación Conceptual.Cuadernos de Administración. (42):43-61. Recuperado de: en: http:// redalyc.uaemex.mx/src/inicio/ArtPdfRed. jsp?iCve $=225014900004$ 
Gil, A., Muñoz, M. \& Delgado, A. (2008). El liderazgo transformativo en el ámbito escolar: Un esfuerzo de investigación en acción cooperación entre instituciones de educación superior. (9): 13-33. Recuperado de: http://redalyc.uaemex.mx/pdf/410/41011135001.pdf

Gómez, R. (2008). El liderazgo empresarial para la innovación tecnológica en las micro, pequeñas y medianas empresas. Pensamiento $y$ Gestiónn. Recuperado el 24 dejunio, 2012, : 157-194. Recuperado de: http://www.redalyc. org/src/inicio/ArtPdfRed.jsp?.

González,O. (2008). Liderazgo Transformacional en el docente universitario.Multiciencias, (v.1). Recuperado de: http://redalyc.uaemex.mx/ pdf/904/90480105.pdf.

Instituto Hijas de María Auxiliadora. (2005). Para que tengan vida y vida en abundancia. Roma: CCS, Madrid

Likert, R. (2009). Administración II, Ingeniería en transporte.Teoría del clima organizacional. Recuperado de Likert.de:http://administracion2transporte.blogspot.com/2009/02/teoría-del-clima-organizacional-de.html

Martínez, R. \& Guadarrama, J. (2001). El clima organizacional en una institución tecnológica de educación superior. Tiempo de Educar.(005): 105-131. Recuperado http://redalyc.uaemex. $\mathrm{mx} / \mathrm{pdf} / 311 / 31103505 . \mathrm{pdf}$.

Mejía, E., Zea, A. \& Pérez, G. (2004). Caracterización de los estilos de liderazgo en algunas ONG.
71. (143): 13-23. Recuperado de: http:// redalyc.uaemex.mx/src/inicio/ArtPdfRed.jsp?

Mejía, S. (2007). Predominio del estilo de liderazgo en la evolución de la administración. Recuperado de: http://redalyc.uaemex.mx/ src/inicio/ArtPdfRed.jsp?

Mellado, C. (2005). Gestión de la Comunicación Interna en la Pequeña Empresa Industrial: un Análisis de los Procesos Organizacionales Clima y Liderazgo. Recuperado de: http://www.razonypalabra.org.mx/anteriores/n43/cmellado.html.

Morales, M. (2009). Administradores y clima organizacional.de:http://www.slideshare.net/69deme/ administradores-y-clima-organizacional

Rodríguez, S. \& Ponce,E. (2007). Estilos de liderazgo, toma de decisiones estratégicas y eficacia: un estudio empírico en pequeñas y grandes empresas". Asociación Interciencia, Caracas Venezuela, 32 (008): 522-528. Recuperado, de:http://redalyc.uaemex.mx/ pdf/339/33932805.pdf

Salcedo, I. \& Romero, J. (2006). Cultura Organizacional y Gestión de la Calidad en una Empresa del Estado venezolano.Revista venezolana de gerencia. Recuperado de: http://www.scielo. org.ve/scielo.php?

Vargas, I. (2010). Por qué es importante discutir acerca del liderazgo en la gestión escolar.Revista electrónica Educare. XIV (1):59-66. Recuperado de:http://www.revistas.una.ac.cr/index.php/ EDUCARE/article/download/1509/1429 


\section{Memoria académica}

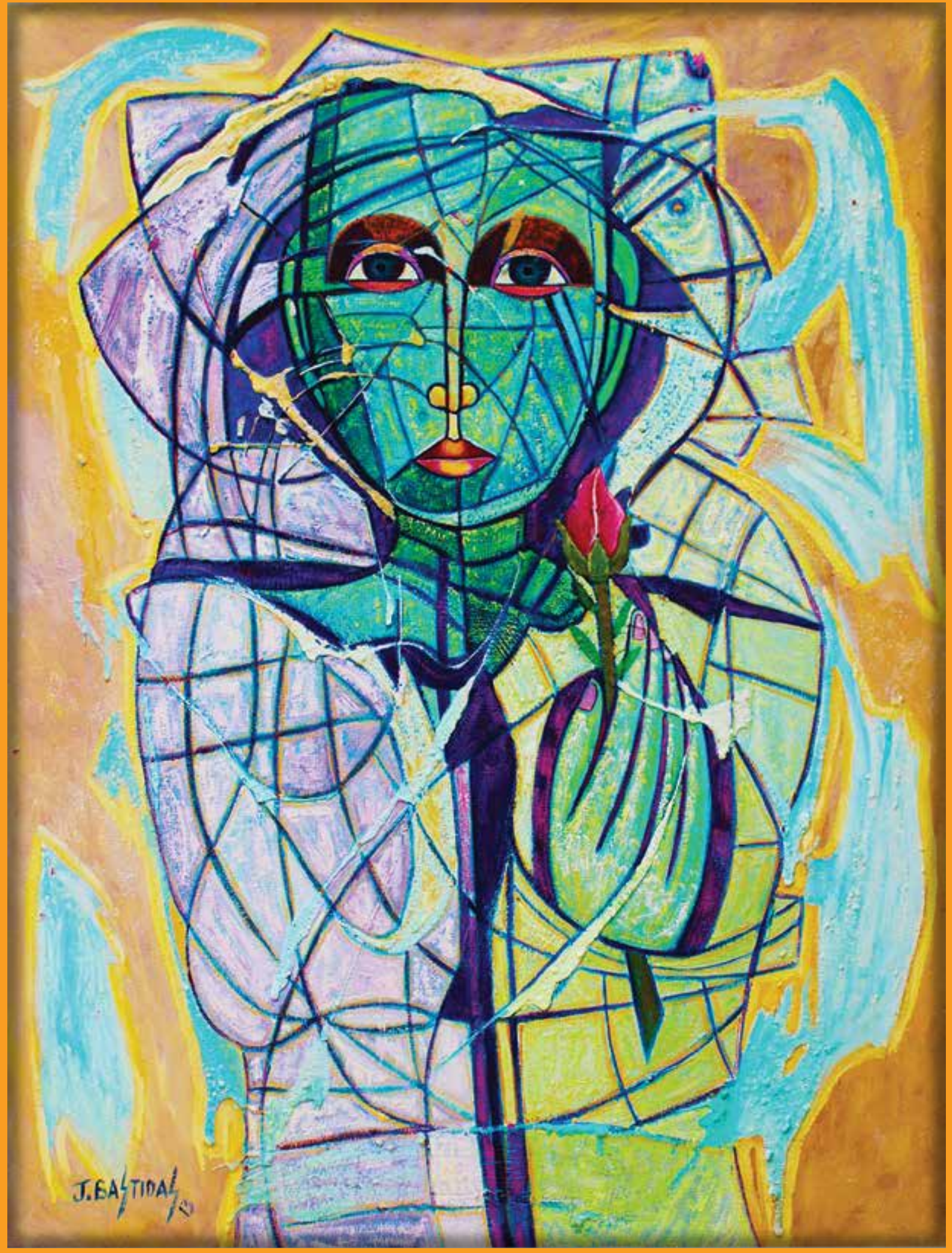




\section{Alteridad, Volumen 8, No 2}

\section{Memoria académica julio-diciembre 2013}

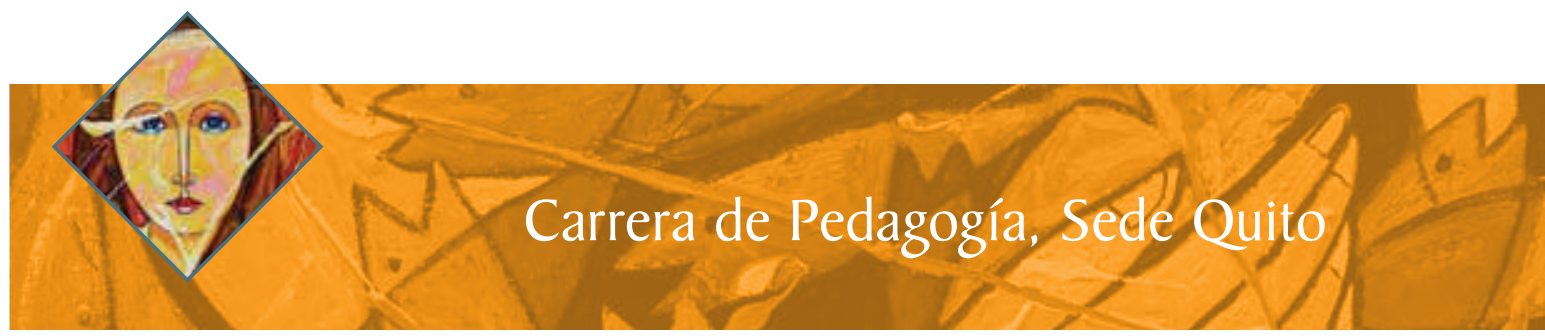

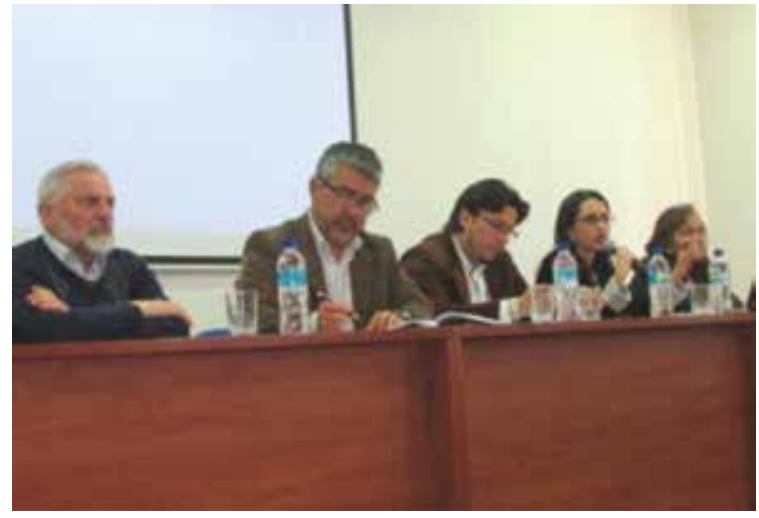

Jornadas Pedagógicas. Con el propósito de revalorizar el rol docente en la sociedad y momento histórico actual, en el mes de julio de 2013 se desarrollaron, en la carrera de Pedagogía, varias actividades. Se realizó un conversatorio sobre el tema "El valor de ser docente" con la participación de P. Juan Botasso, sdb, Msc. Tatiana Rosero, Msc. Paúl Córdova y las Dra. Gladys Báez, quienes desde los ámbitos públicos y privados, seglares y religiosos resaltaron los compromisos, vivencias, experiencias y retos de la formación de niños, niñas, jóvenes; y en general del quehacer en el ámbito educativo. Además se contó con la presencia de la Dra. Dolores Boada, funcionaria del Ministerio de Ambiente, quien presentó el tema "Desafíos de la educación ambiental en la labor pedagógica" y del funcionario de la DINAPEN Miguel Chimarro, que presentó su conferencia sobre la el tema: "Prevención de acciones en contra de la integridad física y psíquica de niños, niñas y adolescentes"; ambos resaltaron el rol del docente como agente de cambio y principal protagonista en la prevención de agresiones contra el ser humano y su ambiente.

Festejo navideño a los niños y niñas de las guarderías que apoya el P. Juan Bottasso. Los estudiantes de primer nivel, de la carrera de Pedagogía, compartieron con entusiasmo y alegría con aproximadamente 100 niños y niñas, en un emotivo programa navideño que se desarrolló en las instalaciones de la sede Quito de la Universidad Salesiana, el pasado martes 17 de diciembre del 2013. Los niños y niñas disfrutaron de actividades recreativas y artísticas, juguetes, golosinas y sobre todo, mucho amor.

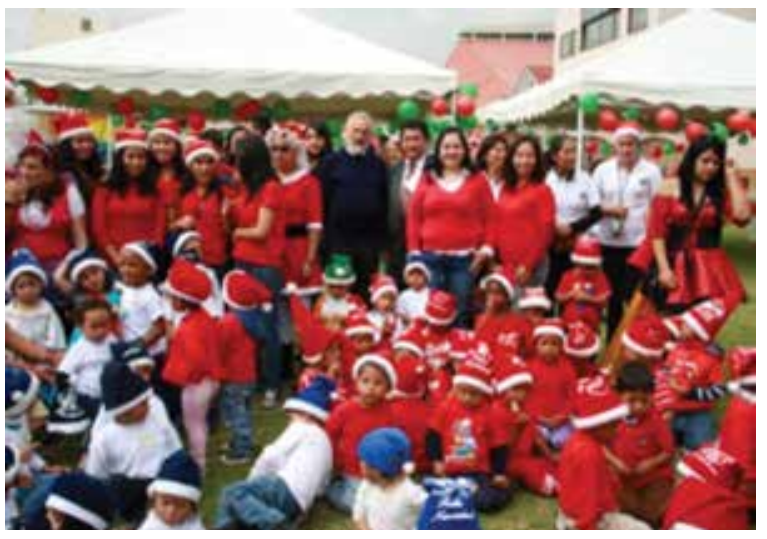


Campaña "Mambrú no va a la guerra”. Dentro del marco del convenio firmado entre la UPS y SERPAJ (Servicio de Paz y Justicia del Ecuador) se realizó la Campaña "Mambrú no va a la guerra", desde octubre hasta diciembre. Participaron de manera activa 60 estudiantes de tercer nivel de la Carrera de Pedagogía, en 12 caravanas que se desplazaron por los barrios y parroquias de Quito, compartiendo lo aprendido en una fase previa de formación (en juegos cooperativos, caritas pintadas y expresión dramática). El objetivo principal de esta campaña fue aportar a la construcción de una cultura de paz desde alternativas creativas y lúdicas que aporten a disminuir la violencia en nuestra sociedad.

Foro "Acciones y alternativas contra la Violencia a la Niñez en el Ecuador". Con el auspicio de la Conferencia Episcopal Ecuatoriana y la Universidad Politécnica Salesiana, el 8 de noviembre de 2013 se realizó el primer foro interreligioso y ecuménico "Acciones y Alternativas contra la Violencia a la Niñez en Ecuador". Contó con la participación de representantes de las iglesias Metodista, Luterana, Católica, Fe Bahaí; y del Ministerio de Inclusión Económica y Social. En representación de la Universidad Politécnica Salesiana y de la carrera de Pedagogía intervino el docente Jesús Loachamín con la ponencia: "Situación actual de la violencia escolar y propuesta de intervención". El evento se desarrolló en el Aula Magna Fray Bartolomé de las Casas de la UPS, al que concurrieron niños, niñas, padres, madres de familia y estudiantes de la carrera de Pedagogía.

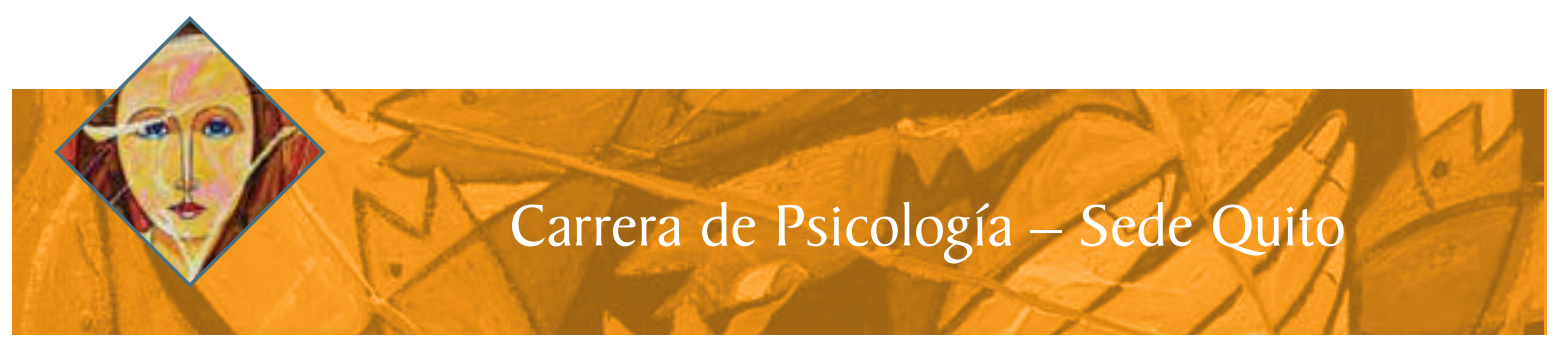

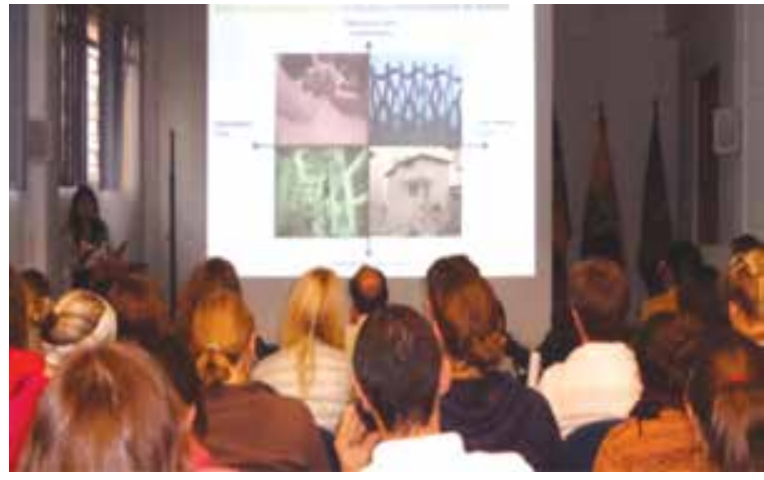

Simposio Internacional "Imaginando el Barrio del Buen Vivir a través del Diseño y Planificación Participativa" (Agosto, 2013). La organización internacional Arquitectos Sin Fronteras del Reino Unido (ASF-UK), en conjunto con el Grupo de Investigaciones Psicosociales de la carrera de Psicología, el Instituto de Altos
Estudios Nacionales, la Confederación Nacional de Barrios del Ecuador, el gobierno barrial de Atucucho y el comité de desarrollo comunitario Los Pinos; se dieron cita para iniciar un proceso de vinculación y discusión sobre formas alternativas de producción y gestión social del hábitat popular. Marcelo Rodríguez dio la bienvenida, destacando el potencial aporte de la psicología ambiental y comunitaria en la producción del hábitat. Se contó con la participación de dirigentes sociales como Jenny Díaz y Luis Robles, quienes expusieron las experiencias de las luchas urbanas. El Dr. Alex Apsan y la Dra. Isis Núñez de la University College of London, presentaron las metodologías de diseños participativos y de fortalecimiento comunitario. Intervino la concejala María Luisa Maldonado quien enfatizó la necesidad de potenciar organizaciones cooperativas y solidarias para 
gestionar la producción del hábitat. A su vez, Javier Alvarado, coordinador de la Gerencia de Acompañamiento Social del MIDUVI, expuso la importancia de la vinculación de procesos de construcción comunitaria y el fortalecimiento de la organización territorial como política social que acompañe las dinámicas de urbanización popular. La jornada de trabajo permitió articular alianzas y aportar a la reflexión de la línea de investigación sobre movimientos sociales urbanos que desarrolla el grupo de investigaciones psicosociales de la Universidad Politécnica Salesiana.

XXXIV Congreso Internacional de la Sociedad Interamericana de Psicología (Julio, 2013). Este congreso, organizado por la Sociedad Interamericana de Psicología y que se realizó en la ciudad de Brasilia-Brasil, es el más importante a nivel regional en esta disciplina; en él participaron dos docentes de la carrera de Psicología e investigadores del grupo de investigaciones psicosociales: Marcelo Rodríguez quien presentó la ponencia "Disputas simbólicas y apropiación inclusiva del espacio público comunitario: el caso de investigación-acción participativa en el barrio patrimonial La Ronda del Centro Histórico de Quito"; y, Gino Grondona, participó con la ponencia "Ecuador y Políticas Sociales: hacia la sociedad del Buen Vivir".

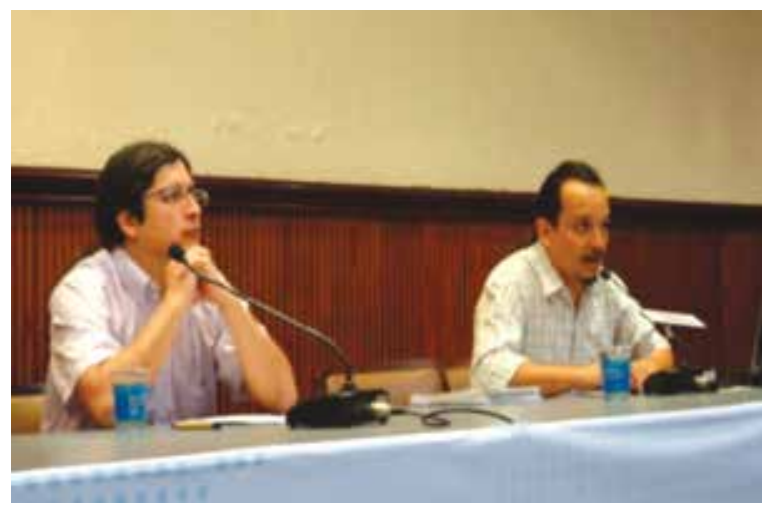

Cine Foro: Día mundial del hábitat. Por el derecho a la ciudad y el hábitat (Octubre, 2013). Con ocasión de la celebración del día mundial del hábitat, la fundación Somos Ecuador, el Contrato Social por la Vivienda y la carrera de Psicología, implementan un cine foro con el objeto de reflexionar sobre los actuales procesos de desarrollo urbano, a partir de la proyección del documental Urbanized de Gary Hustwit. La jornada se inicia con las palabras de bienvenida de Marcelo Rodríguez, quien enfatiza que la psicología social nace y se convierte en un campo relevante por los problemas derivados del hecho urbano. Mónica Quintana, gerente del Programa UN-HABITAT (Ecuador), describe los principales aportes de su organización al desarrollo urbano en el país; destaca la vinculación de la psicología como una ciencia relevante que puede aportar a los procesos urbanos y sociales. Luego de la proyección del documental se abrió el foro a los estudiantes y representantes de organizaciones vinculadas con la temática; fue facilitado por Vanessa Pinto y se reflexionó, desde la experiencia cotidiana de los participantes de habitar la ciudad, su rol como ciudadanas y ciudadanos.

Primeras Jornadas de Metodologías, ¿Cómo investigar los asuntos públicos? (Octubre, 2013). el departamento de Asuntos Públicos de FLACSO, Ecuador, organizó las Primeras Jornadas de Metodología en Quito, realizadas el 30 y 31 de octubre del 2013. Fue invitado Marcelo Rodríguez, psicólogo, magíster en estudios urbanos, docente de la UPS, a presentar la investigación de su tesis: "Producción social del espacio: el caso de renovación urbana del barrio patrimonial La Ronda del Centro Histórico de Quito”. Este trabajo corresponde a un proyecto de investigación generativa de psicología ambiental y comunitaria del Grupo de Investigaciones Psicosociales de la UPS. El profesional realiza una presentación centrada en los aspectos metodológicos para estudiar las principales contradicciones que presenta la política pública de renovación urbana y gestión de la ciudad en centralidades históricas. Se destaca el enfoque interdisciplinar del estudio y la necesidad de problematizar la mercantilización e instrumentación del patrimonio cultural de la ciudad. 


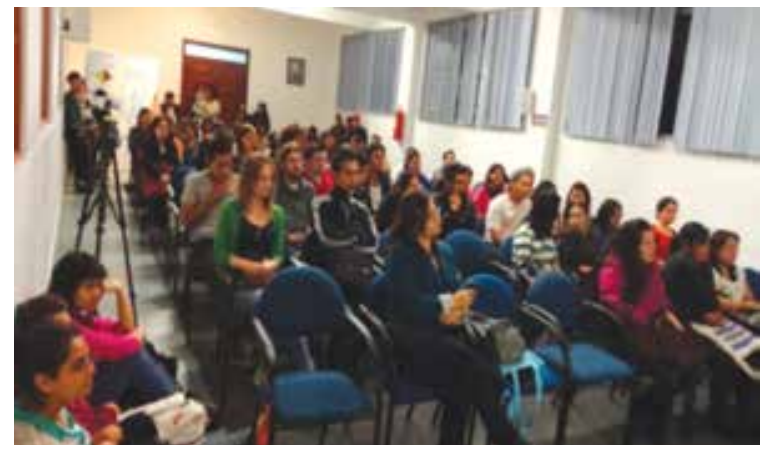

Seminario "Sistemas de Acreditación y Formación de Psicólogos en Las Américas" (Diciembre, 2013). Este seminario fue organizado por la carrera de Psicología y la Red para el Mejoramiento de la Calidad de las Carreras de Psicología del Ecuador. Se realizó en el campus El Girón de la Universidad Politécnica Salesiana, en la ciudad de Quito (Ecuador). Contó con la participación del Dr. Julio Villegas, miembro vitalicio, de la Sociedad Interamericana de Psicología (SIP) y Director General del Grupo de Trabajo sobre
Formación del Psicólogo en Las Américas, organismo oficial de la SIP y referente para la acreditación internacional de programas de formación en psicología. En el seminario participaron representantes de carreras y facultades de psicología de 13 universidades del Ecuador; se abordaron temas relacionados con el proceso de acreditación de las carreras de psicología, entre ellos la necesidad de fortalecer la Red para posicionarse como interlocutores ante los organismos de regulación de la educación superior, y aportar a los procesos de formación y mejoramiento de la psicología en Ecuador.

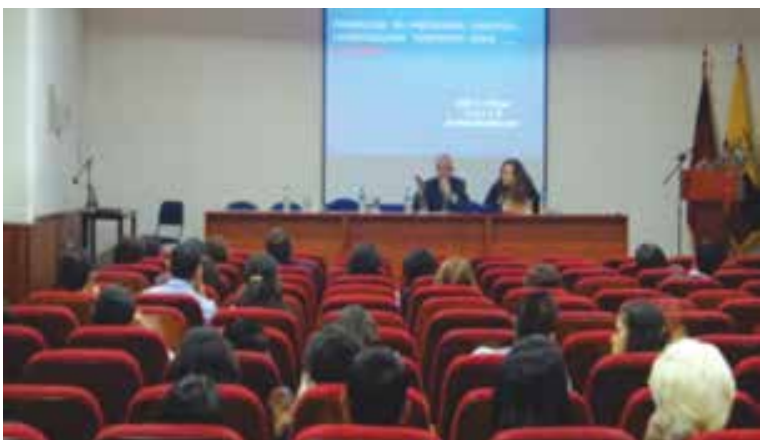

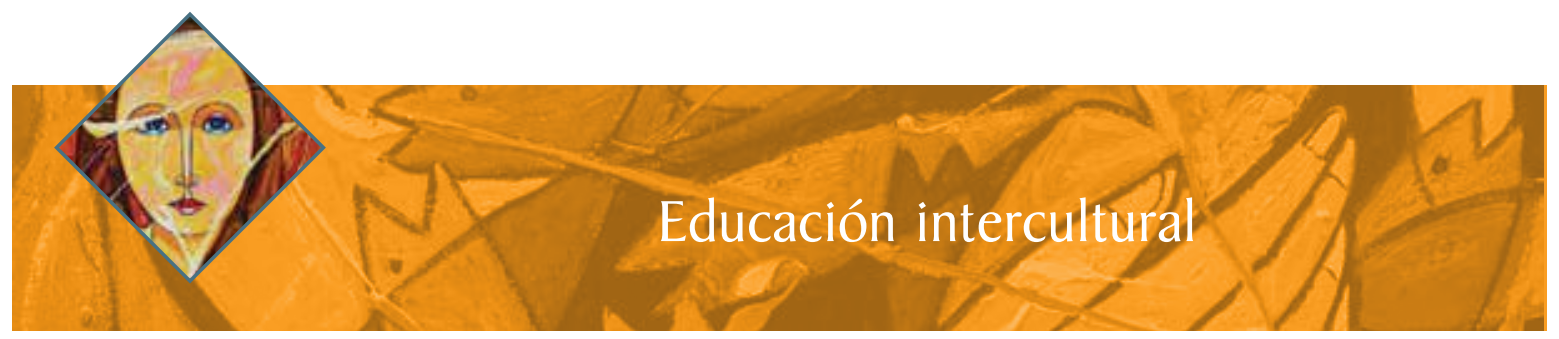

Taller de formación permanente para graduados de la Carrera de Educación Intercultural Bilingüe (Zona Norte). De acuerdo a la programación prevista dentro del plan de mejoras de graduados y egresados de la carrera EIB, se realizó el primer taller de formación permanente de la zona norte, durante los días 7 y 8 de diciembre de 2013. Contó con la participación de 33 personas, siendo la temática del taller la "Actualización curricular”, tomando en consideración las sugerencias de los graduados recogidas en el primer encuentro de graduados y egresados realizado en las zonas norte y sur el 13 y el 20 de julio del 2013.
El taller fue facilitado por la docente Luz Marina Viera y tuvo una duración de 12 horas.

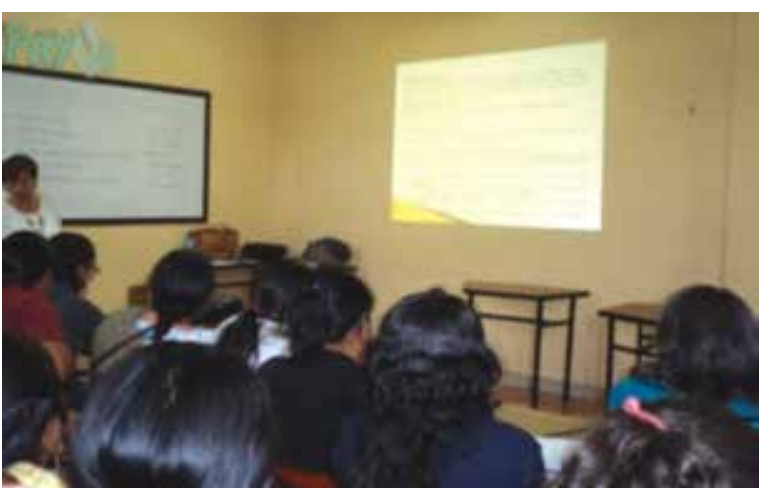


Foro "Educación intercultural bilingüe: pasado, presente y futuro". El día sábado 8 de febrero de 2014 entre las $14 \mathrm{~h} 00$ y 17h00, se desarrolló el foro "Educación intercultural: pasado, presente y futuro". Este foro fue organizado por las y los estudiantes de segundo ciclo de la Carrera de Educación Intercultural Bilingüe del Centro de Apoyo Cayambe. Participaron como panelistas: Guillermo Churuchumbi (Presidente de la Confederación Pueblo Kayambi), Segundo de la Torre (Delegado del Distrito Educativo Cayambe - Pedro Moncayo) y Albeto Masapanta (Secretario Ejecutivo del Concejo Cantonal de Niñez y Adolescencia de Cayambe). Este foro convocó a estudiantes y graduados de los Centros de Apoyo Cayambe y Otavalo. Las distintas ponencias de los panelistas enfatizaron en la necesidad urgente de operativizar en la práctica y dentro del sistema educativo, las relaciones interculturales. Manifestaron de modo reiterado que la interculturalidad, más que una práctica, sigue siendo un discurso.

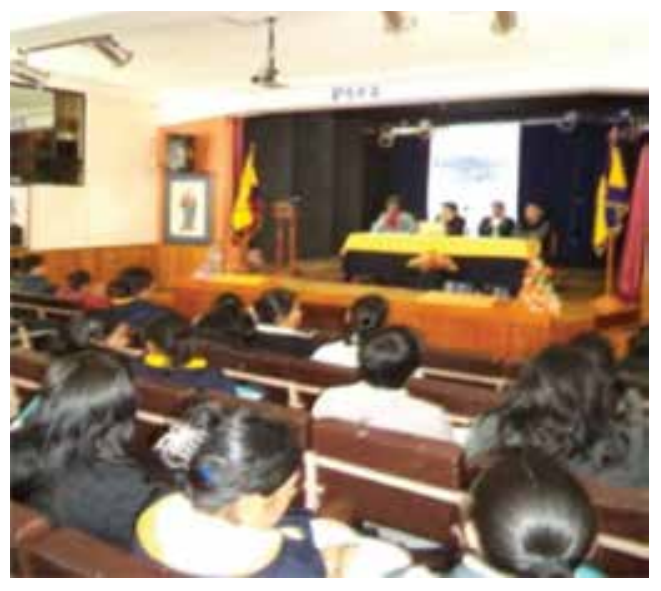

Proyecto de intervención socio-educativo para la prevención de la violencia contra la infancia en el cantón Cayambe. Desde enero del año en curso, la carrera de Educación Intercultural Bilingüe se encuentra impulsando, en el cantón Cayambe, el
Proyecto de intervención socio-educativo para la prevención de la violencia contra la infancia. El proyecto tiene como propósito central sensibilizar a niños y niñas, padres, madres de familia y profesores de la zona, sobre la problemática de la violencia intra-familiar y al interior de las escuelas. A la vez, se intenciona desarrollar habilidades básicas para prevenir y enfrentar situaciones de violencia. En el proyecto participan 16 escuelas rurales del cantón Cayambe, siendo los beneficiarios alrededor de 4000 personas (niños-as, padres de familia y docentes). El equipo encargado de llevar adelante el proyecto son 4 docentes de la Carrera de EIB y 32 estudiantes del centro de apoyo de Cayambe.

El proyecto tiene el aval de la Dirección del Distrito Educativo de los Cantones Cayambe y Pedro Moncayo y del Concejo Cantonal de Niñez y Adolescencia de Cayambe.

Primer Congreso de Educación Popular e Interculturalidad (Octubre, 2013). Este congreso, organizado por el Centro de Interdisciplinario de Investigación e Intervención Social (CIIIS) tuvo lugar en la Universidad del Valle- Meléndez, en la ciudad de Cali (Colombia). En este espacio se profundizó en el debate académico, social y político que la interculturalidad y la educación popular contiene como proyecto, discurso y/o modo de vida, desde diferentes disciplinas y contextos. Participaron Daniel Arroyo, asistente de investigación del Grupo de Investigaciones Psicosociales de la UPS, con la ponencia "Propuesta para el análisis intercultural a partir de los factores psicosociales asociados a las prácticas culturales"; y los estudiantes de la carrera de psicología Henry Jiménez y Mónica Cansignia, con la ponencia "Apropiación del espacio público para la construcción de ciudadanía a través de la educación popular en niñas, niños y adolescentes de la escuela móvil de Fe y Alegría, en la plaza 24 de Mayo". 


\section{Novedades bibliográficas}

\section{Pueblos indígenas y educación 63}

- ISBN: 978-9942-09-171-0

- Editora: Abya-Yala

- Presentación: $15 \times 21 \mathrm{~cm}-424$ páginas

La formación superior indígena cobra cada día mayor importancia en América Latina. Confluyen para ello diversos factores: desde las demandas de los propios pueblos indígenas, hasta la consolidación de políticas públicas que favorecen, con distintas ópticas, la incorporación y participación efectiva de pueblos indígenas y afrodescendientes en los sistemas de educación superior de la región.

Si bien, los avances ocurridos en este terreno marcan pautas para la democratización e inclusión educativa de pueblos originarios y comunidades afrodescendientes, todavía deben despejarse en la región el cómo asumir los retos que presenta la diversidad sociohistórica, lingüística y cultural latinoamericana, para responder al imperativo de una educación respetuosa de la interculturalidad, el ambiente y los derechos individuales y colectivos.

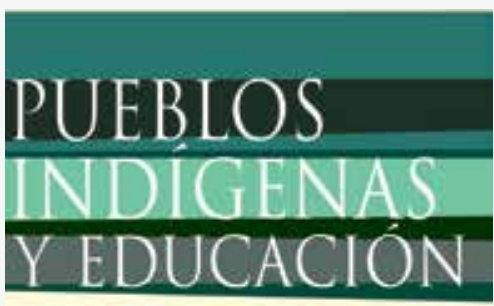

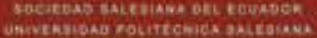

CONGRESO NACIONAL Pedagogía de Don Bosco: Reflexiones, experiencissy destios

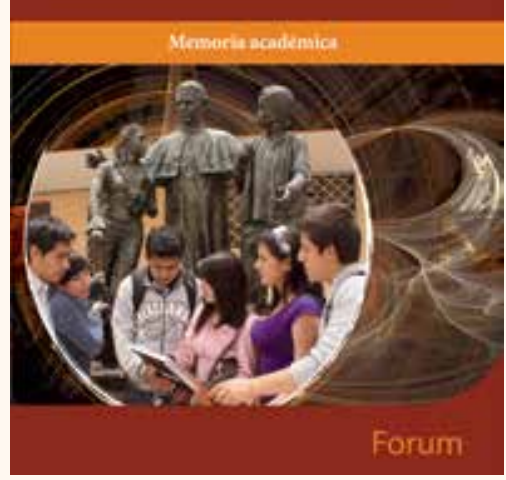

CONGRESO NACIONAL. Pedagogía de Don Bosco: Reflexiones, experiencias y desafíos

- ISBN: 978-9978-10-163-6

- Editora: Abya-Yala / UPS

- Presentación: $15 \times 21 \mathrm{~cm}-436$ páginas

La Sociedad Salesiana en el Ecuador y la Universidad Politécnica Salesiana llevaron a cabo el Congreso Nacional "Pedagogía de Don Bosco: reflexiones, experiencias y desafíos" (Cuenca, 29-31 de mayo del 2013), con el fin de evidenciar la riqueza del legado pedagógico salesiano y comprometer a los participantes, miembros y actores del proyecto educativo, a resignificar la dimensión pedagógica salesiana en el marco de la opción preferencial por los pobres.

Esta obra constituye la memoria académica del Congreso y recoge los aportes de académicos, docentes, religiosos y estudiantes articulados según tres ejes: el contexto contemporáneo y los nuevos escenarios pedagógicos (reflexiones); el legado pedagógico salesiano y prácticas locales significativas (experiencias); y los desafíos pedagógicos y prioridades para la comunidad salesiana en Ecuador (propuestas). 


\section{Educación cimarrona \\ memorias, reflexiones y metodología}

- ISBN: 978-9978-10-149-0

- Editora: Abya-Yala / UPS

- Presentación: 15 x $21 \mathrm{~cm}-230$ páginas

La presente obra consta de tres partes bien definidas: la primera expone el resultado de los talleres y el trabajo de las coordinadoras de los Centros de Educación Cimarrona de los siguientes barrios de Sucumbíos: El Cisne, Amazonas, San Valentín y la Parroquia Pacayacu; recupera historias de vida de hombres y mujeres así como la tradición oral presente en su memoria colectiva y recuperada por el grupo de trabajo. La segunda parte consta de las reflexiones teóricas sobre el cimarronaje y los fundamentos conceptuales que inspiran los Centros de Educación Cimarrona. La tercera y última sección ofrece, en primer lugar, el relato reflexivo de los talleres de grafoplástica identitaria; $y$, una guía para niños investigadores al servicio de la revitalización de la cultura, las identidades y las memorias vivas de los pueblos cimarrones.
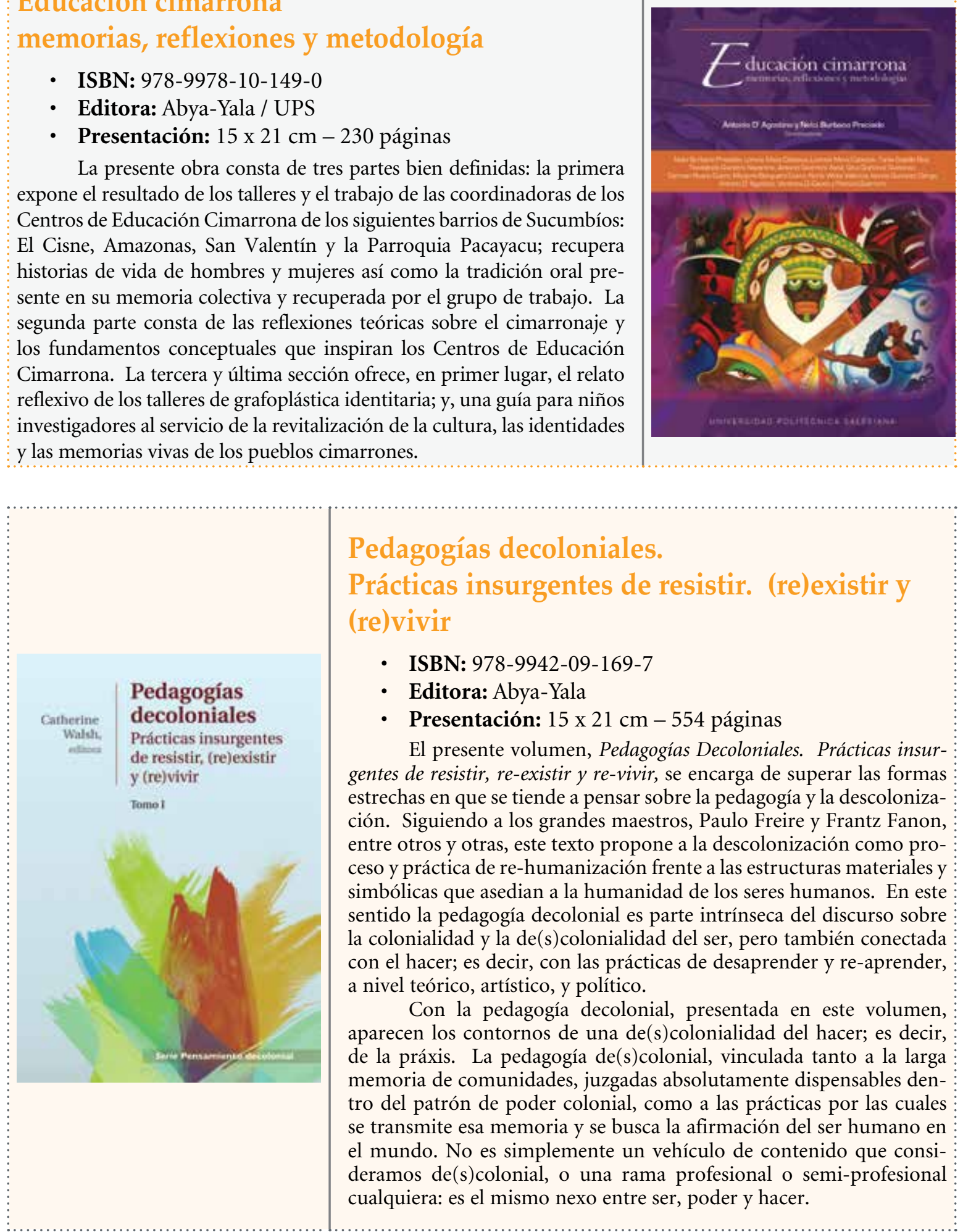

\section{Pedagogías decoloniales. Prácticas insurgentes de resistir. (re)existir y (re)vivir}

- ISBN: 978-9942-09-169-7

- Editora: Abya-Yala

- Presentación: 15 x $21 \mathrm{~cm}-554$ páginas

El presente volumen, Pedagogías Decoloniales. Prácticas insurgentes de resistir, re-existir y re-vivir, se encarga de superar las formas estrechas en que se tiende a pensar sobre la pedagogía y la descolonización. Siguiendo a los grandes maestros, Paulo Freire y Frantz Fanon, entre otros y otras, este texto propone a la descolonización como proceso y práctica de re-humanización frente a las estructuras materiales y simbólicas que asedian a la humanidad de los seres humanos. En este sentido la pedagogía decolonial es parte intrínseca del discurso sobre la colonialidad y la de(s)colonialidad del ser, pero también conectada con el hacer; es decir, con las prácticas de desaprender y re-aprender, a nivel teórico, artístico, y político.

Con la pedagogía decolonial, presentada en este volumen, aparecen los contornos de una de(s)colonialidad del hacer; es decir, de la práxis. La pedagogía de(s)colonial, vinculada tanto a la larga memoria de comunidades, juzgadas absolutamente dispensables dentro del patrón de poder colonial, como a las prácticas por las cuales se transmite esa memoria y se busca la afirmación del ser humano en el mundo. No es simplemente un vehículo de contenido que consideramos de(s)colonial, o una rama profesional o semi-profesional cualquiera: es el mismo nexo entre ser, poder y hacer. 


\section{Alteridad. Revista de Educación http://alteridad.ups.edu.ec/ ISSN No. 1390-325X}

\section{Normas para autores}

Alteridad. Revista de Educación, es una revista académica de la Universidad Politécnica Salesiana. Se edita desde el 2005 con una periodicidad semestral, durante los meses de junio y diciembre.

Su objetivo es contribuir, desde el contexto latinoamericano, a la socialización y debate de la producción académica en el ámbito de la Educación.

Es una publicación arbitrada que utiliza el sistema de revisión externa por expertos (peerreview). Se edita en versión impresa (ISSN: 1390325X); además, los artículos están disponibles en la Web de la revista (http://alteridad.ups.edu.ec/).

\section{Tipos de artícullos}

1. Alteridad publica resultados de investigación, estudios, experiencias y reseñas bibliográficas sobre los diversos ámbitos de la educación, escritos preferentemente en español, pero aceptados también en inglés o portugués.

- Investigaciones: investigación empírica original relacionada con la educación, usando enfoques cualitativos, cuantitativos o mixtos. Entre 4.500/6.000 palabras de texto (incluyendo referencias).

- Informes, Estudios, Propuestasy Experiencias. Entre 3.500/5.000 palabras de texto (incluyendo referencias).

- Reseñas: Textos descriptivos y críticos sobre una publicación novedosa y de calidad del área de Educación, editada como máximo dos años antes a la edición de la revista. La extensión de texto será de 600/630 palabras. El autor ha de remitir directamente,

1 Adaptado de la normativa de la Revista Científica Iberoamericana de Comunicación y Educación (Comunicar) http://www.revistacomunicar.com/, elaborado por Jaime Padilla y revisado por los Consejos Editoriales de Alteridad (14 de febrero de 2013). o a través de la editorial pertinente, un ejemplar original del texto a reseñar para su escaneo, que quedará posteriormente en depósito.

\section{Componentes de los escriitos}

2. La estructura de los artículos presentados contendrán al menos los siguientes apartados: encabezamiento, cuerpo del trabajo y referencias bibliográficas.

3. El encabezamiento debe incluir la siguiente información:

a) El título del artículo: conciso e informativo (máximo 80 caracteres);

b) Un resumen en español e inglés: cada versión debe estar en un solo párrafo (220/230 palabras), donde se describirá el motivo y el objetivo de la investigación, la metodología empleada, los resultados más destacados y las principales conclusiones. Ha de estar escrito de manera impersonal: "el presente trabajo analiza...".

c) Palabras clave en español e inglés (5/8 descriptores). Con este fin se utilizará el Vocabulario Controlado del IRESIE (disponible en: http://www.iisue.unam.mx/ iresie/vocabulario_controlado.php), o el Tesauro de la UNESCO (Consulte en: http://databases.unesco.org/thessp/).

4. El cuerpo del trabajo debe considerar la siguiente información:

a) Introducción: Debe incluir los fundamentos y el propósito del estudio, utilizando citas bibliográficas, así como la revisión de la literatura más significativa del tema a nivel nacional e internacional.

b) Fundamentación teórica y metodológica: Se presentará una pertinente fundamentación teórica y se expondrá con claridad 
la estrategia metodológica instrumentada (elección de sujetos, procedimientos metodológicos cuantitativos o cualitativos seguidos en el estudio e instrumentos) cuidando su coherencia con los fundamentos.

c) Análisis y resultados: Se procurará resaltar las observaciones más importantes, describiéndose, sin hacer juicios de valor, las observaciones efectuadas con el material y métodos empleados. Aparecerán en una secuencia lógica del texto, las tablas o figuras imprescindibles, evitando la redundancia y reiteración.

d) Discusión y conclusiones: Resumirá los hallazgos, relacionando las propias observaciones con otros estudios de interés, señalando aportaciones y limitaciones, sin reiterar datos ya comentados en otros apartados. Se debe mencionar las inferencias de los hallazgos y sus limitaciones, incluyendo las deducciones para una investigación futura, así como enlazar las conclusiones con los objetivos de estudio, evitando afirmaciones gratuitas y conclusiones no apoyadas completamente por los datos del trabajo.

5. La Bibliografía referencial debe incluir todas y únicamente las publicaciones referidas en el texto. Su número ha de ser suficiente y necesario, y se presentarán alfabéticamente por el apellido primero del autor (agregando el segundo solo en caso de que el primero sea de uso muy común). Las citas bibliográficas deberán extraerse de los documentos originales.

6. Apoyos y agradecimientos: El Council Science Editors recomienda a los autores especificar la fuente de financiación de la investigación.

\section{Normas de estilo}

7. Los trabajos deben venir en formato Word para PC, se presentarán con letra Times New Roman de 12 puntos, con interlineado simple, justificados completos y sin espacio entre párrafos. Solo se separarán con un retorno los grandes bloques (autor, títulos, resúmenes, descriptores, créditos y apartados).
8. Los cuadros, gráficos, tablas, mapas, figuras, fotografías, etc. deberán incluirse en el cuerpo del documento con una resolución de 300 dpi. Los pies de tabla se colocan en la parte superior de las mismas centradas y los pies de gráficos/figuras en la parte inferior.

9. Para la redacción de los trabajos (citas dentro del texto, referencias, formato de tablas, etc.) los autores deberán apegarse a las pautas del Manual de Estilo de la American Psychology Association (APA - $6^{\circ}$ edición). Consulte: http://www.apastyle.org/. Una presentación resumida en español se puede obtener de http://www.slideshare.net/nilda. figueroa/estilo-de-publicaciones-apa-referencias

\section{Proceso editorial}

10. El documento recibido por el editor responsable pasa por dos procesos de selección:

a) El primero se lleva a cabo en el Consejo Editorial Interno, quien determinará la pertinencia y solvencia científica del manuscrito.

b) El segundo proceso lo realiza el Consejo Editorial Externo, según el sistema de revisión por pares (doble ciego). En el caso de resultados discrepantes se remitirán a un tercer dictamen, el cual será definitivo.

11. Desde la Secretaría del Consejo Editorial se notificará a los autores la decisión de los evaluadores en cuanto a la aceptación, solicitud de revisión o rechazo del artículo.

12. Si el artículo es aceptado para la publicación, los editores combinarán los comentarios de los revisores con sus propias observaciones editoriales y regresarán el manuscrito al autor principal para su revisión final. El autor debe entonces realizar las correcciones y cambios necesarios. Usualmente el tiempo dado para los cambios no será mayor a dos semanas.

13. La coordinación editorial de la revista se reserva el derecho de hacer corrección de estilo y cambios editoriales que considere necesarios para mejorar el trabajo. 
14. Una vez diagramado el texto, se enviará una prueba de composición del artículo para corregir errores y su aprobación. En este punto no será posible hacer cambios en el manuscrito, sino solamente corregir errores. El autor debe retornar la prueba de impresión a los editores máximo una semana después de haberla recibido.

15. Si un artículo es publicado en Alteridad, el primer autor recibirá por correo postal dos ejemplares de la revista en la que ha sido publicado su trabajo.

\section{Compromisos y \\ responsabilidades éticas}

16. Cada autor/es presentará una declaración responsable de autoría y originalidad, así como sus responsabilidades éticas contraídas.

a) Originalidad: Los trabajos deben ser originales y no deben estar siendo evaluados simultáneamente en otra publicación, siendo responsabilidad de los autores el cumplimiento de esta norma. Las opiniones expresadas en los artículos publicados son responsabilidad del autor/es.

b) Autoría: En la lista de autores firmantes deben figurar únicamente aquellas personas que han contribuido intelectualmente al desarrollo del trabajo. Haber colaborado en la recolección de datos no es, por sí mismo, criterio suficiente de autoría. "Alteridad" declina cualquier responsabilidad sobre posibles conflictos derivados de la autoría de los trabajos que se publiquen.

c) Transmisión de los derechos de autor: se incluirá en la carta de presentación la cesión de derechos del trabajo para su publicación en "Alteridad".

17. Las obras que se publican en esta revista están sujetas a los siguientes términos:

a) El Servicio de Publicaciones de la Universidad Politécnica Salesiana (la
Editorial) conserva los derechos patrimoniales (copyright - () Universidad Politécnica Salesiana, Ecuador) de las obras publicadas, y favorece y permite la reutilización de las mismas bajo la licencia de uso indicada en el literal $b$.

b) Alteridad se publica en versión escrita y electrónica bajo una licencia http://creativecommons.org/licenses/by-nc-nd/3.0/ ec/. Se pueden copiar, usar, difundir, transmitir y exponer públicamente, siempre que: i) se cite la autoría y la fuente original de su publicación (revista, editorial y URL de la obra); ii) no se usen para fines comerciales; iii) se mencione la existencia y especificaciones de esta licencia de uso.

18. Los autores se comprometen a participar en la difusión de su manuscrito una vez publicado, así como toda la revista mediante todos los medios a su alcance y en su contexto (comunidad universitaria, investigadores).

\section{Presentación}

19. Deben remitirse simultáneamente: la carta de presentación, la portada y el manuscrito.

a) Carta de Presentación: contiene la declaración responsable de autoría y originalidad, y las responsabilidades éticas contraídas, así como, opcionalmente la justificación de la elección de la revista, aportaciones al trabajo.

b) Portada: Hoja de identificación del trabajo, con todos sus datos que sirven de presentación del manuscrito.

c) Manuscrito: escrito original, conforme a las "Normas para autores". En este documento no puede ir ninguna referencia al autor/res, dado que este fichero es el que se envía a la evaluación ciega por expertos.

20. Los documentos deben ser enviados mediante archivos adjuntos al e-mail: alteridad@ ups.edu.ec, con copia al Editor responsable: jpadilla@ups.edu.ec 


\section{Alteridad. Revista de Educación \\ http://alteridad.ups.edu.ec/ \\ ISSN No. 1390-325X}

\section{Authors' guidelines}

Alteridad. Revista de Educación, is an academic magazine published by the Salesian Polytechnic University, edited twice a year, in June and December, since 2005.

Its objectives are to contribute to the academic socialization and debate of Education within the context of Latin America.

It is a peer-reviewed mediated publication that goes through external reviews by experts. There is a printed edition (ISSN: 1390-325X), as well as an online version available on the web (http://alteridad.ups.edu.ec/).

\section{Topic areas}

1. Alteridad publishes investigation results on diverse issues about research, practices and bibliographic reviews on Education. Articles are published in Spanish, but we also consider those written in English and Portuguese.

- Research: Original empirical research related to Education, that has a qualitative, quantitative, or mixed focuses. Each article's extension should be between 4,500 and 6,000 words (including references).

- Reports, analysis, proposals, and field study: The article's extension should be between 3,500 and 5,000 words (including references).

- Reviews: A critical, descriptive assessment of a new and quality publication in the area of Education, that was edited no more than two years before this year's magazine's

Adapted from Revista Científica Iberoamericana de Comunicación y Educación (Comunicar), author guidelines, http://unww.revistacomunicar.com/, prepared by Jaime Padilla and reviewed by Alteridad's editorial board (February 14, 2013). edition. The article extension should be between 600 and 630 words. The author should submit directly, or through the corresponding publisher, an original copy of the book to be reviewed, which will be stored in our repository.

\section{Article components}

2. The article should have the following structure: heading, body of text, and bibliographic references.

3. The heading should include the following information:

a) Title: concise and informative (80 characters at most).

b) An abstract in Spanish and English: One paragraph for each (220-230 words), describing the research objective and purpose, methodology applied, highlighted results, and main conclusions. It should be written in an impersonal style: "The present work analyzes..."

c) Keywords in Spanish and English (5-8 words). Please use the Controlled Lexicon from IRESIE (available at: http:// www.iisue.unam.mx/iresie/vocabulario controlado.php) or UNESCO thesaurus (see: http://databases.unesco.org/thessp/) for this purpose.

4. The body of text should include the following information:

a) Introduction: Including the basis and purpose of the study; cite bibliographic sources, as well as a revision of the national and international key literature on the subject. 
b) Theoretical and methodological background: Including a theoretical basis with a clear methodological strategy and type of research data used (subjects chosen, quantitative and qualitative methodological procedures followed, research tools), and a coherent argument.

c) Analysis and results: Highlighting the most important observations, without value judgment, about the material and methods employed. These will appear in a logical sequential manner, with tables or figures as needed, avoiding redundancy and reiteration.

d) Discussion and conclusions: Including findings and related studies, plus the author's observations, denoting contributions and limitations, without duplicating data from other sections. Analysis about the findings and limitations, including results for future investigation, as well as a link between the study's objectives and conclusions, should be included. Try to avoid gratuitous affirmations and conclusions that are not supported on data drawn from the research.

5. The bibliography should include all and only those publications cited within the text, it must be listed alphabetically with the first author's last name (include the second last name only if the first is a very common name). All cited references must come from the original documents.

6. Acknowledgements and support: The Council of Science Editors recommends that authors list any funding allocated for the research.

\section{Style guilde}

7. All papers should be in Word format for PCs, in Times New Roman, 12 pt. font, single spaced and justified, leaving no spaces between paragraphs. All main sections should be separated by a double space (author, title, abstract, keywords, credits, and appendices).
8. Include all charts, graphics, tables, maps, figures, photographs, etc., in the body of the text with a 300 dpi resolution. Table references should be centered above the table, while references for graphics and figures should be included below them.

9. The style guide (references within the text, bibliography, table formatting, etc.) should follow the American Psychology Association style manual (APA, $6^{\text {th }}$ edition). See: http:// www.apastyle.org/.

\section{Editorial process}

10. The document received by the chief editor goes through two selection processes: a) first, it goes through the Internal Editorial Board, which will determine its required scientific relevance and qualifications; b) then it goes through an external, peer-reviewed Editorial Board. If there is a discrepancy in the decision, it will go through a third, definitive selection process.

11. The authors will be notified of the evaluators' decision, whether the paper was accepted, sent back with suggested changes, or rejected, by the Secretariat of the Editorial Board.

12. If the article is accepted for its publication, the editor will combine all reviewers' comments and his/her own observations, sending those and the manuscript back to the author for a final revision. The author must make all changes, which should take no longer than two weeks.

13. The Editorial Board reserves the right to edit the paper based on style and whatever else is needed to improve the article.

14. Once the text goes through the designing stage, a proof will be sent back for corrections and approval. From this point on, changes will not be allowed on the manuscript, only modifications due to mistakes. The author must return the press proof to the editors no later than a week after receiving it. 
15. If the article is published in Alteridad, the author will receive two samples of the magazine with his/her published work via mail.

\section{Compromises and ethical responsibilities}

16. Each author will hand in an author's statement of authorship and responsibility, as well as the ethical responsibilities as detailed:

a) Originality: All papers must be original and cannot be simultaneously evaluated by another entity or publication, a norm that all authors must comply with. The opinions expressed in the published articles are the author's responsibility.

b) Authorship: Only those people who have contributed intellectually to the paper's development must be listed on the authors' list. Collaboration in the recollection of data is not itself, enough criteria for authorship. Alteridad denies any responsibility for possible conflicts deriving from authorship rights issues on any papers published by the magazine.

c) Transferal of author's rights: The transferal of author's rights will be included in the letter of presentation for its publication in Alteridad.

17. All works published in the magazine are subject to the following terms:

a) The publishing services at the Salesian Polytechnic University (the editors) keeps all patrimonial rights (copyright - (C) Universidad Politécnica Salesiana, Ecuador) of published documents, and favors and allows their publication under license, as established on item $b$. b) Alteridad is published in print and electronic form under license http://creativecommons.org/licenses/by-nc-nd/3.0/ec/. Its material can be copied, used, disseminated, transmitted, and presented publicly as long as: i) the authorship and original source of the material are cited (magazine, publisher, and URL); ii) it is not used for commercial purposes; iii) the present license and its stipulations are cited.

18. The authors agree to participate in the dissemination of their manuscript, once published, as well as the magazine via any means available to them and within their network (community, university, colleagues).

\section{Presentation}

19. The following materials must be presented jointly: letter of presentation, title page, and manuscript.

a) Letter of presentation: It should include the authorship statement of responsibility and originality, the ethical responsibilities, as well as (optional) the reason for selecting this magazine, and work contributions.

b) Title page: In order to identify the material, with all data that could help identify the manuscript.

c) Manuscript: One original, based on the “Authors' Guidelines". This document should not carry the author's name since it will be sent for peer review.

20. All documents must be sent as attachments to alteridad@ups.edu.ec, with a copy to the chief editor: jpadilla@ups.edu.ec.

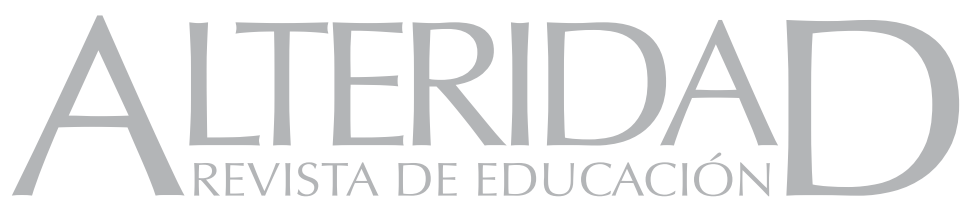

